\title{
DESIGN GUIDELINES FOR INTEGRATING AMPHIBIAN HABITAT INTO \\ GOLF COURSE LANDSCAPES
}

\author{
A Thesis \\ Presented to \\ The Faculty of Graduate Studies \\ of \\ The University of Guelph \\ by \\ DANIEL BRIAN JACKSON \\ In partial fulfillment of requirements \\ for the degree of \\ Master of Landscape Architecture \\ December, 2008
}

(c) Daniel Brian Jackson, 2008 


$\begin{array}{ll}\begin{array}{l}\text { Library and } \\ \text { Archives Canada }\end{array} & \begin{array}{l}\text { Bibliothèque et } \\ \text { Archives Canada }\end{array} \\ \begin{array}{l}\text { Published Heritage } \\ \text { Branch }\end{array} & \begin{array}{l}\text { Direction du } \\ \text { Patrimoine de l'édition }\end{array} \\ \begin{array}{l}\text { 395 Wellington Street } \\ \text { Ottawa ON K1A 0N4 } \\ \text { Canada }\end{array} & \begin{array}{l}\text { 395, rue Wellington } \\ \text { Ottawa ON K1A 0N4 } \\ \text { Canada }\end{array}\end{array}$

Your file Votre référence ISBN: 978-0-494-47778-6 Our file Notre référence ISBN: 978-0-494-47778-6

NOTICE:

The author has granted a nonexclusive license allowing Library and Archives Canada to reproduce, publish, archive, preserve, conserve, communicate to the public by telecommunication or on the Internet, loan, distribute and sell theses worldwide, for commercial or noncommercial purposes, in microform, paper, electronic and/or any other formats.

The author retains copyright ownership and moral rights in this thesis. Neither the thesis nor substantial extracts from it may be printed or otherwise reproduced without the author's permission.
AVIS:

L'auteur a accordé une licence non exclusive permettant à la Bibliothèque et Archives Canada de reproduire, publier, archiver, sauvegarder, conserver, transmettre au public par télécommunication ou par l'Internet, prêter, distribuer et vendre des thèses partout dans le monde, à des fins commerciales ou autres, sur support microforme, papier, électronique et/ou autres formats.

L'auteur conserve la propriété du droit d'auteur et des droits moraux qui protège cette thèse. $\mathrm{Ni}$ la thèse ni des extraits substantiels de celle-ci ne doivent être imprimés ou autrement reproduits sans son autorisation.
In compliance with the Canadian Privacy Act some supporting forms may have been removed from this thesis.

While these forms may be included in the document page count, their removal does not represent any loss of content from the thesis.
Conformément à la loi canadienne sur la protection de la vie privée, quelques formulaires secondaires ont été enlevés de cette thèse.

Bien que ces formulaires aient inclus dans la pagination, il n'y aura aucun contenu manquant.

\section{Canada}




\section{ABSTRACT \\ DESIGN GUIDELINES FOR INTEGRATING AMPHIBIAN HABITAT INTO GOLF COURSE LANDSCAPES}

Daniel Brian Jackson

University of Guelph, 2008
Advisor:

Sean Kelly

Amphibian populations have been declining worldwide due to a number of environmental and human factors, the primary cause being habitat destruction and fragmentation. Golf courses present a valuable opportunity to provide amphibian habitat as both terrestrial and aquatic environments necessary for population persistence are commonly found within course layouts. Through key informant interviews, golf course architects and superintendents described the most suitable areas within the course layout to integrate naturalized habitat areas. A set of design guidelines was synthesized from the interviews and literature review and applied to the design of a golf course in the Golden Beach Resort, near Rice Lake, Ontario. The design was evaluated from ecological, golf course architecture and maintenance perspectives to assess the appropriateness of the design. By understanding and respecting aspects of the game which influence the spatial arrangement of natural areas, golf courses can provide critical habitat and support diverse amphibian populations. 


\section{Acknowledgements}

I would like to express my deepest gratitude to my advisor, Sean Kelly, for his guidance and patience throughout the development and completion of my thesis. His expertise and advice not only enriched my research but my entire graduate experience. I would like to thank Dr. Robert Brown for serving on my thesis committee and for being a source of inspiration throughout my education at the University of Guelph. I would also like to thank Dr. Karen Landman for chairing my defense and for her insightful comments.

Special Thanks to Michael Hurdzan, Doug Carrick, Thomas McBroom, Ian McQueen, Doug Taylor, and Brian Beemer for providing their knowledge and experience as key informants. I am grateful for Dr. Raymond Semlitsch, Michael Hurdzan and Ian McQueen for their evaluation of my design. Their comments were invaluable to my thesis and to my education.

My deepest appreciation goes to my mother Arlene, for her love and support over the past 25 years and to my father, Brian, for the inspiration to follow my dreams. I would not be where I am today without the foundation they provided. I want to thank my sister, Jennifer, to whom I have looked up to for advice throughout my life.

I want to thank my friends and classmates for the memorable experiences in Guelph. I am grateful to Cory Becker, who helped arrange interviews and Kirsten Brown who provided assistance throughout the development of the design. Finally, to my best friend Neeltje, whose love, support, and encouragement kept me motivated throughout the entire process. 


\section{Table of Contents}

Acknowledgments ......................................................................... i

List of Tables ................................................................................ iv

List of Figures ............................................................................ v

Chapter One - Introduction............................................................. 1

Overview ........................................................................... 1

Goals and Objectives ..................................................... 3

Research Design............................................................. 4

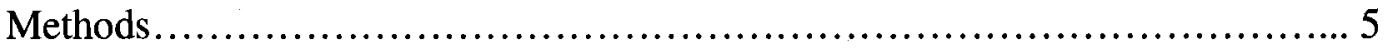

Chapter Two - Review of Literature ................................................................. 14

Introduction ................................................................ 14

Part One - Amphibian Habitat .................................................... 15

Landscape Ecology and Golf Course Landscapes............................. 15

Why Amphibians........................................................... 16

Amphibians in Decline ...................................................... 18

Amphibian Population Dynamics and Habitat Configuration................... 22

Core Terrestrial Habitat and Buffer Zones.................................... 27

Composition of Terrestrial Habitat.......................................... 30

Composition of Aquatic Habitats............................................. 33

The Effects of Road Density................................................. 35

The Golf Course Matrix................................................... 36

Part Two - Golf Course Design and Maintenance.............................. 39

General Design Principles........................................................ 39

Terrestrial and Aquatic Environments Within the Course Layout................ 44

Conclusion.................................................................... 49

Chapter Three - Key Informant Interviews........................................5 51

Golf Course Architects.................................................. 51

Golf Course Superintendents............................................ 64

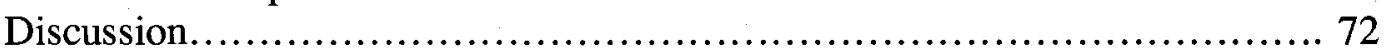

Chapter Four - Synthesis of Design Guidelines...................................... 78

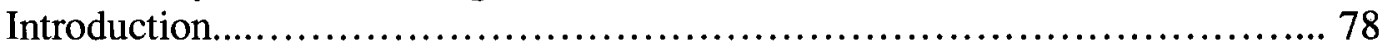

Amphibian Conservation Design Guidelines............................... 78

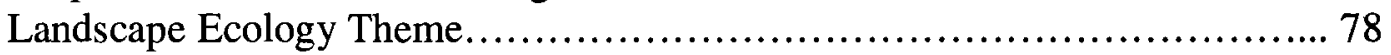

Habitat Composition Theme.............................................. 80

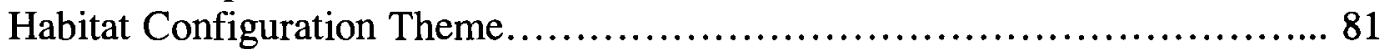

Golf Course Design Theme........................................... 82

Chapter Five - Application of Design Guidelines.................................... 87

Introduction.............................................................. 87

Rice Lake and the Oak Ridges Moraine................................. 87

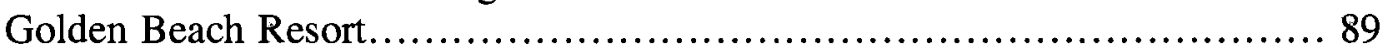


Official Plans.......................................................... 90

Site Inventory........................................................ 94

Site Analysis..................................................... 101

The Design......................................................... 104

Design Guidelines Application................................................................. 118

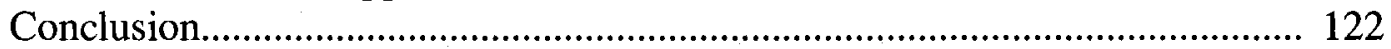

Chapter Six - Evaluation and Discussion ............................................. 123

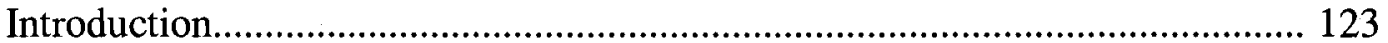

Golf Course Design and Maintenance......................................................... 123

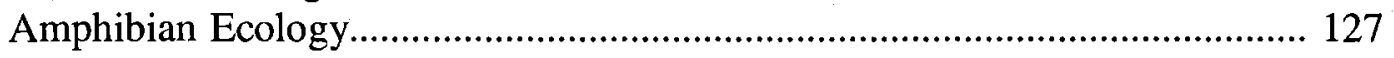

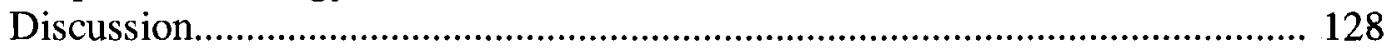

Chapter Seven - Observations and Conclusions.................................. 131

Summary of Research................................................ 131

Applicability of Guidelines............................................. 133

Limitations of the Study................................................ 134

Future Research..................................................... 136

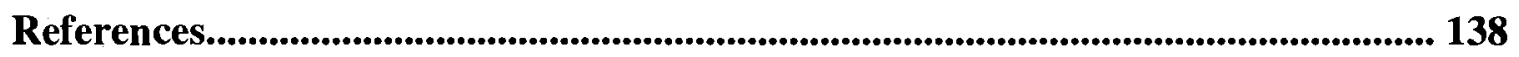

Appendix A - Key Informant Interview Questions................................... 146

Appendix B - Evaluative Responses.......................................................................... 153 


\section{List of Tables}

\section{Chapter Three - Key Informant Interviews}

Table 3.1. Summary of the Key Informant Interviews........................ 71

\section{Chapter Four - Synthesis of Design Guidelines}

Table 4.1. Landscape Ecology Principles - Patches........................ 79

Table 4.2. Landscape Ecology Principles - Edges and Boundaries........... 79

Table 4.3. Landscape Ecology Principles - Corridors and Connectivity..... 80

Table 4.4. Habitat Composition Guidelines - Terrestrial..................... 81

Table 4.5. Habitat Composition Guidelines - Aquatic...................... 81

Table 4.6. Habitat Configuration Guidelines................................ 82

Table 4.7. Golf Course Design Guidelines............................... 83

Table 4.8. Landscape Ecology Principles and the Golf Course Elements They Affect................................................ 84

Table 4.9. Design Guidelines and the Golf Course Elements They Affect...85

\section{Chapter Five - Application of the Design Guidelines}

Table 5.1. Summary of the Ecological Features............................108

Table 5.2. Scorecard of the Proposed Golf Course............................114

Table 5.3. Approach Shot Distances........................................114

Table 5.4. Demonstration of the Applied Design Guidelines 1................... 119

Table 5.5. Demonstration of the Applied Design Guidelines 2................... 120

Table 5.6. Demonstration of the Applied Design Guidelines 3................... 121 


\section{List of Figures}

\section{Chapter One - Introduction}

Figure 1.1. General Procedure of Methodology.......................... 5

Figure 1.2. Interview Question Design................................... 10

\section{Chapter Five - Application of the Design Guidelines}

Figure 5.1. Regional Context Map........................................................ 88

Figure 5.2. Aerial Image Showing Extent of the Golden Beach

Resort Property...................................................................... 90

Figure 5.3. Land Use Designations of the Township Official Plan and the ORMCP................................................. 93

Figure 5.4. Site Inventory Illustrating Existing Land Uses and Natural Features.................................................. 95

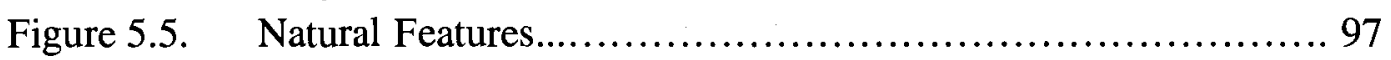

Figure 5.6. Elevation Model........................................... 98

Figure 5.7. Slope Analysis............................................... 99

Figure 5.8. View of Rice Lake from Wedding Hill..................... 100

Figure 5.9. View Looking Southeast from Wedding Hill................... 100

Figure 5.10. View of Surrounding Landscape from Max's Lookout........ 101

Figure 5.11. View of Rice Lake from Max's Lookout....................... 101

Figure 5.12. Site Analysis Demonstrating Opportunities and Constraints of Development............................................ 103

Figure 5.13. Golden Beach Resort Golf Course Master Plan............... 105

Figure 5.14. Overview of the Integration of the Design Guidelines into the Golf Course Layout .............................................107

Figure 5.15. Section Illustrating the Vertical Structural Diversity between Fairways and Terrestrial Environments...........................110

Figure 5.16. Section Illustrating a Littoral Shelf and Natural Edges on Golf Course Ponds.

Figure 5.17. Configuration of Aquatic and Terrestrial Habitats................112

Figure 5.18. Configuration of Patches Within a 200m Radius...............113

Figure 5.19. Plan Illustrating Safety Considerations........................116

Figure 5.20. Demonstration of the Applied Design Guidelines 1................... 119

Figure 5.21. Demonstration of the Applied Design Guidelines 2.................. 120

Figure 5.22. Demonstration of the Applied Design Guidelines 3................. 121 


\section{Chapter One - Introduction}

\section{Overview}

Amphibian populations have been experiencing declines worldwide due to a number of environmental and human causes (Collins \& Storfer, 2003; Wake, 1991; Wyman, 1990). Habitat destruction, alteration, and fragmentation is considered to be the primary cause of amphibian decline (Cushman, 2006). The concern with respect to amphibian conservation is the spatial arrangement of terrestrial and aquatic habitats within a landscape (Semlitsch \& Bodie, 2003). Connectivity between the two environments as well as with neighbouring populations is essential to allow dispersal, recolonization, and the exchange of genetic material between subpopulations (Marsh \& Trenham, 2001).

Golf courses present opportunities to provide both terrestrial and aquatic habitats as forested areas and water hazards are commonly used as strategic and aesthetic features within golf course landscapes. If incorporated in areas that are out-of-play, these environments can be left natural and can therefore provide the critical habitat requirements needed to support amphibian populations. There are, however, areas within the course layout that are not suitable for natural areas because they adversely affect aspects of the game. It is important for amphibian conservation that natural areas are integrated in suitable areas where they will not negatively impact the playability and aesthetics of courses. This will reduce the pressure for golf course superintendents to regularly maintain the areas, and thus avoid degrading the quality of the habitat.

This thesis concentrates on the composition of terrestrial and aquatic habitats and the configuration of these patches and corridors necessary to support diverse amphibian 
populations and to maintain regional metapopulations. By understanding and respecting aspects of the game of golf which influence the spatial arrangement of natural areas, golf courses can provide critical habitat and support healthy amphibian populations. 


\section{Goals and Objectives}

The goal of this research is:

- To explore an integrative approach to golf course design that supports amphibian habitat needs while maintaining playability, strategy, and aesthetics.

The objectives of this study are to:

- Identify the environmental and human causes of amphibian population decline;

- Synthesize terrestrial and aquatic habitat requirements of amphibians in general;

- Identify the influences of golf course architecture and maintenance which affect the opportunities for the integration of naturalized wildlife habitat into golf course landscapes;

- Develop a design framework that synthesizes amphibian habitat requirements and golf course design principles to ensure the successful integration of amphibian habitat into golf course landscapes;

- Apply these design guidelines to an existing site to demonstrate a suitable spatial arrangement of habitat areas within the golf course layout that respects the principles of golf design and maintenance;

- Evaluate the design from a golf course architecture, course maintenance, and an amphibian ecology perspective;

- Consider the applicability of the guidelines to other golf course developments. 


\section{Research Design}

The approach to this research combines a literature review with information derived from interviews with key informants. Design criteria and guidelines will be developed based on the information compiled through the research and then applied to a design for an 18-hole golf course. The course will then be evaluated individually by a golf course architect, a course manager and an amphibian ecologist to assess how the design satisfies the principles of golf design and maintenance as well as how suitable the landscape is for amphibian populations.

This research makes the assumption that the provision of quality habitat will support healthy populations. Changes to and fragmentation of amphibian habitat is considered to be the primary cause of population decline (Collins \& Storfer, 2003; Cushman, 2006; Gardner, Barlow, \& Peres, 2007; Harding, 1997). Since habitat destruction and degradation is one of the more reversible factors contributing to amphibian population declines (Semlitsch, 2002), golf course environments present opportunities to provide suitable habitat for amphibian populations, especially in urban and sub-urban landscapes (Hodgkison, Hero, \& Warnken, 2007). 


\section{Methods}

The general procedure of the method, as shown in figure 1.1, is presented in the following sections: the Literature Review, Key Informant Interviews, Design Criteria Development, Design Implementation, and Design Evaluation.

\section{Literature Review}

Golf Course Design/Maintenance Amphibian Habitat Wetlands

Key Informant Interviews

Golf Course Architects Course Managers

Design Criteria Development

Golf Course Design Matrix

\section{Design Implementation}

Golf Course Design

\section{Design Evaluation}

Golf Course Architect Course Manager Amphibian Ecologist

Figure 1.1. General Procedure of Methodology 


\section{Literature Review}

A literature review was completed to serve the following five functions:

1. To place the study into context with previous research and scientific knowledge (Babbie, 1998), to identify gaps within the literature and to illustrate how the study addressed them (Marshall \& Rossman, 2006).

2. To demonstrate the researcher's knowledge of related studies (Marshall \& Rossman, 2006).

3. To establish the importance of the study (Creswell, 1994).

4. To provide information on amphibian habitat requirements that can be used in guideline development.

5. To explore principles of golf course design and maintenance that may influence the integration of amphibian habitat into golf course landscapes.

Characteristics of the literature reviewed:

1. Literature on amphibian ecology, conservation, and biology was analyzed to understand metapopulation dynamics, life history, and critical habitat characteristics.

2. Design philosophies of established golf course architects were explored to identify major influences affecting course routing, composition, and elements.

3. Golf course management practices were reviewed to understand maintenance regimes and to identify potential opportunities and constiaints to integrating amphibian habitat on golf courses. 
4. Wetland design and construction was researched to summarize principles of design from the engineering, landscape architecture, and conservation fields.

\section{Key Informant Interviews}

Six key informants representing golf course designers (3) and course managers/superintendents (3) were interviewed to provide current perspectives of golf course architecture design principles and philosophies and golf course maintenance practices from top designers and courses in Canada and the United States. The following describes the method used to select the key informants:

Golf Course Architects Characteristics:

1. The informants consisted of three architects identified through professional and academic contacts. Their participation in the study was entirely voluntary.

2. They must be currently practicing in Canada and the United States and have designed courses in Southern Ontario. Their firm must specialize in golf course architecture.

3. The architects must be a member of the American Society of Golf Course Architects. Membership in the ASGCA requires a minimum of eight years of practical experience in golf course architecture and the design of at least five 18hole golf courses. Designation as a member is also dependent on a peer review and sponsorship by existing ASGCA members.

4. It was preferred that participants represent a wide range of personal and professional experience. 
5. It was preferred if the architect had designed courses listed on the Top 100 Courses in Canada by SCOREGolf Magazine. These rankings are compiled by a panel made up of media members, professional players, public golfers and other golf industry members who rank courses based on beauty, strategy, challenge, design, par-3 holes, par- 4 holes, par-5 holes, condition, and fun. These rankings provide a current perspective of golfer's expectations of courses in Canada.

\section{Course Managers/Superintendents:}

1. Key informants were selected from golf courses which were designed by the three architects that participated in the research.

2. The courses must be located within the Greater Toronto Area.

3. The informants had to be a Member of the Canadian Golf Course Superintendent's Association or the Golf Course Superintendent's Association of America.

4. Superintendents were chosen to represent courses found in rural and suburban landscapes as well as an Audubon Cooperative Sanctuary course. This was done to sample management practices and their response to different surrounding landscapes as well as to Audubon certification, where the goal is to improve the environmental performance of golf courses and to provide wildlife habitat on courses. Rural and suburban landscapes were chosen since the majority of golf course development is occurring in these areas. 
Limitations of Key Informant Selection Process:

The following were limitations due to their implications on the methodological approach and procedure.

1. Key informants do not provide a representative sample of their professions.

2. The limited number of informants was based on the resources, time, and professionals available.

\section{Interview Procedure}

Semi-structured in-depth interviewing was chosen as the method of inquiry. This qualitative research involves using a set of prepared questions to guide the interview but allows flexibility for the respondent to direct the conversation (Hakim, 1987). This method of collecting survey data was chosen because it allows the interviewer to clarify misunderstood questions as well as to pursue perspectives and topics revealed through the process in greater depth (Babbie, 1998). As a result, relevant responses can be obtained for the developed questions. The following criteria were satisfied in the selection and structure of appropriate questions. The process of developing the questions is illustrated in figure 1.2.

1. The specific purpose of the study was initially withheld in order to avoid biasing the interviewee's responses. Informants were fully debriefed upon completion of the interview (Kvale, 1996).

2. Sufficient variety of design, management, environmental, and habitat issues should be provided to understand what influences decisions. 
3. Questions were structured to increase the probability of the participant's perspective, and not that of the researcher (Marshall \& Rossman, 2006).

4. The number of questions was limited in order to complete the interviews in less than two hours.

5. Questions were selected to represent the experience of the participants, meaning they were not required to have knowledge of other professional fields (Babbie, 1998).

6. Interviews were conducted at the professional's place of employment (Bailey, 2007).

7. Interviews were tape recorded and later transcribed into text by the researcher into a formal written style; the result is a readable report representing personal perspectives of their professions (Kvale, 1996).

Research Purpose

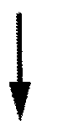

Central Research Questions

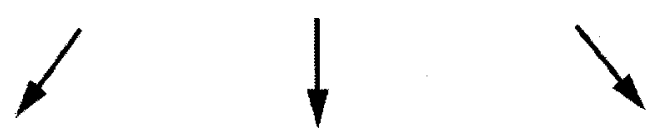

Theory Question 1

Theory Question 2
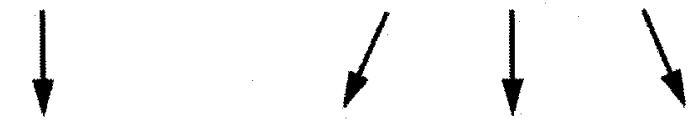

Theory Question 3

IQ 1a

IQ 2a IQ 2b

IQ 2c
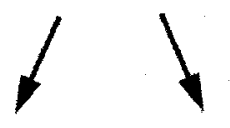

IQ: Interview Questions

Figure 1.2. Interview Question Design (Wengraf, 2001 p. 63). 


\section{Response Interpretation}

No standard method of analysis was used to analyze the interview material.

Rather, an ad hoc meaning generation method, as outlined by Kvale (1996), was

employed to get an overall understanding of the interview as well as to explore individual responses in greater detail. The responses collected during the semi-structured depth interviews were specifically analyzed for the following:

1. The informant's perspectives on the factors influencing golf course architecture and course maintenance.

2. The opportunities and constraints of integrating amphibian habitat into golf course landscapes.

3. Similarities, universals and differences (Babbie, 1998).

\section{Design Criteria Development}

Design criteria and guidelines on the integration of amphibian habitat into golf course layouts were developed based on the information compiled through the literature review and key informant interviews. Research revealed critical habitat requirements and suitable spatial arrangement of aquatic and terrestrial environments necessary to support amphibian life cycles and diverse populations. The literature review and key informant interviews also revealed the fundamental philosophies influencing the opportunities and constraints to integrating habitat into golf course landscapes. Criteria development addressed both amphibian habitat requirements and golf course design principles in order to create guidelines that would result in golf courses that could support healthy 
populations while not adversely affecting the course of play. The design guidelines were developed to satisfy the following:

1. Provide principles of landscape ecology that relate to the provision of amphibian habitat in order to provide opportunities for architects to influence the spatial arrangement of landscape elements.

2. Compile the critical terrestrial and aquatic requirements to meet the habitat composition characteristics outlined in the literature review.

3. Summarize guidelines for the configuration of terrestrial and aquatic patches based on the physiological constraints and dispersal behavior described in the literature review.

4. Promote guidelines based on the opportunities and constraints to integrating amphibian habitat into golf course landscapes uncovered through the key informant interviews and literature on golf course design and maintenance.

Limitations of design criteria development:

1. The critical habitat requirements are not species specific but rather a composition of several anuran and caudate species habitat preferences and requirements from several different studies. The intent of the guidelines was to aide in the provision of quality habitat representing a diverse range of amphibian species. If conservation efforts are aimed at the protection of an individual species, consultation of studies related to that specific species may lead to more effective efforts. 


\section{Design Implementation}

One site was chosen to apply the design guidelines to a new 18-hole golf course. The criteria used in the selection of the site to be designed were:

1. The site had to be located in the Greater Toronto Area.

2. The site had to be zoned for golf course development or the owner of the property had to be interested in developing a course.

3. Sufficient base material, topographic information, and environmental assessments had to be easily attained.

\section{Design Evaluation}

The final design will be submitted to one golf course architect and one course manager selected from the six participating key informants along with a specialist in the field of amphibian ecology to be evaluated based on their respected experience and expertise with the elements of the design. Criteria used in the development of the evaluation:

1. Participation in the evaluation was entirely voluntary.

2. Closed ended questions with ordered responses were used to elicit an assessment of design objectives included in the master plan (Dillman, 2000).

3. A Likert scale with labels was used to provide a sense of meaning to the evaluative responses for each design objective (Dillman, 2000).

4. Questions were designed to be relevant to the key informant's experience as they were not expected to have knowledge of other professional fields in order to complete the evaluation (Babbie, 1998). 


\section{Chapter Two - Review of Literature}

\section{Introduction}

The focus of this study is to define the landscape composition and configuration requirements critical to amphibian conservation and discuss opportunities to integrate these features within golf course landscapes. The literature review is separated into two sections, the first deals specifically with amphibian habitat characteristics, and the second with golf course design philosophies and maintenance practices that influence the spatial arrangement of elements within a golf course layout.

Wildlife management on golf courses stresses the importance of providing the four basic components of habitat: food, water, cover, and space to carry out life cycle activities (Dodson, 2000). The first section defines the characteristics of terrestrial and aquatic environments which satisfy the basic components with respect to amphibian populations and describes the configuration of habitat patches suitable to amphibian dispersal. An understanding of the composition and configuration requirements of amphibian habitats will provide golf course architects and course superintendents with the necessary information on the habitat characteristics needed within a course layout in order to support diverse amphibian populations.

The second section deals with the integration of terrestrial and aquatic environments into golf course layouts. Design philosophies of golf course architecture and theories of hazards along with golf course maintenance practices are reviewed to identify suitable locations to integrate amphibian habitat with respect to aspects of the game of golf. The goal is to locate areas which will not adversely impact the game or 
maintenance of course components so that terrestrial and aquatic habitats are left natural and more suitable for amphibian populations.

\section{Part One - Amphibian Habitat}

\section{Landscape Ecology and Golf Course Landscapes}

Landscape ecology is the study of the spatial pattern, processes, and dynamics of patches, corridors, edges, and ecosystems in a land area (Forman \& Godron, 1986). It encompasses the spatial arrangement of landscape elements, the movement of biotic and abiotic components, and the dynamics in the structure and function over time of landscape mosaics (Dramstad, Olson, \& Forman, 1996). A mosaic refers to the pattern or structure of patches, corridors, and matrix found within a landscape (Forman, 1995a).

Patches are defined as relatively homogenous environments which differ from their surroundings (Forman, 1995a). Edges refer to the perimeter of patches and differ from interior environments in both vegetation structure and species composition and abundance (Dramstad et al., 1996). The widths of edges are dependent on edge effects, which are predominately influenced by the affects of solar exposure and prevailing winds (Forman \& Godron, 1986). Corridors are similar to patches in that they are different environments than the land adjacent to their boundaries but they differ in form as they are generally in a wide or narrow strip (Forman, 1995a). Corridors function in a landscape by providing linkages between patches and other landscape elements (Dramstad et al., 1996). A matrix is the dominant land use type in a mosaic and is characterized by extensive cover, high connectivity, and/or major control over dynamics (Forman, 1995a). 
The spatial arrangement of these landscape elements play a critical role in the movement of species, materials, and energy through landscapes (Forman, 1995b). Golf course environments are characterized by patches, corridors, and matrix in the form of forested areas, ponds, stream corridors, and areas of turf. These elements play a pivotal role not only as golf course features but also as elements in larger landscapes. The spatial arrangement of elements within golf course layouts affects the flow and movements of abiotic and biotic components through the site and to the surrounding landscape. The composition and configuration of patches, corridors, and matrix play a critical role in amphibian conservation and will be discussed in greater detail in the subsequent sections of the literature review.

\section{Why Amphibians}

Amphibians have very specific habitat needs requiring both aquatic and terrestrial habitats at different stages throughout their life cycles (Crawford \& Semlitsch, 2007; Semlitsch \& Bodie, 2003). As a result, declines in amphibian populations will have ecological impacts in both ecosystems (Halliday, 2008; Ranvestel, Lips, Pringle, Whiles, \& Bixby, 2004). Both habitats are commonly incorporated on golf courses as hazards in order to enhance the strategy, playability, and aesthetic aspects of the game (Hurdzan, 2006). Golf courses present an opportunity to provide critical habitat for amphibians which will have positive affects in surrounding trophic systems.

Amphibians are key components in wetland and terrestrial ecosystems as they are often the most abundant vertebrates present in terrestrial habitats (Blaustein \& Kiesecker, 2002; Gibbons et al., 2006; Ranvestel et al., 2004; Wake, 1991). Amphibians serve as 
both consumers and prey for a diverse range of animals in both aquatic and terrestrial habitats. Adult amphibians are carnivorous eating mostly invertebrates as well as small vertebrates such as snakes, mice, birds, and other frogs (Harding, 1997). Amphibians also serve as prey for a variety of predators including mammals, fish, reptiles, birds, and other frogs (Harding, 1997). Tadpoles are herbivores feeding on algae and other organic sediments found in aquatic environments (Ranvestel et al., 2004). One of the major contributions of amphibians is the source of energy provided by the thousands of eggs laid by frogs in order to balance the loss to predators (Harding, 1997). Less than one egg in a hundred survives to reach adulthood, the rest being lost to the organisms which feed on them (Harding, 1997).

Aquatic larvae which metamorphose into adult amphibians leave their wetland ecosystem and migrate to terrestrial habitats where they spend the majority of their lives, returning only to lay their eggs (Hofrichter, 2000). This migration constitutes an exchange of energy and biomass from aquatic to terrestrial ecosystems (Gibbons et al., 2006; Halliday, 2008; Ranvestel et al., 2004; Willson \& Dorcas, 2003) thus supplying the surrounding habitats with a significant source of food (Meyer et al., 2007). The absence of amphibians from an ecosystem would constitute a considerable loss in biomass and available energy for organisms dependent on them as a source of food. Amphibian declines would disrupt trophic systems by negatively impacting predator populations as well as by changing the community structures of algae vegetation and prey species (Halliday, 2008; Ranvestel et al., 2004). By improving habitat conditions and by enhancing the connectivity between the two environments, the critical transfer of energy 
and biomass carried out by amphibians can be maintained and their role in the trophic system preserved.

Due to their integral role in aquatic and terrestrial ecosystems, amphibians are generally described as being bioindicators of environmental health (Collins \& Storfer, 2003; Hecnar \& M'Closkey, 1996; Wake, 1991; Willson \& Dorcas, 2003). Therefore, the presence of healthy amphibian populations in a landscape may signify a healthy environment which is capable of supporting a diverse range of organisms. Designing for the specific habitat requirements of amphibians may be an effective way to create environments which can host a diverse range of flora and fauna. Species of birds, mammals, and reptiles all benefit and depend on the closed canopy terrestrial habitat critical for amphibians (Hodgkison et al., 2007). Bird and mammal abundance is positively associated with vegetation structural complexity while the species richness of reptiles is related to coarse woody debris (Hodgkison et al., 2007). The provision of quality habitat for amphibians would not only preserve the transfer of energy in the trophic system but it would benefit a wide variety of organisms.

\section{Amphibians in Decline}

Amphibian populations have been experiencing declines worldwide (Collins \& Storfer, 2003; Wake, 1991; Wyman, 1990) which makes the conservation of amphibian assemblages and habitats critical in order to preserve their integral role in ecosystems. Amphibians have the highest amount of threatened species amongst all terrestrial vertebrates (IUCN, 2007). With higher levels than both birds and mammals, the decline in amphibian populations warrants concern. Alien species, over exploitation, land use 
change, global warming, ultraviolet radiation, increased pesticide and other toxic chemical use, pollutants, and infectious disease have all been identified as factors contributing to the decline of amphibian populations (Collins \& Storfer, 2003; Hofrichter, 2000; Wake, 1991; Wyman, 1990). The first three factors represent direct effects which have influenced amphibian species for decades while the latter five are more recent with fewer studies researching their impacts (Collins \& Storfer, 2003).

Changes to and fragmentation of amphibian habitat is considered to be the primary cause of amphibian decline (Collins \& Storfer, 2003; Cushman, 2006; Gardner et al., 2007; Harding, 1997). Structural alterations to the landscape caused by urban and suburban development, draining of wetlands, regulation of flowing waters, and agricultural land use affect both the terrestrial and aquatic habitats critical to amphibian species (Hofrichter, 2000). Hecnar and M'Closkey (1996) reported that wetlands in southwestern Ontario had been reduced from 68.9 percent in presettlement times to coverage of between 2.9 and 10 percent at the time of their research. This significant loss of habitat threatens populations because it alters the environments necessary for amphibians to carry out their life cycles (Semlitsch, 2000) and it results in highly fragmented landscapes (Cushman, 2006; Wake, 1991). Populations become isolated from one another due to limited dispersal distances (Hofrichter, 2000) reducing the probability of colonization following local extinctions and reducing the exchange of genetic materials (Marsh \& Trenham, 2001). Loss and fragmentation of habitat is one of the more reversible causes of amphibian decline (Semlitsch, 2002) and steps should be taken to protect and enhance aquatic and terrestrial habitat. Golf courses present an 
opportunity to provide both aquatic and terrestrial habitats as approximately 70 percent of the area is defined as out-of-play (Boone, Semlitsch, \& Mosby, 2008).

Amphibian habitats can also be altered by the introduction of predatory fish and exotic species which negatively impact amphibians through predation, competition, and foreign pathogens (Collins \& Storfer, 2003; Semlitsch, 2000). Native species are adversely affected by aliens due to a lack of evolutionary experience with the introduced species (Kats \& Ferrer, 2003). Exotic organisms often become dominant in the new habitats resulting in native amphibians becoming endangered or locally extinct (Hofrichter, 2000). One of the most common sources of alien species is the stocking of aquatic habitats with fish to support recreational and sport fishing industries (Kats \& Ferrer, 2003). Whether alien species are introduced intentionally or by accident, they pose a serious threat to indigenous species and have caused declines in amphibian populations around the world (Collins \& Storfer, 2003). Golf courses can reduce the threat of exotic species and predatory fish by providing a range of ponds that dry at varying times throughout the year or by draining ponds (Boone et al., 2008).

Humans can directly affect amphibian populations through overexploitation. Frogs are harvested as a delicacy (frog legs) as well as for medicinal and educational purposes (Harding, 1997; Logier, 1952). In France, 3000 to 4000 metric tonnes of frog legs are consumed a year which constitutes a significant decrease in local populations considering approximately 20000 frogs are sacrificed for each tonne (Blaustein \& Wake, 1995). If populations are harvested at levels greater than their ability to reproduce and replace their losses, the species will decline. 
The effects of global warming, UV radiation, pollutants, and disease on amphibian populations are less known (Collins \& Storfer, 2003). Global climate change can adversely impact amphibian populations by altering weather conditions such as temperature and rainfall (Semlitsch, 2000). Amphibians are dependent on moist environments and aquatic habitats for breeding and larval development (Duellman \& Trueb, 1986) which means any changes in climatic conditions could threaten amphibian populations (Semlitsch, 2000). Another global climate change, ultraviolet radiation, has been found to increase egg mortality in species which lay their eggs in open, shallow water (Blaustein et al., 1998) as well as to kill insect larvae and aquatic algae which reduces food resources (Blaustein \& Wake, 1995). Chemical contaminants and pollution, such as acid rain, can affect both aquatic and terrestrial habitats (Semlitsch, 2000) impairing reproduction and development of individuals (Blaustein \& Wake, 1995). Diseases and pathogens, specifically the chytrid fungus, have been linked to mass mortalities throughout the world (Beebee \& Griffiths, 2005; Carey, Cohen, \& RollinsSmith, 1999).

The interaction between these factors and their influence on amphibian populations needs to be researched in greater detail (Wake, 1991). It is likely that multiple factors are responsible for the decline of amphibian species and the problems will continue to compound as human populations continue to increase (Beebee \& Griffiths, 2005). 


\section{Amphibian Population Dynamics and Habitat Configuration}

Due to the prominence of habitat fragmentation and alteration as a cause in amphibian declines, many researchers have adopted a metapopulation approach to describe amphibian population dynamics (Marsh \& Trenham, 2001). A metapopulation is a group of spatially connected subpopulations that experience processes such as extinction, migration, and colonization which affect their ability to perpetuate in a landscape (Hofrichter, 2000). Amphibians exhibit metapopulation characteristics due to their dependence on both aquatic and terrestrial habitats and their migration amongst regional ponds (Hecnar \& M'Closkey, 1996), which is typically carried out by juveniles (Rothermel \& Semlitsch, 2002). Amphibian metapopulations are controlled by the number of individuals dispersing among ponds and the spatial arrangement of aquatic and terrestrial environments in a landscape, both of which affect the probability of success of migration between habitats and colonization of unused habitats (Semlitsch, 2002).

Subpopulations are subject to local extinctions due to deterministic and stochastic events and rely on re-colonization from neighbouring populations to reestablish species presence in suitable habitats (Marsh \& Trenham, 2001). Whether the declines are a result of human activity or natural fluctuations, the ability of metapopulations to persist in a region is dependent on the balance between local extinctions and colonization (Pechmann \& Wilbur, 1994). Therefore it is critical to maintain connections between aquatic and terrestrial habitats as well as linkages between subpopulations to facilitate colonization through dispersing individuals in the case of local extinctions (Semlitsch, 2002).

Due to physiological constraints, relatively low movement patterns, and site fidelity amphibians may be less likely to recolonize areas which suffer local extinctions 
(Blaustein, Wake, \& Sousa, 1994). Amphibian skin is permeable to water and therefore susceptible to evaporative water loss which limits amphibians to cool moist microclimates (Duellman \& Trueb, 1986; Semlitsch, 2002). Movement can also be restricted due to thermoregulation requirements whereby individuals will avoid environments where they are unable to maintain their body temperature in vital ranges (Hofrichter, 2000). Amphibians typically have small home ranges and do not travel long distances between habitats (Sinsch, 1990). Semlitsch and Bodie (2003) estimated core terrestrial habitat ranges from 159 to 290 metres from the edge of aquatic sites for amphibians. Finally, adult amphibians are highly philopatric meaning they return to the same breeding pond every year (Gamble, Kevin, \& Compton, 2007). These physical constraints reduce opportunities for dispersal and migration to nearby habitats therefore increasing the probability of local extinctions (Hecnar \& M'Closkey, 1996).

Amphibians require both aquatic and terrestrial habitats during different stages of their life history so conservation efforts should be directed at the preservation and spatial arrangement of both environments within a landscape (Semlitsch \& Bodie, 2003). Laan and Verboom (1990) found that colonization of suitable habitat patches was positively associated with decreases in the distance to source populations and an increasing connectivity of habitats within the landscape. Terrestrial environments were found to be the most effective elements enhancing connectivity of amphibian habitat (Laan \& Verboom, 1990). Pond occupancy may be more dependent on the spatial arrangement of terrestrial habitat rather than the relationship between neighboring breeding ponds (Marsh \& Trenham, 2001). 
Hecnar and M'Closkey (1996) argue that the ultimate cause of amphibian population declines is reduced opportunities for colonization which increases the likelihood of extinction. Fragmentation and habitat loss can result in suitable habitats being unpopulated because they are isolated and cannot be reached by dispersing amphibian individuals (Hofrichter, 2000). Connectivity becomes more important in landscapes which have undergone large-scale alterations by human development since terrestrial and aquatic habitats may become divided by environments which pose barriers to migration for amphibian species (Marsh \& Trenham, 2001). The rearrangement, removal, and or addition of elements to a mosaic affects the structure and function of the landscape (Dramstad et al., 1996). Increased fragmentation results in smaller patch sizes, greater distances between patches and a greater risk of extinction (Cushman, 2006). Therefore it is critical to maintain connections between aquatic and terrestrial habitats as well as connections between subpopulations (Semlitsch, 2002).

Metapopulation dynamics has implications for the design and planning of golf courses. Local extinction and colonization are functions of the size and spatial arrangement of terrestrial and aquatic habitats (Marsh \& Trenham, 2001). The spatial relationships of terrestrial habitats is the most critical element in the landscape which increased connectivity of subpopulations (Laan \& Verboom, 1990). Therefore it is critical that golf course design addresses the connectivity of terrestrial habitat to breeding ponds as well as the connections between aquatic environments if amphibian conservation is a focus.

Landscape composition and configuration are two terms used to characterize the area of patches and their spatial configuration within the landscape (Guerry \& Hunter Jr., 
2002). Composition refers to the type and size of patches while configuration refers to how the components are spatially related to each other. Both the physical characteristics and the spatial arrangement of patches within a landscape influence species occupancy and abundance (Knutson et al., 1999). At the individual level, landscape composition plays a more critical role due to limited dispersal abilities, philopatric behavior, and moisture requirements (Guerry \& Hunter Jr., 2002). At the population or metapopulation level, landscape configuration may be more important due to connectivity and colonization between local subpopulations (Guerry \& Hunter Jr., 2002). To attract a range of species, patch diversity in size, shape, and composition as well as providing connections between terrestrial patches and breeding ponds should be addressed (Guerry \& Hunter Jr., 2002; Knutson et al., 1999).

Hodgkison et al. (2007) found that local conservation efforts on golf courses that enhance the size and structure of habitats can improve species abundance and provide refuge for species in urban environments. Small scale changes to site design and management practices can result in improved quality and availability of habitat. The importance of spatial conservation plans at both the site specific and landscape scale are critical to enhancing and developing suitable amphibian habitat (Cushman, 2006). While local efforts at individual sites may improve the quality of terrestrial and aquatic habitat, it is important to address the relationships between these two environments with respect to species specific dispersal abilities.

At a local scale level on golf courses, species abundance is influenced by the size and spatial arrangement of terrestrial and aquatic habitats (Hodgkison et al., 2007). This implies that simply maximizing the area of wooded and aquatic habitat on golf courses 
will not necessarily result in increased biodiversity (Hodgkison et al., 2007).

Connectivity and the spatial relationships between aquatic and terrestrial habitat is critical to providing suitable amphibian habitat. Connectivity between wooded upland and breeding ponds is highly dependent on the dispersal abilities of juveniles (Cushman, 2006). Both landscape composition and configuration need to be addressed when developing conservation plans; size cannot mitigate fragmentation and arrangement cannot mitigate habitat loss (Guerry \& Hunter Jr., 2002). Furthermore, a diversity in terrestrial and aquatic environments will attract a more diverse range of species (Snodgrass, Komoroski, Bryan Jr., \& Burger, 2000). Design of golf courses can address these issues by incorporating appropriate corridors, patch sizes and shapes, and diverse habitats as well as by considering the dispersal abilities of specific species.

At a patch scale level on golf courses, management practices can be altered to provide more suitable habitat. Under-storey vegetation is often removed to increase playability and as a result diversity of terrestrial habitat is reduced and species are exposed to predation, noise, competition, and disturbance (Hodgkison et al., 2007).

In addition to local conditions, regional locations of golf courses and landscape context can affect the course's ability to support amphibian populations (Hodgkison et al., 2007). Area of adjacent native vegetation, proportion of built land, number of connecting streams (Hodgkison et al., 2007), and road density (Eigenbrod, Hecnar, \& Fahrig, 2008) all influence species populations on golf courses. To address this issue, Hodgkison et al. (2007) advocates that golf course design be integrated with regional and urban planning to ensure that golf courses and other urban green spaces are ideally located to provide adequate connections between habitats. 
It is important to determine the scale of recovery plans in order to tailor conservation efforts. If the goal is to help recover a declining population, then, quality of the aquatic and terrestrial habitat is critical while if the goal is to improve regional metapopulations, corridors and new wetlands to serve as stepping stones between habitats are needed to enhance connectivity (Semlitsch, 2002).

\section{Core Terrestrial Habitats and Buffer Zones}

Amphibians are dependent on both aquatic and terrestrial habitats for different stages in their life cycles. Regulations tend to focus on the preservation of aquatic environments and as a result fail to consider the impacts on wildlife that require both habitats and adequate connections between them (Crawford \& Semlitsch, 2007; Semlitsch \& Bodie, 2003). Amphibians spend the majority of their life in terrestrial habitat, using it for foraging, growth, and development, which makes the preservation of terrestrial areas critical to amphibian conservation (Semlitsch, 1998).

Different amphibian species have varying habitat requirements at different stages in their life cycles (Semlitsch, 1998; Semlitsch \& Bodie, 2003) which means buffer zones around breeding sites need to respond to the specific dispersal limitations of local species. To achieve greatest diversity, a buffer zone which protects the species with the furthest dispersal ability will therefore provide the greatest protection. A number of studies have estimated core terrestrial habitats aimed at protecting 95 percent of local populations resulting in suggestions for zones ranging from $42.6 \mathrm{~m}$ for salamanders (Crawford \& Semlitsch, 2007), 164 m (Semlitsch, 1998), 159-290 m (Semlitsch \& Bodie, 2003), to $370 \mathrm{~m}$ (McDonough \& Paton, 2007). Sizes of core terrestrial zones can be adjusted to 
protect different portions of the population but the impacts this has on the persistence of populations is unknown (Semlitsch \& Bodie, 2003). Furthermore, the effects of varying habitat quality within the terrestrial habitat on the requirements of zone size is unknown (Semlitsch \& Bodie, 2003). However, increases in amphibian population density can result in decreased larval development, survival, and reproduction due to increased competition (Semlitsch, 1998, 2002) which could have negative consequences for populations.

The conservation of core terrestrial buffer zones around breeding habitats only protects local populations (Semlitsch, 1998). If adequate corridors and connections to neighboring populations are not provided, local populations are subject to extinction. Additional wetlands and terrestrial habitats need to be conserved in order to accommodate migration and emigration between populations and to improve connectivity between metapopulations.

The integration of core terrestrial buffer zones up to 290 metres around breeding pools is impractical on golf courses because the pond would lose its strategic and aesthetic characteristics. At least a portion of the pond must be free of terrestrial vegetation in order to be incorporated into the game. Core terrestrial habitat conservation on private lands such as golf courses can be impractical because too small of an area may be conserved due to land use requirements which may result in critical habitat features being omitted or too large of an area may be conserved which is inefficient (Baldwin, Calhoun, \& deMaynadier, 2006).

Rather than protecting large core terrestrial habitat zones in circular patterns around breeding ponds, Baldwin et al. (2006) suggest conserving a network of habitat 
elements such as breeding pools, forested upland, and forested wetlands within the migratory range of amphibian species. This method is more conducive to private land uses such as golf courses since complementary activities can be incorporated into areas of habitat conservation. However, this approach to habitat provision is dependent on the intervening matrix providing suitable environments for amphibian dispersal and migration (Baldwin et al., 2006). Agricultural fields, pastures, and steep banks can isolate patches of habitat because they present environmental conditions which may not be conducive to amphibian dispersal (Laan \& Verboom, 1990). To integrate golf courses into the mosaic of aquatic and terrestrial habitat and corridors, its features must be suitable to accommodate amphibian migration between patches. This will be discussed in greater detail in subsequent sections.

In addition to the spatial arrangement of wetlands, ponds, and forested patches within a landscape, there are associations between amphibian abundance and species richness and the size of habitats. Woodlot area has been found to be positively associated with species richness (Knutson et al., 1999; Vallan, 2000). Salamanders, which are more susceptible to evaporative water loss due to larger surface areas, are affected by the edge to area ratio of terrestrial patches (Weyrauch \& Grubb Jr., 2004). Exposure to sunlight and wind can alter the microclimates of forest habitats creating environments less suitable for both anurans and caudates. Vallan (2000) argues that larger fragments of forested areas provide more diversity of microhabitats which can support a greater range of species while smaller patches tend to be more homogenous in vegetation. Larger areas provide possibilities for varied microclimates, vegetation, understory, and substrate material which can support a greater range of species. Furthermore, larger areas will 
decrease the densities of populations which is more beneficial to populations (Semlitsch, 1998, 2002). No association has been found between the size of aquatic habitats and species richness or abundance (Hodgkison et al., 2007; Laan \& Verboom, 1990). To improve amphibian conservation, it is important to preserve or create large core areas of terrestrial habitat to provide suitable microhabitats.

\section{Composition of Terrestrial Habitat}

The composition of terrestrial habitat is a critical factor influencing amphibian activity and population persistence (Dupuis, Smith, \& Bunnell, 1995). Quality habitat must be provided to ensure individuals have sufficient environments for foraging, refuge, overwintering, and dispersal between habitats (Guerry \& Hunter Jr., 2002; Semlitsch \& Bodie, 2003). Amphibians are dependent on cool moist environments due to their permeable skin and respiration requirements (deMaynadier \& Hunter Jr., 1998). Anurans and caudates generally have low tolerances of hot and dry conditions (Dupuis et al., 1995) and are susceptible to desiccation from solar exposure and wind (Logier, 1952; Paton \& Egan, 2002). These physiological characteristics of amphibians make microclimatic conditions of terrestrial habitats and forest floor substrates crucial to conservation efforts.

The characteristics of old growth forests have been found to present the most suitable microclimates and microhabitats critical to amphibian individuals (Dupuis et al., 1995; Welsh Jr., 1990). Dense canopies reduce the level of ambient light that reaches the forest floor creating moist surface conditions which are more suitable for amphibian species (Faccio, 2003). Ambient temperatures are cooler and soil moisture content is 
higher under the closed canopies of mature forests (Dupuis et al., 1995). Forest stands that are older, taller, and more structurally diverse help regulate cool moist microclimatic conditions and provide more stability of substrate temperatures throughout the season (Welsh Jr., 1990). Managed or young forests, which have less developed canopies and less structural diversity, potentially create hotter and drier conditions which can restrict amphibian activity to the wet and cool conditions of the spring and fall (Dupuis et al., 1995). This may limit reproduction and foraging which can have adverse affects on amphibian populations (Dupuis et al., 1995). Even more hospitable to amphibian activity are areas that have been clear cut. These open areas receive more direct solar radiation, lose more long-wave radiation, and experience higher rates of evapotranspiration which creates sunnier, warmer, windier, and drier environments than within interior areas of forest (Carlson \& Groot, 1997; Chen, Franklin, \& Spies, 1993). The conservation of old growth forests adjacent to younger less mature terrestrial areas within landscapes is essential for amphibian persistence as older forests can act as source populations providing individuals for recolonization (Dupuis et al., 1995).

Edge effects also play a crucial role affecting species composition and activity within terrestrial environments by altering conditions up to 50 metres into forest patches (Murcia, 1995). Microclimate conditions within edges are influenced by solar radiation, wind, and relative humidity. Chen et al. (1993) found that edges experienced intermediate levels of wind velocity and solar radiation while temperature and relative humidity were higher than in clear cut areas. The higher temperatures and humidity were explained by the relatively stable air conditions caused by winds which are weaker around edges than in open areas (Chen et al., 1993). 
Edge effects can penetrate several metres into forested areas deteriorating the microclimate conditions and reducing the quality of habitat for amphibians. Solar radiation and wind exert stronger effects on forested areas when there is a greater variation in vegetation structure between the two ecosystems (deMaynadier \& Hunter Jr., 1998). Providing structural diversity through layers of dense shrubs and understory, called the mantel, located along the boundary between two types of vegetation or land uses, can filter wind, light, and heat altering the microclimate within the forest edge (Forman \& Godron, 1986).

On the forest floor, coarse woody debris, an undisturbed layer of leaf litter, small mammal burrows, boulders, a dense low shrub layer, and high soil moisture content create ideal surface and subterranean microhabitats necessary for overwintering and refuge (Faccio, 2003; Semlitsch, 2002; Semlitsch \& Bodie, 2003). Closed canopies play an important role in maintaining the cool moist conditions of substrate elements such as logs and other cover materials (Dupuis et al., 1995). Providing these microhabitats in cool moist forested areas will provide suitable habitats necessary to satisfy the terrestrial portions of amphibian life cycles.

Some species, such as the American toad (Bufo americanus) and leopard frogs (Rana pipiens), are negatively associated with forest cover and require open space as habitat (Guerry \& Hunter Jr., 2002; Kolozsvary \& Swihart, 1999). Golf courses can provide a diverse range of habitats ranging from forested terrestrial areas, to naturalized areas with native grasses and small shrubs, to maintained turf areas. 


\section{Composition of Aquatic Habitats}

Aquatic environments play a critical role in the development of pond-breeding amphibians. Despite the fact that amphibians spend only a small portion of their life cycles in aquatic habitats, the conditions of these environments influence which species will survive and how many tadpoles or larvae will transform into juvenile frogs and salamanders and migrate into the terrestrial habitat to join the adult population (Semlitsch, Boone, \& Bodie, 2007). The quality and suitability of aquatic habitats is determined by hydroperiods, biotic community structure, littoral shelves, and water chemistry (Semlitsch, 2002).

Hydroperiod refers to the length of time in which a pond holds water, thus providing aquatic habitat for amphibian species (Semlitsch, 2002). Larval development varies between species, ranging from several days to several years (Hofrichter, 2000) thus making the hydroperiod of a pond critical in determining the biotic structure of aquatic environments. Eggs and larvae of amphibians are intolerant of drying and if habitats dry too often or for too long, it will have adverse effects on amphibian populations (Maret, Snyder, \& Collins, 2006).

Maintaining long hydroperiods may have adverse effects on amphibian populations because they allow for predatory fish and American bullfrogs (Rana catesbeiana) to establish populations in habitats (Boone et al., 2008; Kats \& Ferrer, 2003; Maret et al., 2006). Bullfrogs negatively influence amphibian populations by reducing algal food resources and by preying on tadpoles (Boone et al., 2008). Ponds with long hydroperiods favour bullfrogs because they have longer larval development, are larger 
after overwintering (Boone et al., 2008) and they are unpalatable to fish (Maret et al., 2006).

Golf courses typically construct only permanent ponds which provide favourable conditions for predatory species of fish and bullfrogs (Hodgkison et al., 2007). In a study assessing pond-breeding amphibian use of ponds on golf courses, Paton and Egan (2002) found the most abundant species were bullfrogs and green frogs (Rana clamitans melanota). To increase species diversity, ponds with varying hydroperiods should be provided (Hodgkison et al., 2007; Semlitsch, 2002). This will accommodate the varying larval development periods of a diverse range of amphibian species.

An alternative approach is to drain ponds every two years which has been proven to be an effective control of bullfrog populations (Doubledee, Muller, \& Nisbet, 2003). Drying of wetlands is a natural process that should be included in conservation plans to eliminate predatory and invasive species (Semlitsch, 2002). Bullfrogs and green frogs are native to the Great Lakes region and Eastern Canada and the United States (Harding, 1997), so therefore should be conserved. Permanent ponds should be maintained, in addition to ponds with varying hydroperiods, in order to provide habitat for these species. To successfully support a diverse range of amphibian species, a diverse range of ponds with varying hydroperiods from ephemeral to permanent should be provided.

Littoral shelves play a crucial role for amphibians during the aquatic stages of their life cycles (Porej \& Hetherington, 2005). A shallow littoral zone provides microhabitats for oviposition, foraging, and refuge for pond-breeding amphibians (Semlitsch, 2002). Hodgkison et al. (2007) found that amphibian abundance and species richness was negatively associated with increasing waterbody bank steepness and 
turfgrass cover on banks, while there was a positive relationship with floating vegetation. Shallow littoral zones of slopes 15:1 or less promote the growth of sedges and grasses which provide sites for nesting and refuge, while also providing foraging areas and sources of food for larvae (Porej \& Hetherington, 2005; Semlitsch, 2002).

Chemical contaminants in golf course ponds caused by runoff from surrounding turf areas causes concern for amphibian conservation efforts (Boone et al., 2008). Contaminants can affect vegetation structure and disrupt trophic systems which could adversely affect amphibian populations (Boone et al., 2008). Through Best Management Practices (BMPs) and careful application of chemicals, pesticide runoff can be minimized reducing the negative effects on aquatic habitats (Davis \& Lydy, 2002). Vegetated buffer zones can be used between maintained turfgrass and waterbodies to filter runoff as well as to separate human activity from core amphibian habitat (Dodson, 2005).

Research on wetland size and amphibian species richness has revealed there is no relationship (Hecnar \& M'Closkey, 1996; Snodgrass et al., 2000). Therefore, a diverse array of ponds which creates variation in seasonal filling and drying should be provided (Semlitsch et al., 2007). Small wetlands and ponds can also improve biodiversity by serving as stepping stones, connecting larger patches of habitat within a landscape (Semlitsch \& Bodie, 1998).

\section{The Effects of Road Density}

Eigenbrod et al. (2008) found that the negative association between species richness and road density was larger than the positive association between species richness and forest cover. In their study, traffic density was measured rather than length 
of paved roads within a $1 \mathrm{~km}$ radius which resulted in a more accurate relationship between amphibian populations and road traffic. The negative association between species abundance and road traffic is due to direct mortality of amphibians migrating between habitats (Fahrig, Pedlar, Pope, Taylor, \& Wegner, 1995). The effect of traffic intensity on amphibian populations was found to be as detrimental as forest destruction and therefore needs to be addressed in amphibian conservation efforts (Eigenbrod et al., 2008).

\section{The Golf Course Matrix}

Due to complex life cycles and physiological constraints, amphibian dispersal is influenced by the conditions of the matrix between habitats (Rothermel \& Semlitsch, 2002). Some amphibian species behaviorally avoid grassland environments and migrate towards forested areas which offer more suitable conditions in interior habitat (Rittenhouse \& Semlitsch, 2006). Amphibians tend to avoid open fields which offer no canopy cover, because of higher rates of mortality due to predation and evaporative water loss (Rothermel \& Semlitsch, 2002). The behavior of amphibian species within golf course landscapes, which consist of grassland and forest environments, is important to understand in order to improve conservation efforts.

Dispersal and migration of spotted salamanders (Ambystoma maculatum) and green frogs across golf course landscapes have been tracked to determine the effect of maintained grassed areas on behavior. Salamanders were tracked using radiotags and transmitters crossing fairways over 80 metres wide (McDonough \& Paton, 2007) as well as over cart paths 2 metres wide (Montieth \& Paton, 2006). A negative effect of dispersal 
across open areas on golf courses was the increased risk of predation, especially by snakes (McDonough \& Paton, 2007). Green frogs demonstrated a preference for the shorter grass $(<8 \mathrm{~cm})$ found on golf courses since these environments offer the path of least resistance (Birchfield \& Deters, 2005). Individuals remained close to the edge of taller grass $(34 \mathrm{~cm})$ since these habitats could offer potential refuge from predators and unfavourable environmental conditions (Birchfield \& Deters, 2005).

These three studies demonstrate the suitability of golf course landscapes for amphibian dispersal. The open environments consisting of short maintained grasses do not pose as a barrier preventing migration between habitats. However, the open areas do not provide suitable environments for refuge, foraging, or overwintering and expose individuals to desiccation and predation (Rothermel \& Semlitsch, 2002). Dispersal across open areas was directed towards forest patches making the provision of terrestrial environments critical to amphibian conservation on golf courses.

To avoid desiccation and overheating, many amphibian species are only active during the night or twilight hours (Logier, 1952). They avoid the potentially lethal temperatures from sunlight by seeking refuge in cool, dark places (Logier, 1952). The higher humidity and lower temperatures characteristic of nights offers more suitable environmental conditions for breeding, foraging, and other life cycle processes (Porter, 1972). Amphibians have the ability to cool themselves in higher temperatures through evaporation but to avoid overheating they must be able to absorb water from the environment (Pough et al., 2004). Amphibians that are active during the day are generally aquatic or semi-aquatic and remain in or close to permanent bodies of water which allows them to absorb water when needed (Porter, 1972). Furthermore, amphibian 
migration and activity is positively associated with precipitation (Timm, McGarigal, \& Compton, 2007; Vasconocelos \& Calhoun, 2004). Rainfall helps to prevent desiccation and therefore can be more conducive to amphibian activity in or across environments that were previously dry (Timm et al., 2007). Golf course maintenance practices and play may be complementary to these behavioral practices as the majority of activity is completed after sunrise and throughout the day when conditions are not as favourable for amphibian activity. Furthermore, maintenance and play is typically suspended during precipitation events. However, care should be given to respect the life cycle activities of amphibians in order to ensure successful conservation of a diverse range of species. 


\section{Part Two - Golf Course Design and Maintenance General Design Principles}

Each golf course architect has their own unique style of design but there is commonality between general principles that influence the design and layout of golf courses. There is no predetermined set of guiding principles but playability, strategy, and aesthetics are regularly mentioned in literature pertaining to the design philosophies of established golf course architects. These principles are influential throughout the design process affecting the routing, layout, and detail design of golf courses and specific features within the golf environment. Understanding the general principles of golf course design will allow for the successful integration of habitat into golf course landscapes that complement the game of golf.

\section{Playability}

Playability plays a significant role in golf course design in order to ensure the course can accommodate a diverse array of players with varying skill levels (Hurdzan, 2006). Designing a fair course which is suitable for all skill levels provides an enjoyable experience for the greatest amount of people (Fazio \& Brown, 2000). Knowing the intended clientele and how the course will be played is essential to designing a playable course (Nicklaus \& Millard, 2002). The playability of a course is largely dependent on the placement of hazards, which are features that influence decisions and shot making (Hurdzan, 2006). Their arrangement within the course layout can be used to challenge and penalize the shots of golfers, which makes it critical to understand how hazards affect players of varying skill levels (Fazio \& Brown, 2000). 
There are general principles in the design of hazards that architects consider to ensure playability is maintained. High handicap players, which comprise the majority of golfers, generally slice the ball from left to right which means hazards placed on the right side of fairways will have a greater impact on the less-skilled player (Hurdzan, 2006). Hazards placed perpendicular to lines of play have a greater impact on high handicap players because it creates target golf, where players are forced to play through the air from one target to the next (Fazio \& Brown, 2000). Forced carries, which are situations where golfers have no option but to play in the air over the feature, across hazards should be avoided but when necessary they should be incorporated in front of tee boxes where the distance required to carry can be controlled (Doak, 1992). Providing openings to greens and alternate routes around hazards accommodates high handicap players who tend to hit the ball along the ground (Fazio \& Brown, 2000). Dr. Alister Mackenzie argues the course should be arranged so that a less-skilled golfer always has an alternate route around a hazard and the penalty for doing so is subtle (Mackenzie, 1982).

Providing wider landing zones and greater margins for error in places where lessskilled golfers typically hit while placing hazards to challenge scratch golfers, or highlyskilled players, can create an enjoyable and challenging course for players of all skill levels (Hurdzan, 2006). Doak (1992) stresses the importance of variety in hazard placement to ensure one type of player is not penalized more than another. These flexible guidelines help ensure that the average player can enjoy the course because they are not forced to execute shots which do not fall within their abilities. For the successful integration of habitat into the golf landscape, ensuring the environments do not adversely impact playability is critical. 


\section{Strategy}

Similar to playability, strategy is dependent on the placement of hazards. Strategic golf design presents golfers with alternate routes to play a hole that forces golfers to make decisions to negotiate hazards based on their skill level (Graves \& Cornish, 1998). The goal of adding strategy to the game is to entice golfers to dare a hazard and reward those who successfully negotiate it while those who choose to avoid the hazard and play safe are faced with a longer or more difficult second shot (Thomas, 1927).

The various hazards affect strategy differently based on the level of severity and the chance of recovery (Richardson \& Fine, 2006). Water hazards and trees present severe hazards to golfers because recovery is often very difficult or impossible, resulting in penalty strokes for those who are unable to negotiate their presence (Doak, 1992). Other hazards, such as sand traps (bunkers) and roughs consisting of longer grasses, are less severe because recovery is more likely and the penalties are less harsh. Stanley Thompson describes a successful course as one that balances playability and strategy by challenging the most-skilled players while not discouraging the less-skilled players (Barclay, 2000). Intelligence is critical in strategic design as players who can strategically position their ball based on their own abilities have the advantage over someone who attempts a shot which they do not posses the skills to successfully execute (Nicklaus \& Millard, 2002).

Strategy plays an important role in golf course design, influencing the spatial arrangement of hazards within the course layout. By understanding how hazards affect 
the strategies of golfers of all skill levels will ensure a design that is both challenging and enjoyable for a wide range of players.

\section{Aesthetics}

Aesthetics play an influential role, affecting the layout of individual holes and golf courses. Hurdzan (2006) ranks aesthetics higher than the actual playing experience arguing that golfers want highly maintained courses with spectacular views. Holes are laid out to capture long range views of the surrounding landscape and to take advantage of special features both on and offsite (Fazio \& Brown, 2000). Courses are routed to direct golfers to the most dramatic points on the property in order to enhance the aesthetic experience and to make the course more memorable and unique (Doak, 1992).

When it comes to the design of golf course features, nature is often described as the model to follow and emulate (Barclay, 2000). Jack Nicklaus stresses the importance of designing the course so it blends in with its surroundings and provides a natural setting allowing golfers to get in touch with nature (Nicklaus \& Millard, 2002). Habitat features such as wetlands, ponds, streams, meadows, and forested areas can be integrated into golf course layouts to enhance the aesthetics and to improve the natural experience for golfers.

\section{Philosophies of Design}

In addition to playability, strategy, and aesthetics, there are five philosophies of design that influence how hazards are integrated into golf course layouts: penal, strategic, heroic, freeway, and framing. An understanding of these design theories reveals the motivation of architects in the design and integration of hazards into golf course layouts. 
Each philosophy utilizes hazards in a different manner in order to create a desired effect influencing how golfers play individual holes.

In penal design, only a single route between the tee and green is provided and hazards are placed to create target golf (Shackelford, 2003). This style of design rewards those who can accurately position the ball while punishing those who do reach the intended landing zones (Hurdzan, 2006). Penal designs can discourage less skilled players who are not as accurate and cannot hit the ball long enough to successfully negotiate penal hazards (Graves \& Cornish, 1998). Strategic design is characterized by risk and reward. Golfers are presented with options on how to play individual holes, rewarding those who choose the more daring alternative and execute it well while those who choose the safer route endure only subtle penalties of a more difficult or longer approach shot (Shackelford, 2003). These subtle penalties are less punishing than those experienced in penal design and therefore strategic design is more accommodating and enjoyable for golfers of all skill levels. Similar to strategic designs, heroic holes present golfers with a choice of how much of a hazard to carry. Diagonal hazards are utilized to force golfers to decide how much of the hazard they wish to challenge, rewarding those who successfully carry the most with a better angle and shorter approach into the green (Graves \& Cornish, 1998). In freeway designs, golfers are offered only a single path from tee to green and all hazards are placed outside the lines of play (Hurdzan, 2006). This style requires very little strategic thought as players are not required to make decisions in order to negotiate hazards. Finally, the framing school of design pushes hazards even further away from play and uses them to frame the hole and to enhance the aesthetics rather than using them as strategic or penal features (Shackelford, 2003). 
Based on the literature from leading architects, playability, strategy, and aesthetics play a critical role in the design and layout of golf courses. The literature also revealed how the philosophies of design influence the spatial arrangement of hazards within the course layout. An understanding of these general philosophies is important to ensure the desired effect of hazards is achieved and they are placed in suitable locations which complement the game of golf. Knowing how the principles of playability, strategy, and aesthetics influence the design of golf courses in combination with the influence of the philosophies of hazard placement, habitat environments that are incompatible with the game of golf can be successfully integrated into the golf course landscape. To further ensure the successful integration of habitat into golf courses, a better understanding of the specific impacts of such habitats on the game of golf and maintenance practices is needed.

\section{Terrestrial and Aquatic Environments within the Course Layout}

Terrestrial and aquatic habitats of amphibians, as defined in the previous section of the literature review, present severe hazards to golfers if integrated in areas of play. Naturalized forested areas, long grasses, wetlands, and other aquatic habitats can create conditions where golfers are unable to recover from an errant shot and get their ball back in play. Therefore, their arrangement within the course is greatly influenced by how their location will affect the playability and strategy of the course. It is important to understand the potential effects of amphibian habitat on the game of golf as well as on maintenance practices in order to spatially arrange them in suitable areas where habitat quality can be preserved. The design philosophies and theories of hazards need to be 
considered to ensure the successful integration of terrestrial and aquatic environments required by amphibian populations into golf course layouts.

As noted earlier, terrestrial environments suitable for amphibian populations require an undisturbed forest floor consisting of leaf litter, coarse woody debris, and understory vegetation along with a dense canopy to create cool moist microclimates. These areas present golfers with conditions which can be very difficult to recover from and get their ball back in play. Due to their spatial characteristics, trees can be severe obstacles to negotiate and can be punishing to errant shots (Doak, 1992). Trees, if incorporated too close to lines of play, can make a course unfair by reducing the visibility of target areas and by knocking down approach shots (Hurdzan, 2006). Hurdzan advocates using trees to frame holes ensuring 50 metres between driplines is provided around landing zones and no less than 30 metres when dealing with shorter shots.

To maintain playability with respect to terrestrial areas, it is important that golfers are able to recover from them and get their golf ball back in play (Doak, 1992). It is also important that golfers are able to find their ball in order to maintain the pace of play (Richardson \& Fine, 2006). This often requires the removal of the understory and lower branches as well as a separation of $7-8$ metres between tree trunks (Hurdzan, 2006). These actions can potentially reduce the quality of terrestrial habitat patches by creating environments that are not as ideal for amphibian populations. Therefore it is important to locate areas where forested patches will not adversely affect playability to ensure quality habitat is provided.

Suitable locations for trees are also influenced by their effects on growing conditions for turf. Trees can degrade the growing conditions for turf through 
competition for moisture and nutrients, by shade, and by reduced air circulation (Lilly, 1999; White, 2000). Shade from trees can negatively affect growing conditions by reducing both the quantity and quality of light that turf receives as well as by affecting the time that light falls on the surface (Lilly, 1999; White, 2000). These poor light conditions can lead to sparse turf which is more susceptible to disease resulting in inadequate playing surfaces (Gilchrist, 1983). Morning shade is most deleterious, especially on greens, as turf has greater growth activity in the hours after sunrise (White, 2000). Furthermore, it takes longer for affected areas to warm up and moisture remains on the turf longer making it more vulnerable to diseases (Hurdzan, 2004).

Trees also have detrimental affects on turf conditions on putting surfaces by restricting air movement. Low hanging branches or understory growth can reduce the flow of air to a green (White, 2000). To dry the surface and reduce temperatures, an air flow of 3-4 mph is needed (White, 2000).

Trees can also deteriorate growing conditions for turf by competing for moisture and nutrients. Gilchrist (1983) advocates providing a minimum of 16 metres between trees and tees and greens in order to avoid root competition. Root pruning can also be employed to control the encroachment of roots into areas of turf (White, 2000).

To improve turf conditions, pruning, removal of understory, and tree removal is often used (Lilly, 1999). Potentially, this can reduce both the size and quality of a terrestrial environment and thus reduce the available amphibian habitat on a golf course. The negative effects of trees are best managed during the design process when forested areas and golf course components such as greens and tees can be arranged to not adversely affect each other. 
Water is the most penal hazard as golfers have very little chance of recovery which makes the design and location of them very important (Hurdzan, 2006). Doak (1992) states the three rules for designing holes around water hazards: the hazard must be visible, there must be a way around it for less skilled players, and it should be used to challenge scratch golfers who are more skilled and can negotiate the severity of water. Hurdzan (2006) describes the most critical feature influencing the location of water hazards on golf holes is their spatial relationship to lines of play for the average golfer. It is best to avoid forcing golfers to carry water, but if it cannot be avoided it is best to arrange forced carries from the tee (Doak, 1992). Another way is to use multiple tees to ensure a short carry for less skilled players and a longer carry to challenge moreskilled golfers (Hurdzan, 2006). Forced carries on approaches to greens can be quite penal to weaker players as they may not be able to carry more than 75 yards (Doak, 1992).

The proximity of water hazards to target areas and landing zones must also be considered. The average length of drives for a PGA Tour player is 290 yards, so water should be placed at this distance from the Championship tees to challenge the highly skilled players while larger areas should be provided short of the hazard to accommodate less-skilled players (Hurdzan, 2006). Furthermore, less-skilled players tend to slice the ball left to right which means hazards located on the right side of fairways will adversely affect less-skilled golfers more (Hurdzan, 2006). Placing a hazard on the left side will challenge scratch golfers, who tend to hit from right to left, while reducing the probability of less-skilled golfers hitting into the water (Hurdzan, 2006). 
Important to amphibian conservation is the design and protection of aquatic environments to ensure water quality is maintained and adequate habitat is provided. Water hazards on golf courses are typically permanent which allows the establishment of predatory fish and bullfrog populations that can be detrimental to native amphibian species (Boone et al., 2008). The draining of ponds to remove these predators may not always be practical, therefore ponds should be designed to include extensive marshy areas that are too shallow for fish to prey on tadpoles (Dodson, 2000).

It is important to protect seasonal wetlands or vernal ponds which fill with water in the spring and dry later in the season. These wetlands provide breeding and larval development sites free of fish and bullfrogs for most pond-breeding amphibians (Scott, Metts, \& Gibbons, 2002). However, vernal pools are often seen as a nuisance to golf courses because of drainage issues and their provision of breeding areas for mosquitoes (Libby, Harker, \& Harker, 2004). It is important to identify seasonal wetlands during the site analysis and to take steps to provide a forested buffer around the vernal pool (Paton \& Egan, 2002). Seasonal wetlands differ aesthetically from permanent water hazards and this should be considered when incorporating them into course layouts. They do, however, provide a natural and varied aesthetic as well as critical amphibian habitat (Scott et al., 2002).

There are several ways to protect the water quality of aquatic environments, including vegetative filtration, grassed swales, buffers, and phytozones, which can be included in the design of new courses and renovations of existing ones (Dodson, 2005). Infiltration, reduced surface flow rates, and absorption within these vegetated zones can protect water quality from chemical and sediment runoff from turf areas (McCarty, 
2005). The widths of vegetated filter strips is influenced by the vegetation used, the slope, and the quantity of runoff to filter but studies have shown $5-8$ metres $(15-25$ feet) is sufficient (Dodson, 2005). Buffers consisting of turf should have a minimum width of 8 metres ( 25 feet) next to fairways and tees and 16 metres ( 50 feet) when next to greens (Dodson, 2005). Turf is an effective buffer vegetation due to its canopy and extensive root system which has a strong soil stabilizing and filtering ability (Dodson, 2005). Turfgrass filter strips maintained at widths of $5-10$ metres ( $15-30$ feet) and mowed at heights of $6 \mathrm{~cm}$ ( 3 inches) can reduce nutrient runoff by 90 to 99 percent and remove sediment at rates of 70 percent (Dodson, 2005). Phytozones can also be used to protect the quality of water entering large ponds and lakes. These zones slow the movement of runoff before entering the main body of water which allows pollutants and sediment to settle and vegetation to absorb and filter the runoff (Libby et al., 2004). Designing to accommodate vegetated filtration processes around aquatic environments can protect water quality and preserve the function of habitats.

\section{Conclusion}

The literature review outlines the critical habitat characteristics needed to support diverse amphibian populations. The composition and configuration of aquatic and terrestrial habitats is described to ensure the provision of quality habitat with respect to dispersal and migration abilities. This information, combined with an understanding of how playability, strategy, aesthetics and theories of hazard placement influence the design of golf course features, will allow for a more successful integration of amphibian habitat into golf course landscapes. By integrating habitat into areas that will not 
adversely affect less-skilled players while challenging scratch players, quality habitat can be provided. These environments can benefit golf courses by enhancing the natural setting and strategic aspects while mitigating the loss and fragmentation of wetlands and terrestrial habitats. Golf course design and maintenance is explored in greater detail in Chapter Three through key informant interviews to provide a current perspective of the influences which affect the integration of amphibian habitat into golf course layouts. 


\section{Chapter Three - Key Informant Interviews}

As indicated earlier, interviews were conducted with individuals having expertise in fields relating to golf course design and maintenance. The following is a summarized version of the information gathered during the in-depth interviews. The questions posed to the key informants can be found in Appendix A.

\section{Golf Course Architects}

Three golf course architects were selected to represent top designers practicing in Canada. The three key informants have a combined total of 32 courses listed in the 2008 SCOREGolf Top 100 Golf Courses in Canada. The success of their designs provides a current perspective of golfer's expectations and popular golf course design in Canada.

Dr. Michael Hurdzan, ASGCA

Hurdzan Fry Environmental Golf Design

Columbus, Ohio

Dr. Michael Hurdzan began in golf course architecture in 1957 and completed his first solo design in 1969. He has since designed in excess of 350 courses and remodeled approximately 300 more. Hurdzan earned a Bachelor's degree in Turfgrass Management and a Master's and Ph.D. both in Turf Studies.

Hurdzan identified several influences that affect the design process before the course layout is conceived. Environmental constraints, the golf market, maintenance costs, social climate, and engineering constraints were all described as the main 
influences determining the type of course to be designed. When it came to the design of the course, safety, environmental sensitivity, and maintenance were identified as more influential than strategy and playability. Hurdzan described maintenance as being more important than design because golfers, if given the choice between a well maintained course that is not so well designed and a well designed course that is not well maintained, will always go for the high level of maintenance. Environmental sensitivity plays a critical role in getting the permits to build the course. The influence of safety, environmental sensitivity, and maintenance was consistent for all types of courses. New principles accommodating spectators and corporate tents were added when dealing with Open Championship courses. Hurdzan believes the sophistication of the modern golfer is the main driving force behind the rankings. Television, magazines, increased travel, and more exposure to different golf courses make golfers more knowledgeable and demanding of the courses they want to play.

Due to the importance of safety, maintenance, and environmental sensitivity in the design process, a large enough site, good drainage, and topography were described as the features that make a site suitable for a golf course. View corridors, both onsite and offsite, were also important due to the prominence of aesthetics.

Aesthetics is the primary influence of the surrounding landscape. Hurdzan incorporates elements of adjacent landscapes in order to make the course blend with its surroundings and to make the course feel older, more mature, and more natural. He looks for mature ecosystems and forest communities in surrounding landscapes to get a sense of what would exist on the property if no golf course was present and then integrates those elements into the course design. Hurdzan maintains that golf courses can be 
integrated into regional green space systems and that this should be an objective early in the design development.

Hurdzan identified the areas around tee boxes and behind greens to be the most suitable for natural areas. Playability plays an influential role determining the opportunities for natural areas. As a starting point, Hurdzan uses a guideline of 15 degrees on either side of the centerline which accounts for $92 \%$ of golf shots. He contends that the majority of golfers hit short and right of the intended target area and therefore more space is required on the right side of fairways. Natural terrestrial areas and water hazards are therefore more suitable on the left side. Hurdzan also integrates sensitive areas into the layout around tee boxes in order to control the distance of forced carries. He minimizes them to 100 yards for men and 60 yards for women.

Hurdzan describes water hazards as serving multiple functions such as to correct drainage, stormwater retention, surface harvesting of water, and a way to create biodiversity within the course. Aesthetics is described as the major influence in their design. He prefers larger ponds because they look more natural and they can maintain diverse aquatic populations. When designing the banks of water hazards, Hurdzan describes it as a choice between aesthetics and biodiversity. Vertical walls are more dramatic while sloping banks that are not maintained are more suitable for wildlife. When dealing with wetlands, environmental agencies and regulations were described as the primary influence determining how they are integrated into the course. Hurdzan tends to avoid them and incorporates them into out-of-play areas.

When discussing the influence of existing vegetation, Hurdzan debated the ecological value of core habitat areas. He maintains that the richest ecosystems occur on 
the edge and that creating more edge may enhance biodiversity. He says it is a matter of what the habitat is and the range of the wildlife that use it. Hurdzan realizes fragmenting habitat can have negative affects and takes effort to protect large forested areas. He also questions whether golf courses actually fragment habitats.

Hurdzan identified safety as the main influence of the size and widths of terrestrial areas between fairways. In general, they try to get 80 yards to separate holes centerline to centerline. This number changes if landing areas on adjacent holes are staggered, with the direction of the wind, elevation of tees and landing areas, and the altitude of the course. Suitable space to develop a course was described as an important factor in order to provide safe conditions. Available space can become an obstacle to integrating wildlife habitat such as forest canopy around portions of water hazards. Hurdzan proposed including islands of vegetation in large water hazards as an alternative when faced with limited space.

Hurdzan argues golf course architects can play a huge role in wildlife habitat conservation when a synergistic approach is adopted between designers, course managers, and people who understand local wildlife such as ecologists, biologists, conservation authorities, and wildlife clubs. He feels architects can improve habitat on golf courses by ensuring that wildlife needs such as food, water, cover and breeding areas are adequately provided and protected.

Hurdzan advocates that wildlife can benefit golf courses by allowing the course to be viewed as a community asset as well as by providing a more memorable experience for golfers. He argues that these benefits should be celebrated by golf courses and that they should be used to make courses unique and marketable. 
When asked about amphibians, Hurdzan would definitely incorporate habitat if there were resources available to him. He argues that people generally want to be in a healthier environment and if amphibians are an indicator species, then their presence would signify a safe and healthy landscape. 


\section{Douglas Carrick, ASGCA}

Carrick Design Inc.

Don Mills, Ontario

Douglas Carrick started his own business in 1985 and has since designed 27 courses and remodeled an additional 60 to 70 courses. Carrick earned a Bachelor's degree in Landscape Architecture.

Carrick identified playability and safety as the two most important factors influencing golf course design. They get incorporated into every design in order to create a functional course that is enjoyable to play and safe for golfers and adjacent property owners. Strategy, maintenance and aesthetics were described as more influential during the detail design rather than during the initial routing and special arrangement of the course. Carrick stated the rankings would change in response to the type of course. Strategy would become more important if designing a tournament course whereas aesthetics becomes more influential for resort courses.

Suitable topography, described as gently rolling with some character, is ideal to develop a golf course. Adequate depth of a sandy loam soil, natural drainage, vegetation, and views were all described as features that make a site suitable for a golf course. Suitable topography, soils, and drainage are ideal characteristics for economic reasons since these features make the course easier to develop.

Carrick described the primary reason for renovating an existing course is to upgrade playing conditions. Features are rebuilt in order to provide more consistent turf conditions. The improvement of aesthetics was identified as the second most common 
reason for remodeling while upgrading the challenge of the course to keep up with newer courses was listed third.

Carrick described view corridors and special features as the primary influence of the surrounding landscape on the design of a golf course. The routing of courses and orientations of individual holes are manipulated in order to capture views of external features. Special features and long range views are identified early in the design process and the course is routed to take advantage of them. Changing the experience as golfers move through the course, making each hole memorable, further influences the layout of courses.

Irrigation and stormwater ponds were described as being the primary function of water features on the golf course. They are used to harvest surface water in order to reduce the reliance on groundwater. The location of water hazards is influenced most by the topography as water hazards are typically situated in the low areas in order to incorporate them where they look like they belong, resulting in a more naturalized look. Ponds are also often used to generate earth and to correct drainage by providing low areas to drain to.

Carrick revealed a number of influences affecting the design of water hazards. The size of water hazards is influenced by the storage capacities for irrigation purposes. Carrick prefers to use sloping banks on water hazards rather than vertical walls because they look more natural. He advocates the use of vertical walls in water hazards where there may be fluctuating water levels in order to provide an aesthetically pleasing alternative to exposed muddy banks. A forested canopy around a portion of a water hazard could be used to add definition to the pond's edge while providing habitat value. 
Carrick described environmental agencies and regulations as the primary influence affecting the ecological value of golf courses. The integration of core habitats and vegetated corridors are dependent on the restrictions that determine how natural features are dealt with. Carrick stated the conservation of core areas and corridors are not a major consideration during their designs unless there are restrictions that need to be followed to receive approvals to develop. The classification of wetlands by environmental agencies determines their influence on golf course design. Carrick described wetlands, whether permanent or seasonal, as areas to avoid. He generally tries to incorporate them where golfers can carry them or around tee boxes, behind greens or off to the sides of fairways. Regulations were also revealed to be obstacles to integrating golf courses into regional green space systems as golf courses are not often viewed as compatible land uses by environmental authorities.

Carrick identified the areas around the tee boxes and behind the greens as the most suitable for naturalized terrestrial and aquatic areas. Playability becomes the primary influence of incorporating natural areas into layouts. Carrick tries to create a 60 metre wide playing surface around landing zones to ensure sufficient playing areas. If a forced carry is required, the area around the tee box was described as the most suitable for natural areas because the distance can be controlled. Natural areas between the landing area and the green may negatively impact playability by creating forced carries which are too long.

Safety plays an influential role affecting the opportunities to integrating wildlife habitat on golf courses. A minimum of 200 acres is required for a championship course. 
Safety also influences the size and width of areas between fairways. Carrick uses 80 metres between centerlines as a general guideline.

Carrick describes the benefits of incorporating wildlife habitat as adding interest to the course and providing a natural experience for golfers. He states that architects can play a role in wildlife habitat conservation by preserving large blocks of forested areas, by maintaining existing habitat, and creating links between natural features. Carrick relies on the expertise of environmental consultants and biologists to provide recommendations on local wildlife. 
Thomas McBroom ASGCA, Jane Hunter, Chris Nelson

Thomas McBroom Associates Ltd.

Toronto, Ontario

Thomas McBroom has been in the golf course architecture business for over 25

years. He has designed over 60 courses including major remodels of existing courses. Thomas McBroom, Jane Hunter, and Chris Nelson all earned Bachelor's degrees in Landscape Architecture.

Jane Hunter was reluctant to rank the design principles, maintaining that all six played an important role in golf course design. Hunter and McBroom did identify strategy and playability as the most influential factors. The design has to work as a golf hole and it has to be playable. Safety was also mentioned as playing an important role in golf design. The rankings of the principles change with the type of golf course. Playability becomes more important with resort and public courses while strategy may be more influential for private or tournament courses.

Gentle to undulating topography, good soils, good views, and no wetlands were listed as features that make a site suitable for a golf course. When remodeling an existing course, the main reasons are to bring the course up to modern standards. Upgrading the course conditions, drainage, and irrigation are the primary reasons for course redesigns. Improving shot values is another reason.

McBroom described view corridors and special features as the influential characteristics of the surrounding landscape that influence the design of golf courses. Holes are orientated to try to capture long range views and special features in surrounding 
landscapes are used as backdrops to enhance the aesthetics. McBroom tries to marry the course to the surrounding landscape and does not try to impose a design that does not look natural. He is not a believer of golf courses playing a municipal linkage and stated golf courses are generally not integrated into regional green space systems. There are potential safety concerns due to interactions between users and therefore, he contends, they are better on the periphery.

Several influences were revealed that affect the design of water hazards. The primary function of incorporating water hazards is to serve as an irrigation pond which has to be central if possible. Topography influences the location as ponds are integrated in areas where they look natural. McBroom uses water hazards sparingly as they are too penal and there is a playability issue when incorporating them into designs. The size of water hazards is influenced by topography and storage capacity if it is an irrigation or stormwater pond. Larger ponds are preferred over small ones because they look more natural in the landscape. When designing the banks of water hazards, McBroom prefers sloping walls that are not maintained rather than vertical walls because they look more natural.

The space available was described as the primary influence affecting the integration of natural areas into golf courses. The minimum for a golf course with a practice area is approximately 200 acres. This allows for some trees between fairways but does not provide much opportunity for large core areas. Safety has become more of an issue in design, resulting in a minimum of 80 metres between centerlines as their typical guideline. Providing a forest canopy around a portion of a water hazard in order to provide a change in aesthetics was also dependent on the space available. 
Playability was revealed as the major influence affecting the suitability of areas within the golf course for natural areas. Hunter and Nelson identified the areas around tee boxes and behind greens as the most suitable for both natural terrestrial and aquatic environments. A 60 metre clearance, with fairways 30-35 metres wide and an additional 15 metres of maintained roughs on either side, is a standard used to maintain playability. Areas outside this standard provide opportunities for natural areas. Forested areas tend to be maintained in order to ensure playability as they may become penal hazards when used along the edges of fairways. Hunter and Nelson proposed using grasses instead which are less penal. Playability was also described as an influence when locating natural aquatic areas. The main concern in incorporating them is the impact they can have on visibility. It was identified that behind target areas were the most suitable while the areas around landing zones and in front of the green are the least suitable areas since vegetation may grow up obstructing visibility.

Environmental agencies and regulations were also described as playing an influential factor in determining the habitat areas to be protected. The influence of wetlands, whether permanent or seasonal, is largely influenced by environmental agencies and regulations. These restrictions determine which areas are to be protected. Wetlands are generally avoided at all costs. Required buffers range from $5-15$ metres, sometimes 30 metres. McBroom tends to incorporate them in out-of-play areas, around tee boxes where forced carries can be controlled, and to the sides of fairways. They typically do not use them around putting greens because they may obscure the surface. There are also water quality issues around greens due to high levels of maintenance. 
Hunter and Nelson believe wildlife can benefit golf courses by creating a natural environment and by providing a more memorable experience for golfers. They feel golf course architects can play a role in wildlife conservation by protecting the habitat areas identified by environmental consultants and their assessments. If areas cannot be protected then their loss should be compensated elsewhere onsite. They stated that improving wildlife is not an influential factor in their designs as they described it as a maintenance issue. They advocate using native vegetation and protecting large core areas and corridors when space is available and when it does not affect playability or aesthetics. 


\section{Golf Course Superintendents}

The three golf course superintendents were selected to represent maintenance practices at three golf courses each designed by one of the architects used as key informants. Courses were selected to represent rural and suburban landscapes as well as a certified Audubon Cooperative Sanctuary course. Courses were also selected to represent a public, private, and tournament course in order to provide a sample of maintenance practices on different course types.

Doug Taylor

Superintendent, Angus Glen Golf Club

Markham, ON

Doug Taylor has been a Golf Course Superintendent for 22 years. He studied Turf Management at the University of Guelph. He currently manages both the North and South Courses at Angus Glen Golf Club, which were both designed by Doug Carrick.

Taylor identified playability and environmental sensitivity as the most influential principles affecting golf course maintenance. Angus Glen caters to corporate tournaments which means a diverse range of golfers with varying skill levels play the course everyday. The primary concern for Taylor is to maintain the courses to accommodate these varying skills and to ensure the speed of play is reasonable to accommodate multiple tournaments. He is also concerned with promoting healthy turfgrass conditions in order to satisfy golfer expectations. 
When describing the influence of the surrounding landscape, Taylor stresses the importance of maintaining the course to blend with the surrounding features. $\mathrm{He}$ advocates preserving existing natural areas where they meet the course boundary as well as within the course layout to maintain flow and to create a more natural look for the course.

The areas around tee boxes and behind greens were identified as the most suitable opportunities for natural forested areas. The least suitable areas are located near landing zones where natural areas could potentially slow down play if incorporated too close to the fairway's edge. Taylor maintains rough areas up to $40 \mathrm{ft}$ off the fairways edge in order to provide sufficient playing areas necessary to maintain playability.

Areas between two adjacent holes were also described as not as suitable for natural areas; the understory of treed areas are typically maintained to accommodate play from both fairways. Taylor feels that golf holes that are more on their own provide more opportunity for habitat areas as they provide more space to integrate zones that can be left natural. Par-3s were also identified as more suitable because they typically require only a single shot from the tee with the majority falling in close proximity to the green. Several par-3s on Angus Glen have natural areas and environmentally sensitive features between the tees and greens which are not maintained. Par-5s are more difficult to integrate natural areas because it takes multiple shots to reach the green which requires a greater margin of error to accommodate play.

When discussing the opportunities to integrate natural riparian zones along pond edges, Taylor described the area around the greens as the least suitable as there is more pressure to maintain the banks to ensure playability. He prefers to leave the slopes not 
maintained because it looks more natural and they require less maintenance but he cautions that they can potentially impede play by making it more difficult to find golf balls. It is also dependent on the nature of the water hazard. If it is an existing water body, the slopes will not be maintained due to environmental regulations as well as to enhance the natural aesthetics.

Taylor stated that the primary obstacle to integrating more natural areas is that it could adversely affect the speed of play or playability of the course. His method for identifying out-of-play areas to leave natural is based on the abilities of the average golfer. He then determines how it will impact the course of play. However, he maintains that more natural areas can benefit maintenance by reducing the costs of labour, fertilizers, and pesticides while providing a more natural look for the course. Safety plays an important part in how areas are maintained. Some trees and branches have to be removed if there is a danger of it falling in play.

Taylor feels environmental sensitivity is more influential now in his career than when he first started as a superintendent because of society's general concern for the health of the environment. Reducing chemical applications, increasing natural areas, and enhancing wildlife habitat are ways in which golf course maintenance has responded to this concern. He believes that wildlife can benefit golf courses by demonstrating to the public that golf courses are healthy environments. Superintendents can play a role in habitat conservation by preserving and incorporating existing natural areas in out-of-play areas. Lastly, he feels golfers enjoy seeing wildlife on the course and that it provides a more memorable experience of the golf course. 
Brian Beemer

Superintendent, King's Riding Golf Club

King City, ON

Brian Beemer has been a Golf Course Superintendent for 10 years. He studied Turfgrass Management at the University of Guelph and Horticulture at Humber College. He currently manages King's Riding Golf Club which was designed by Thomas McBroom. King's Riding is a private ClubLink course which is a certified Audubon Cooperative Sanctuary.

Beemer identified playability, safety, and aesthetics as the most influential principles affecting golf course maintenance. Playability was the primary influence affecting the opportunities to integrate natural areas into the course layout as the course can become too difficult and play can be slowed down if natural areas are incorporated in areas of play. Beemer maintains roughs $10-15$ yards off the fairway's edge to provide a transition into secondary roughs and to provide sufficient room to accommodate play. Landings areas face more pressure to be maintained because ample room is needed to accommodate the majority of shots which makes these areas less suitable for the incorporation of sensitive habitats. Also, available space is important in determining the extent of natural areas as more room creates greater opportunity to integrate natural areas in out-of-play zones throughout the course. Par-3s were described as being the most suitable because there is less margin of error needed to accommodate play. At the same time, more natural areas would reduce the amount of maintained areas which would reduce maintenance costs. 
As part of its Audubon certification, King's Riding has naturally sloping pond edges which are not maintained. This is done to protect water quality and to provide wildlife habitat. Leaving banks more natural does have the potential to slow down play and may not be as aesthetically pleasing. Beemer advocates providing 10-15 yards of rough between the fairway's edge and the natural bank to provide sufficient room for play. Between the green and the pond edge, 10-15 yards provides enough room for play and reduces the pressure to maintain the slope.

Beemer feels golf courses can play an important role in regional green space systems, especially in urban areas. He feels that being Audubon certified and monitoring water quality and chemical applications can improve a golf course's role. Water quality was described as the major influence of the surrounding landscape on the maintenance of the golf course. Water entering and leaving the property is tested and sampled to ensure quality is maintained or improved.

To improve wildlife habitat on golf courses, Beemer believes superintendents can play a role by providing naturalized zones and other habitat areas and by conducting outreach programs with local schools to demonstrate the benefits of golf courses. $\mathrm{He}$ argues that being Audubon certified is a great communication tool to demonstrate to members, the public, and government agencies that you care about the wildlife and the environment. He believes certification is worth the added water quality and chemical application monitoring. Beemer feels that wildlife should be included in the design process and that more education about the benefits of golf courses is needed to improve habitat on the golf course. 
Ian McQueen

Superintendent, The Club at Bond Head

Bond Head, ON

Ian McQueen studied Turf Management at Penn State University and has five years of experience as a Golf Course Superintendent. He currently manages 36 holes at the Club at Bond Head, which was designed by Hurdzan Fry Environmental Golf Design. The course is public and is in the process of becoming a certified Audubon Cooperative Sanctuary course.

When discussing the influences in golf course maintenance, McQueen ranked budget, safety of employees, and human resources as the most influential principles from a management standpoint. From a golfer's perspective, aesthetics and playability were the primary concerns for a public course. Maintaining a course that is both playable and aesthetically pleasing to a wide array of golfers is essential to attract and retain players for a public course.

Playability and aesthetics play a pivotal role in determining the opportunities to integrate natural areas into the golf course layout. Secondary roughs consisting of fescue grasses and terrestrial patches can negatively affect playability by increasing the probability of losing golf balls from errant shots and they can slow down the pace of play. McQueen identified the areas around tee boxes and behind greens as the most suitable for natural terrestrial zones because they are out of play. The areas parallel to fairways, especially on the right side, were described as the least suitable because they are more in play and can therefore impact playability and the speed of play. To maintain 
playability and the aesthetics of the course, McQueen creates a transition from the fairway's edge to secondary roughs, consisting of maintained roughs that are 10-15 yards wide. This transition slows or stops the ball before it goes into the taller unmaintained grassed areas. This results in a 60 yard clearance which provides a fair playing surface to accommodate shots.

Visibility is the primary concern with respect to naturalizing pond edge, especially when golfers must hit over a water hazard. As a result, areas around tee boxes and behind greens were described as the most suitable, while areas around landing zones and in front of greens were the least suitable. Maintaining visibility so golfers can see the playing surface and ensuring that natural pond edges do not affect speed of play and do not make the course too difficult influence the suitability of areas to integrate these areas.

Par-3s were described as the most suitable for the integration of environmentally sensitive areas because golfers are typically using short irons and can get to the green area with a single shot. Par- $4 \mathrm{~s}$ and-5s are more difficult to integrate natural areas because they involve multiple shots of varying length which require greater margins of error.

McQueen feels that golf courses provide valuable green space, especially in developed areas, and can play an important role in regional green space systems. He believes that the creation of wildlife habitat, dedication of low maintenance areas and environmental zones, buffering waterways, monitoring water quality of water entering and leaving the course, and corridors throughout the course can help improve the course's function in a regional green space system and aid in wildlife conservation. Educating the public about the benefits of golf courses can demonstrate the role of golf courses as green space. 


\begin{tabular}{|c|c|c|c|c|c|c|}
\hline \multirow[b]{2}{*}{ Interview Topics } & \multicolumn{3}{|c|}{ Architects } & \multicolumn{3}{|c|}{ Superintendents } \\
\hline & 鸹 & 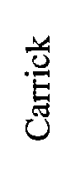 & $\begin{array}{l}\text { E } \\
8 \\
\text { D. } \\
\text { 总 }\end{array}$ & 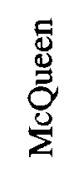 & $\frac{\tilde{c}}{\pi}$ & 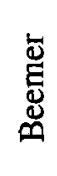 \\
\hline \multicolumn{7}{|l|}{ Design Influences (Listed in Top 3) } \\
\hline Aesthetics & $\bullet$ & & $\bullet$ & $\bullet$ & & $\bullet$ \\
\hline Environmental Sensitivity & $\bullet$ & $\cdot$ & $\bullet$ & & - & \\
\hline Playability & & $\bullet$ & $\bullet$ & $\bullet$ & $\bullet$ & $\bullet$ \\
\hline Safety & $\bullet$ & $\cdot$ & & $\bullet$ & $\bullet$ & $\bullet$ \\
\hline Strategy & & & $\bullet$ & & & \\
\hline \multicolumn{7}{|l|}{ Features Which Make a Site Suitable for Golf } \\
\hline Gentle Sloping Topography & $\bullet$ & $\bullet$ & $\bullet$ & - & - & - \\
\hline Good Soils & - & $\bullet$ & $\bullet$ & - & - & - \\
\hline Good Drainage & - & - & - & - & - & - \\
\hline \multicolumn{7}{|l|}{ Influence of Surrounding Landscapes } \\
\hline View Corridors & - & $\bullet$ & $\bullet$ & & & \\
\hline Existing Vegetation & - & & & & $\bullet$ & \\
\hline Water Quality & & & & $\bullet$ & $\bullet$ & $\bullet$ \\
\hline Blend Course with Surroundings & - & $\bullet$ & $\bullet$ & & - & \\
\hline Golf Courses Can Play a Role in Green Space Systems & $\bullet$ & & . & $\bullet$ & & $\bullet$ \\
\hline \multicolumn{7}{|l|}{ Aesthetics } \\
\hline Natural Aesthetics & - & $\bullet$ & $\bullet$ & & $\bullet$ & \\
\hline \multicolumn{7}{|l|}{ Safety } \\
\hline $80 \mathrm{~m}$ Between Centerlines & $\bullet$ & $\bullet$ & $\bullet$ & - & - & - \\
\hline Adequate Space to Accommodate Golf Features (200 acres) & $\bullet$ & $\bullet$ & $\bullet$ & - & - & - \\
\hline \multicolumn{7}{|l|}{ Playability } \\
\hline $60 \mathrm{~m}$ Clearance to Provide Adequate Playing Space & & $\bullet$ & $\bullet$ & $\bullet$ & & \\
\hline 15 Degrees off Centerline to Provide Adequate Playing Space & $\bullet$ & & & & & \\
\hline Forced Carries from Tee & $\bullet$ & $\bullet$ & & & & \\
\hline Roughs Maintained $10 \mathrm{~m}$ or More Off Fairway's Edge & - & - & - & $\bullet$ & $\bullet$ & $\bullet$ \\
\hline \multicolumn{7}{|l|}{ Opportunities for Habitat } \\
\hline Influenced by Playability & $\bullet$ & $\bullet$ & $\cdot$ & $\bullet$ & $\bullet$ & $\bullet$ \\
\hline Influenced by Available Space & - & & $\cdot$ & & 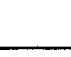 & $\bullet$ \\
\hline Influenced by Environmental Regulations & $\bullet$ & $\bullet$ & $\bullet$ & & $\bullet$ & \\
\hline Most Suitable Around Tee Boxes & - & $\bullet$ & $\bullet$ & $\bullet$ & $\bullet$ & $\bullet$ \\
\hline Most Suitable Behind Greens & $\cdot$ & $\cdot$ & $\cdot$ & $\bullet$ & $\bullet$ & $\cdot$ \\
\hline More Suitable on Left side of Fairways & $\cdot$ & & & $\bullet$ & & \\
\hline Suitable In Front of Tee Boxes to Control Forced Carries & - & $\bullet$ & & & & \\
\hline
\end{tabular}




\begin{tabular}{|c|c|c|c|c|c|c|}
\hline Least Suitable In Front of Greens & & & $\bullet$ & $\bullet$ & $\cdot$ & \\
\hline Least Suitable Around Landing Zones & & & $\bullet$ & $\cdot$ & - & $\cdot$ \\
\hline \multicolumn{7}{|l|}{ Design of Aquatic Features } \\
\hline Primary Function Irrigation & $\bullet$ & $\bullet$ & $\bullet$ & - & - & - \\
\hline Primary Function Stormwater & $\bullet$ & $\bullet$ & & - & - & - \\
\hline Influenced by Topography & & $\bullet$ & $\bullet$ & - & - & - \\
\hline Influenced by Aesthetics & $\bullet$ & $\bullet$ & $\bullet$ & - & - & - \\
\hline Natural Pond Edges & $\cdot$ & $\bullet$ & $\bullet$ & - & $\bullet$ & $\bullet$ \\
\hline \multicolumn{7}{|l|}{ Wildlife on Golf Courses } \\
\hline Described as a Benefit to Golf Courses & $\bullet$ & 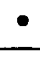 & $\bullet$ & $\bullet$ & - & $\bullet$ \\
\hline Enhances the Natural Experience & $\bullet$ & $\bullet$ & $\bullet$ & & $\bullet$ & \\
\hline Demonstrates Environmental Benefits of Golf & & & & $\cdot$ & $\cdot$ & - \\
\hline Consultants Required to Deal With Environmental Issues & $\cdot$ & $\bullet$ & $\bullet$ & & & \\
\hline
\end{tabular}

\section{Discussion}

In addition to confirming much of the information contained in the literature, the key informants provided insight into key issues important to the integration of amphibian habitat into golf course landscapes from both golf course design and maintenance perspectives. These insights specifically involved the description of influential principles in golf course architecture, the influence of the surrounding landscapes, the design, spatial arrangement and maintenance of specific elements within the layout, the influence of wildlife, and potential problems and barriers to incorporating habitat on golf courses. Finally, the key informants provided insight into the decisions and choices, and the factors influencing them that affect the composition and configuration of golf courses and the elements within.

The three golf course architects have 32 golf courses listed on the 2008 SCOREGolf Top 100 Best Golf Courses in Canada. The high rankings illustrate that the 
three architects are representative of what golfers in Canada are currently expecting in golf course design. The three golf courses selected for superintendent interviews are also highly ranked in Canada. Angus Glen Golf Club and the Club at Bond Head are both listed in the SCOREGolf Top 100 while King's Riding Golf Club is among Ontario's top rated private courses. The three were selected to represent rural and suburban courses as well as a certified Audubon Cooperative Sanctuary. The three courses also represent a public, private, and tournament course. The three superintendents provided perspectives from a variety of course types in varying landscapes. Together, the key informants provide a current perspective of golf course design and maintenance in Canada.

Although the rankings of design principles differed between informants, safety, playability, and aesthetics were consistently described as primary influences affecting the design, routing, and maintenance of courses. Both architects and superintendents were concerned with providing sufficient space to accommodate a varying degree of golfing abilities in an aesthetically-pleasing natural environment that is safe for golfers and maintenance staff. These influences affect the opportunities for incorporating natural wildlife habitat areas within the course layout by determining the suitability of specific zones to provide habitat which does not adversely impact playability, safety, and aesthetics.

Common to all six informants was the importance of providing an enjoyable and playable golf design. Designing to accommodate the skills of the average golfer greatly influences the spatial arrangement and routing of golf holes, especially on public and resort courses where diverse golfing skills are encountered on a daily basis. Natural areas, due to their non-maintained characteristics, become a penal hazard if incorporated 
into areas that experience regular play, and can therefore adversely affect the course of play. As a result, courses can become too difficult for the intended clientele resulting in longer rounds of golf and negative experiences for golfers. It is important for natural or environmentally sensitive areas to be located in out-of-play areas in order to reduce the pressure on superintendents to maintain them to restore playability.

Ensuring the average golfer has ample room in which to play impacts the size and location of naturalized zones within the course layout. The areas to the sides of and behind tee boxes were generally the most suitable because they are not in play and therefore do not affect the difficulty or speed of play. The areas behind greens were also identified as suitable because the average golfer rarely hits shots long over the green. The areas between the front tees and the fairway were described as the most suitable for sensitive areas such as wetlands because the distance required to carry the area can be controlled. Hurdzan described the maximum carries to be 100 yards for men and 60 yards for women which are based on the abilities of the average golfer. When describing the opportunities in areas parallel to the fairway, it is important to ensure a wide enough landing area to accommodate a multitude of golfers. Hurdzan uses a guideline of 15 degrees off the centerline, which he argues accounts for $92 \%$ of all golf shots, to determine the widths of areas in play. Carrick and McBroom use a 60 metre clearance, with 30-35 metres of fairway and 15 metres of rough on either side, to ensure playability. Hurdzan also argues that the majority of golfers will slice the ball to the right and short of the intended target. Therefore he tends to provide a greater margin for error on the right side of fairways while placing hazards typically on the left. Finally, McBroom described the areas in front of target areas and greens as not being suitable for natural areas because 
vegetation can grow up and obscure landing zones which can negatively affect playability. Playability is a primary concern of architects and it can play a crucial role in the arrangement of natural areas. By respecting the general guidelines, naturalized areas can be incorporated in areas which are out-of-play and will therefore face less pressure to be regularly maintained.

Playability also determines the extent of which natural areas are maintained by golf course superintendents. Transition zones between the fairway's edge and secondary roughs or natural areas are maintained at widths of $10-15$ yards in order to provide a margin of error to accommodate shots from golfers with varying skill levels. Areas around landing zones and in front of greens are maintained to a higher degree to accommodate the increase in play and to maintain visibility. Terrestrial areas between two adjacent golf holes face more pressure to have the understory cleared so that golfers can find their golf balls and maintain the pace of play. Understanding how golf course superintendents maintain the course to ensure playability is important in order to determine the most suitable areas to integrate wildlife habitat.

Safety plays a critical role in the design process affecting how natural areas are integrated into layouts. An 80 metre (or 80 yard) width between centerlines of fairways was a common guideline adopted by all three architects in order to ensure safe distances between adjacent holes. Courses are getting longer and therefore require more space to safely accommodate all the features. Carrick and McBroom contend 200 acres of land is needed to develop an 18-hole championship course with practice areas which does not allow much opportunity for large core habitats to be incorporated. These standards dictate how much space is available to set aside as natural out-of-play areas. In order to 
integrate habitat, larger sites will be needed in order to accommodate sufficient core areas, forest canopies around aquatic environments, and corridors while meeting the standards needed to ensure the course is safe for golfers and staff.

A common theme amongst the informants was the preference to create a natural landscape and experience to enhance the aesthetics of the golf course. It was described as important to have the course blend seamlessly into the surrounding landscape in order to make it feel older, more mature, and to make it look like it belongs in the landscape. This desire for natural aesthetics influences both the size and spatial arrangement of aquatic environments. Large water hazards are preferred because they look more natural and they are typically located in low areas in order to make them look like they belong rather than trying to fit them somewhere where they do not look natural. Sloping banks were generally preferred over vertical walls as were banks which were not maintained versus ones which were. This was preferred not only to enhance the naturalness of the course but to protect water quality and to provide habitat. Lastly, wildlife on the course was described as an important part of enhancing the natural experience for golfers. Golfers enjoy seeing wildlife on the course making the experience more memorable.

From a design standpoint, the surrounding landscape exhibits influence over the layout of golf courses. Individual holes are routed in order to capture long range views and to utilize special features as backdrops. It was also important to have the course blend in with the surrounding landscape in order to make the course feel more mature and natural. To achieve this, existing vegetation from climax communities in the surrounding landscape is incorporated into the course layout resulting in consistent vegetation types and similar ecosystems. The primary influence of the surrounding landscape, as 
described by the architects, is related to the aesthetics of the course. Connectivity is a critical factor affecting the success of amphibian populations and the persistence of regional metapopulations. The surrounding landscape should influence more than just the aesthetics of a golf course. The spatial arrangement of both terrestrial and aquatic patches in neighbouring properties should influence the configuration of natural areas within the course layout to ensure adequate connectivity throughout the landscape. Common amongst all three architects was their description of environmental agencies and regulations and how they influence the integration of natural features into golf courses. Regulations determine which terrestrial and aquatic habitats are to be protected and how much to preserve and the design of the course responds to these restrictions. Wetlands were described as a feature that was to be avoided at all costs due to the environmental regulations put in place to protect them. It is important that the layout of the course responds to the composition and configuration of terrestrial and aquatic patches protected by regulations and to integrate additional natural habitat areas where suitable. The patches should be analyzed at a landscape scale and steps should be taken to enhance connectivity between them. 


\section{Chapter Four - Synthesis of Design Guidelines}

\section{Introduction}

In this chapter, information gathered from the literature review and key informant interviews is synthesized to develop a set of principles and guidelines to be used in the design application stage of this thesis.

\section{Amphibian Conservation Design Guidelines}

It is important that amphibian habitat be considered throughout the golf course development process from initial site analysis and inventory through to detail design, construction and final management phases. This approach will help ensure that natural areas, both existing and created, are spatially arranged in the most suitable locations within the course layout. These design guidelines are intended to provide direction for the successful integration of terrestrial and aquatic environments into golf course landscapes that satisfy the habitat composition and configuration requirements necessary to support healthy and diverse amphibian populations.

\section{Landscape Ecology Theme}

The principles discussed in this section are applicable in any landscape and provide opportunities for golf course architects to influence the spatial patterns of patches, corridors, and matrix within the golf course landscape. This spatial pattern strongly influences the movements of biotic and abiotic elements (Dramstad et al., 1996) and therefore plays a pivotal role in the design of golf courses that can support greater biodiversity. The following guidelines are based on the landscape ecology principles by 
Dramstad et al. (1996). The included principles relate to the habitat composition and configuration requirements of amphibians outlined in the literature review. There is no priority to the following principles and they are intended to provide general recommendations on the spatial arrangement of patches, edges, corridors, and matrix which will improve landscapes for amphibian life cycles.

\section{Table 4.1. Landscape Ecology Principles - Patches}

1. Large patches generally provide a range of habitats and therefore contain a greater variety of species than small patches. Large patches also support larger populations than small patches, thereby reducing the likelihood of local extinctions.

2. Fragmenting a large patch into two smaller patches creates more edge habitat while reducing interior habitat. Species reliant on interior habitat are often of conservation importance while edge species are more abundant.

3. Small patches can serve as stepping stones enhancing species dispersal.

4. Removal of a patch reduces the size of a metapopulation and reduces the probability of recolonization after local extinctions.

5. Isolated patches have a higher probability of extinction.

6. The optimal shape of a patch has a rounded core for interior habitat with curvilinear boundaries to promote species dispersal.

7. A patch orientated with its long axis parallel to the route of dispersal will have a lower probability of being recolonized than a patch perpendicular to the route of dispersal.

\section{Table 4.2. Landscape Ecology Principles - Edges and Boundaries}

8. Edges with a high structural diversity, vertically and horizontally, are richer in edge species.

9. Widths of edges are wider on sides facing the predominant wind directions and solar exposure.

10. Straight edges promote movement along the edge whereas curvilinear edges promote movement across the edge. Less edge abruptness between vegetation favours movement across an edge.

11. Curvilinear edges with coves and lobes provide greater habitat diversity than along a straight edge, therefore encouraging higher species diversity.

12. A convoluted patch will have more edge habitat than interior, therefore increasing the proportion of edge species. Convoluted patches create more interaction between the patch and the surrounding matrix. 
Table 4.3. Landscape Ecology Principles - Corridors and Connectivity

13. Similarity in vegetation structure and species between corridors and patches is preferable.

14. Roads commonly serve as barriers that subdivide populations and serve as conduits for invasive exotic species.

15. Wide corridors of dense natural vegetation protect streams against dissolved substances such as nitrogen, phosphates, and toxins.

16. Continuous vegetated stream corridors are essential to maintain aquatic conditions such as cool water temperatures and high oxygen content.

17. Alternative dispersal routes in a network of patches reduce the negative effects of gaps, disturbances, and predators, thus increasing efficiency of movement.

18. Small patches connected to a network of corridors are likely to have slightly more species and a lower rate of extinction than small isolated patches.

19. Small patches along an existing network result in higher survival rates for dispersing individuals.

\section{Habitat Composition Theme}

The composition theme deals specifically with the characteristics of terrestrial and aquatic habitats needed to support amphibian populations. Amphibians require specific features to be present in both habitats in order to carry out their life cycles. Terrestrial environments are used for foraging, overwintering, and dispersal while aquatic areas are used for breeding and larval development. The provision of quality habitat is critical to amphibian conservation. The following guidelines summarize the characteristics of suitable terrestrial and aquatic habitats. 
Table 4.4. Habitat Composition Guidelines - Terrestrial

20. Maximize the amount of native forest cover on the golf course.

21. Provide large core areas to provide interior habitat. Preserve old growth forests which can serve as a species pool for the recolonization of other patches throughout the landscape.

22. Maximize closed canopy forests to maintain cool moist microclimates.

23. Account for predominate winds and solar exposure and the influence of edge effects on microclimates.

24. Provide microhabitats by leaving natural areas consisting of coarse woody debris, an undisturbed layer of leaf litter, small mammal burrows, and boulders on the forest floor.

25. Provide forested areas with horizontal and vertical structural diversity, with layers of ground cover, understory, grasses, shrubs, and trees.

26. Provide vegetated corridors of similar vegetation to connect aquatic and terrestrial habitats that are at least $50 \mathrm{~m}$ wide.

\section{Table 4.5. Habitat Composition Guidelines - Aquatic}

27. Provide a mix of small $<0.2$ hectares natural wetlands and large ponds $>2.0$ hectares with open and closed canopy with depths ranging from $15-60 \mathrm{~cm}$.

28. Provide a range of ponds and wetlands with varying hydroperiods. It is critical to provide wetlands that dry annually in order to discourage predatory fish and bullfrogs which outcompete native amphibian species.

29. Open canopy ponds should have a littoral shelf with native emergent vegetation with slopes of 15:1 or less. Avoid the use of vertical walls which prevent the dispersal of individuals.

30. Floating rafts of emergent plants or created islands can be used where there is no opportunity to reconstruct pond margins or add created wetlands.

31. Provide vegetated buffers to protect against chemical runoff and to provide places of refuge and foraging.

\section{Habitat Configuration Theme}

Due to the physiological limitations of amphibians, the spatial arrangement of quality terrestrial and aquatic habitats is critical to successful conservation. As discussed 
in the literature review, amphibians typically have small home ranges, are site philopatric, and are restricted to cool moist microclimates due to their susceptibility to evaporative water loss. This makes the configuration of aquatic and terrestrial environments in a landscape critical to amphibian conservation. The following guidelines provide strategies for the arrangement of habitats based on the dispersal abilities of amphibians as outlined in Semlitsch et al. (2007).

\section{Table 4.6. Habitat Configuration Guidelines}

32. Maintain natural upland vegetation around wetlands as core amphibian habitat ranging from 142-289 $\mathrm{m}$ from the breeding sites. Seventy-five percent of the uplands should be managed as native habitat.

33. Natural and created aquatic environments should be arranged $200-500 \mathrm{~m}$ apart.

34 . Areas immediately adjacent to wetlands within $93 \mathrm{~m}$ should be left undisturbed.

35 . Corridors should have a minimum width of $50 \mathrm{~m}$ to protect against edge effects caused by wind and solar exposure.

36. Connect core habitats within the course layout as well as with patches in the surrounding landscape.

37. Improve conditions of the intervening matrix to enhance connectivity between habitats.

38. Reduce the road density within the property to lower probability of mortality when dispersing.

\section{Golf Course Design Theme}

Amphibians require microhabitats consisting of coarse woody debris, leaf litter, and moist microclimates in terrestrial habitats, and emergent vegetation and shallow littoral shelves in aquatic habitats. These habitats can only be achieved in naturalized areas that are comprised of native vegetation and are free of regular maintenance. These areas can be integrated into out-of-play areas within the course layout that do not 
adversely affect aspects of the game of golf. By respecting the abilities of the average golfer, naturalized zones that function as amphibian habitat can be integrated in areas that will not make the course too difficult or slow the pace of play. The following guidelines provide direction on how to integrate amphibian habitat in the most suitable areas within the course layout.

\section{Table 4.7. Golf Course Design Guidelines}

39. Provide a $60 \mathrm{~m}$ clearance, $30-35 \mathrm{~m}$ wide fairways and $15 \mathrm{~m}$ wide primary roughs on both sides, to ensure adequate space sufficient to accommodate play from a diverse range of golfers.

40. Fifteen degrees off the centerline of fairways accommodates $92 \%$ of all golf shots. The majority of golfers will slice the ball to the right and land short of the target. Natural areas are most suitable outside of these areas and on the left side of fairways.

41. Provide a minimum of $80 \mathrm{~m}$ between centerlines of fairways to ensure safe conditions for golfers.

42. Areas between tee boxes and the start of fairways are most suitable for environmentally sensitive zones because forced carry distances can be controlled. The maximum distance for men is $100 \mathrm{~m}$ while for women it is $60 \mathrm{~m}$.

43. Areas around tee boxes and behind greens are the most suitable for naturalized zones because they are out-of-play.

44. Naturalized pond edges in front of greens and target areas can obscure visibility and therefore face pressure to be maintained.

45. The least suitable place for natural areas is around landing zones which experience greater play and therefore face pressure to be maintained.

46. Account for shade and root competition when integrating terrestrial areas adjacent to greens and tees. 


\section{Table 4.8. Landscape Ecology Principles and the Golf Course Elements they Affect}

This table demonstrates the features within the course layout which can be designed and spatially arranged to satisfy each principle. A dot represents the elements which are influenced by the principle and are critical to the integration of that specific habitat requirement.

\section{Landscape Ecology Principles}

\section{Patches}

Large patches generally provide a range of habitats and therefore contain a greater variety of species than small patches. Large patches also support larger populations than small patches, thereby reducing the likelihood of local extinctions.

Fragmenting a large patch into two smaller patches creates more edge habitat while reducing interior habitat.

Small patches can serve as stepping stones enhancing species dispersal.

Removal of a patch reduces the size of a metapopulation and reduces the probability of recolonization after local extinctions.

Isolated patches have a higher probability of extinction.

The optimal shape of a patch has a rounded core for interior habitat with curvilinear boundaries to promote species dispersal.

A patch orientated with its long axis parallel to the route of dispersal will have a lower probability of being recolonized than a patch perpendicular to the route of dispersal.

\section{Edges and Boundaries}

Edges with a high structural diversity, vertically and horizontally, are richer in edge species.

Widths of edges are wider on sides facing the predominant wind directions and solar exposure.

Straight edges promote movement along the edge whereas curvilinear edges promote movement across the edge. Less edge abruptness between vegetation favours movement across an edge.

Curvilinear edges with coves and lobes provide greater habitat diversity than along a straight edge, therefore encouraging higher species diversity.

A convoluted patch will have more edge habitat than interior, therefore increasing the proportion of edge species. Convoluted patches create more interaction between the patch and the surrounding matrix.

\section{Corridors and Connectivity}

Similarity in vegetation structure and species between corridors and patches is preferable.

Roads commonly serve as barriers that subdivide populations and serve as conduits for invasive exotic species.

Typical Golf Course Elements
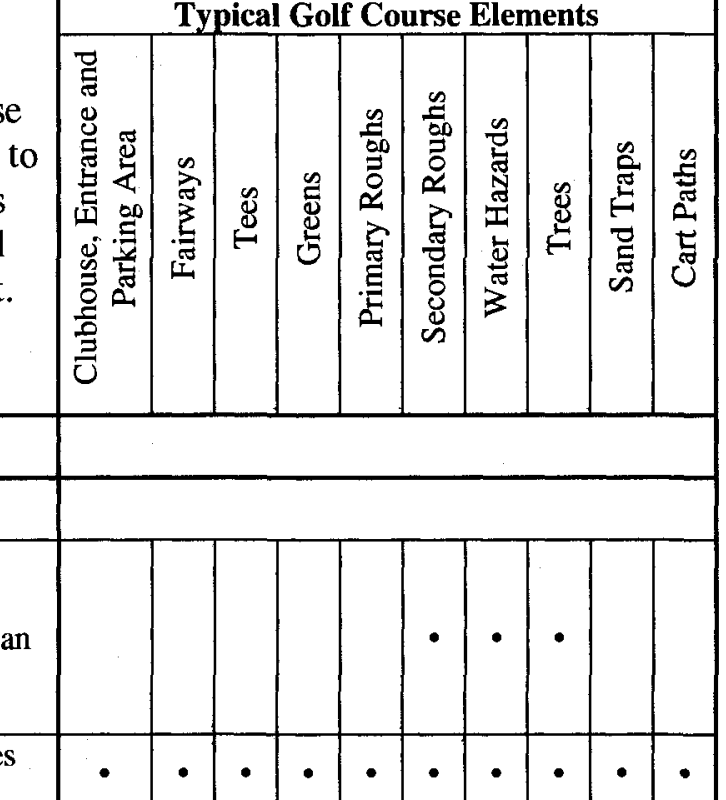
Wide corridors of dense natural vegetation protect streams against dissolved substances such as nitrogen, phosphates, and toxins.

Continuous vegetated stream corridors are essential to maintain aquatic conditions such as cool water temperatures and high oxygen content.

Alternative dispersal routes in a network of patches reduces the negative effects of gaps, disturbances, and predators, thus increasing efficiency of movement.

Small patches connected to a network of corridors are likely to have slightly more species and a lower rate of extinction than small isolated patches.

Small patches along an existing network result in higher survival rates for dispersing individuals.

\section{Table 4.9. Design Guidelines and the Golf Course Elements they Affect}

This table demonstrates the features within the course layout which can be designed and spatially arranged to satisfy each guideline. A dot represents the elements which are influenced by the guideline and are critical to the integration of that specific habitat requirements.

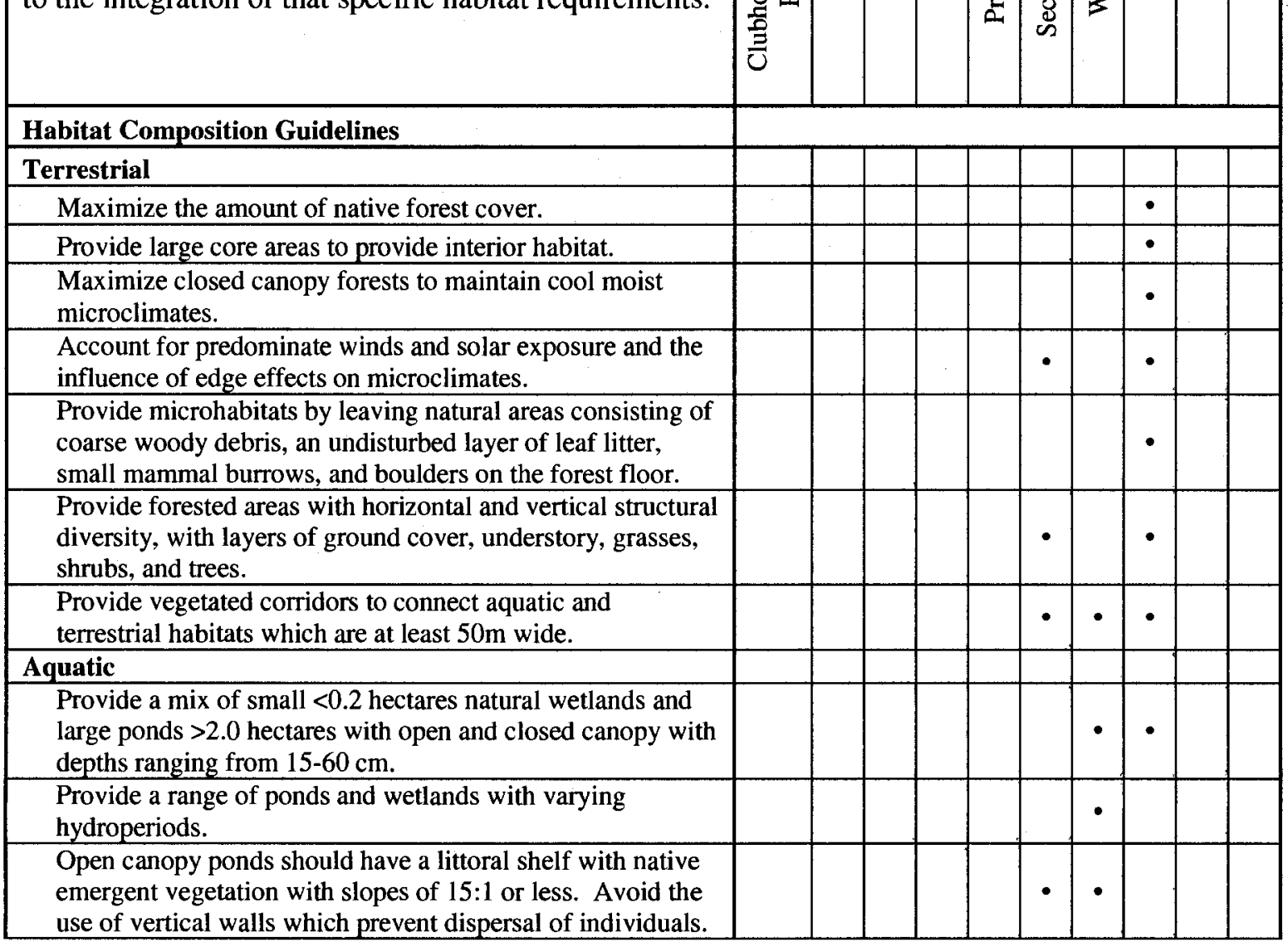


Floating rafts of emergent plants or created islands can be used where there is no opportunity to reconstruct pond margins or add created wetlands.

Provide vegetated buffers at least $8 \mathrm{~m}$ wide to protect against chemical runoff and to provide places of refuge and foraging.

\section{Habitat Configuration Guidelines}

Maintain natural upland vegetation around wetlands as core amphibian habitat ranging from $142-289 \mathrm{~m}$ from the breeding sites. Seventy-five percent of the uplands should be managed as native habitat.

Natural and created aquatic environments should be arranged $200-500 \mathrm{~m}$ apart.

Areas immediately adjacent to wetlands within $93 \mathrm{~m}$ should be left undisturbed.

Corridors should have a minimum width of $50 \mathrm{~m}$ to protect against edge effects caused by wind and solar exposure. Connect core habitats within the course layout as well as with patches in the surrounding landscape.

Improve intervening matrix to enhance connectivity between habitats.

Reduce road density within property.

Golf Course Design Guidelines

Provide a $60 \mathrm{~m}$ clearance, $30-35 \mathrm{~m}$ wide fairways and 10 -

$15 \mathrm{~m}$ wide primary roughs on both sides to ensure adequate space sufficient to accommodate play from a diverse range of golfers.

Fifteen degrees off the centerline of fairways accommodates $92 \%$ of all golf shots. The majority of golfers will slide the ball to the right and short of the target. Natural areas are most suitable outside of these areas and on the left side of fairways.

Provide a minimum of $80 \mathrm{~m}$ between centerlines of fairways to ensure safe conditions for golfers.

Areas between tee boxes and the start of fairways are most suitable for environmentally sensitive zones because forced carry distances can be controlled.

Areas around tee boxes and behind greens are the most suitable for naturalized zones because they are out of play. Naturalized pond edges in front of greens and shot lines can obscure visibility and therefore face pressure to be maintained.

The least suitable place for natural areas is around landing zones which experience greater play and face pressure to be maintained.

Account for shade and root competition when integrating terrestrial areas adjacent to greens and tees.
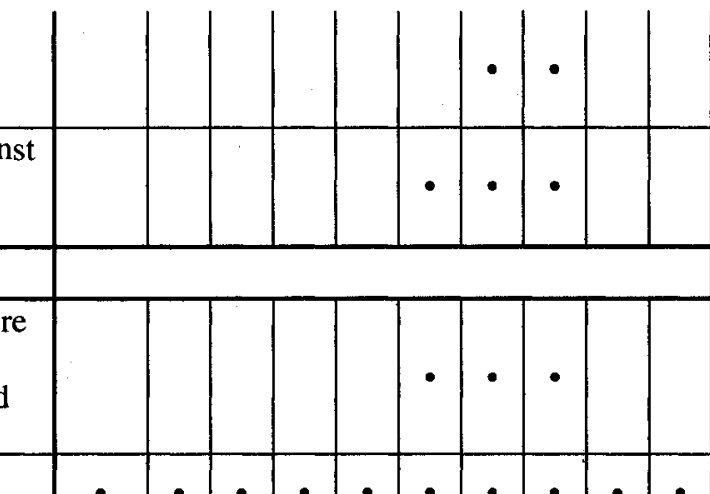

as

\begin{tabular}{|c|c|c|c|c|c|c|c|c|c|}
$\bullet$ & $\bullet$ & $\bullet$ & $\bullet$ & $\bullet$ & $\bullet$ & $\bullet$ & $\bullet$ & $\bullet$ & $\bullet$ \\
\hline$\bullet$ & $\bullet$ & $\bullet$ & $\bullet$ & $\bullet$ & $\bullet$ & $\bullet$ & $\bullet$ & $\bullet$ & $\bullet$ \\
\hline
\end{tabular}

\begin{tabular}{|l|l|l|l|l|l|l|l|l|l|l|}
\hline & & & & & & $\cdot$ & $\cdot$ & $\bullet$ & & \\
\hline & $\cdot$ & $\cdot$ & $\cdot$ & $\cdot$ & $\cdot$ & $\cdot$ & $\cdot$ & $\bullet$ & $\cdot$ & $\bullet$ \\
\hline
\end{tabular}

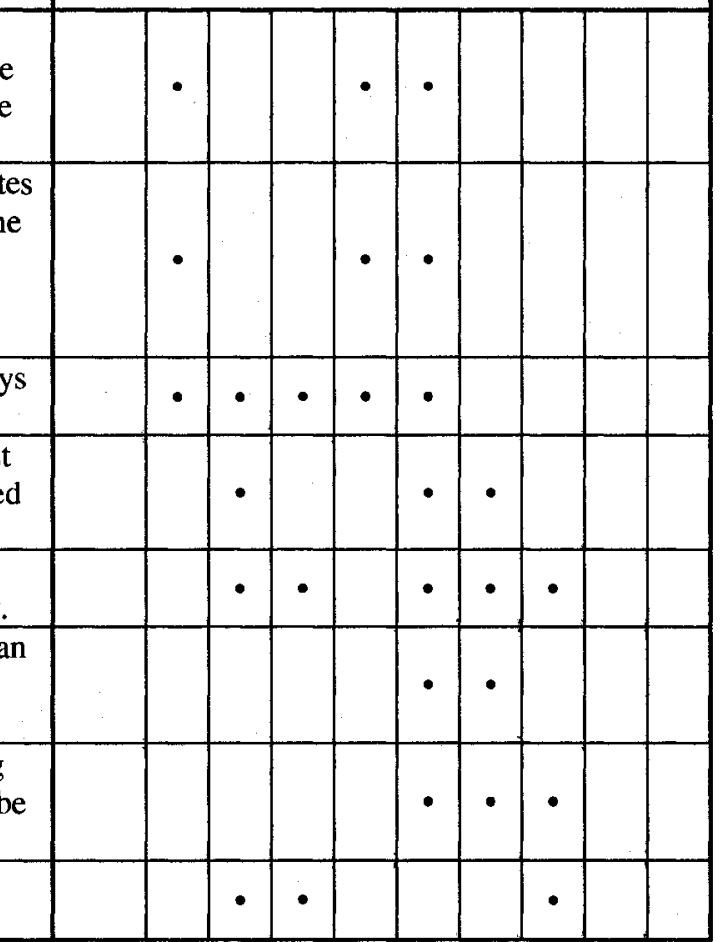




\section{Chapter Five - Application of Design Guidelines}

\section{Introduction}

Chapter Four outlines a set of design guidelines, created from information collected through the literature review and key informant interviews, on the integration of amphibian habitat into golf course landscapes. This chapter focuses on the design component of the thesis which applies the developed guidelines to a design for the Golden Beach Resort situated on Rice Lake in central southern Ontario.

This chapter begins by introducing the Rice Lake area and the Oak Ridges Moraine establishing a regional context for the design site. A summary of the Official Plan of the Township of Alnwick/Haldimand and the Oak Ridges Moraine Conservation Plan is presented to provide an understanding of the land use designations and policies that restrict development on the site. An inventory and analysis of the existing site is presented to highlight the opportunities and constraints of the resort property. Finally, a conceptual plan and supporting images are presented to demonstrate the application of the developed design guidelines.

\section{Rice Lake and the Oak Ridges Moraine}

Rice Lake is located in the Great Lakes Region of central southern Ontario, $110 \mathrm{~km}$ east of Toronto. The Lake is $37 \mathrm{~km}$ long and 5 to $6 \mathrm{~km}$ wide and is part of the Trent Severn Waterway, a $386 \mathrm{~km}$ (240 mile) system of rivers, lakes, canals, and locks. The lake attracts many visitors from both Canada and the United States because of its excellent fishing and natural setting. There are 27 resorts located around the lake offering cottages, inns, and camping and there are over 30 golf courses in the area. 

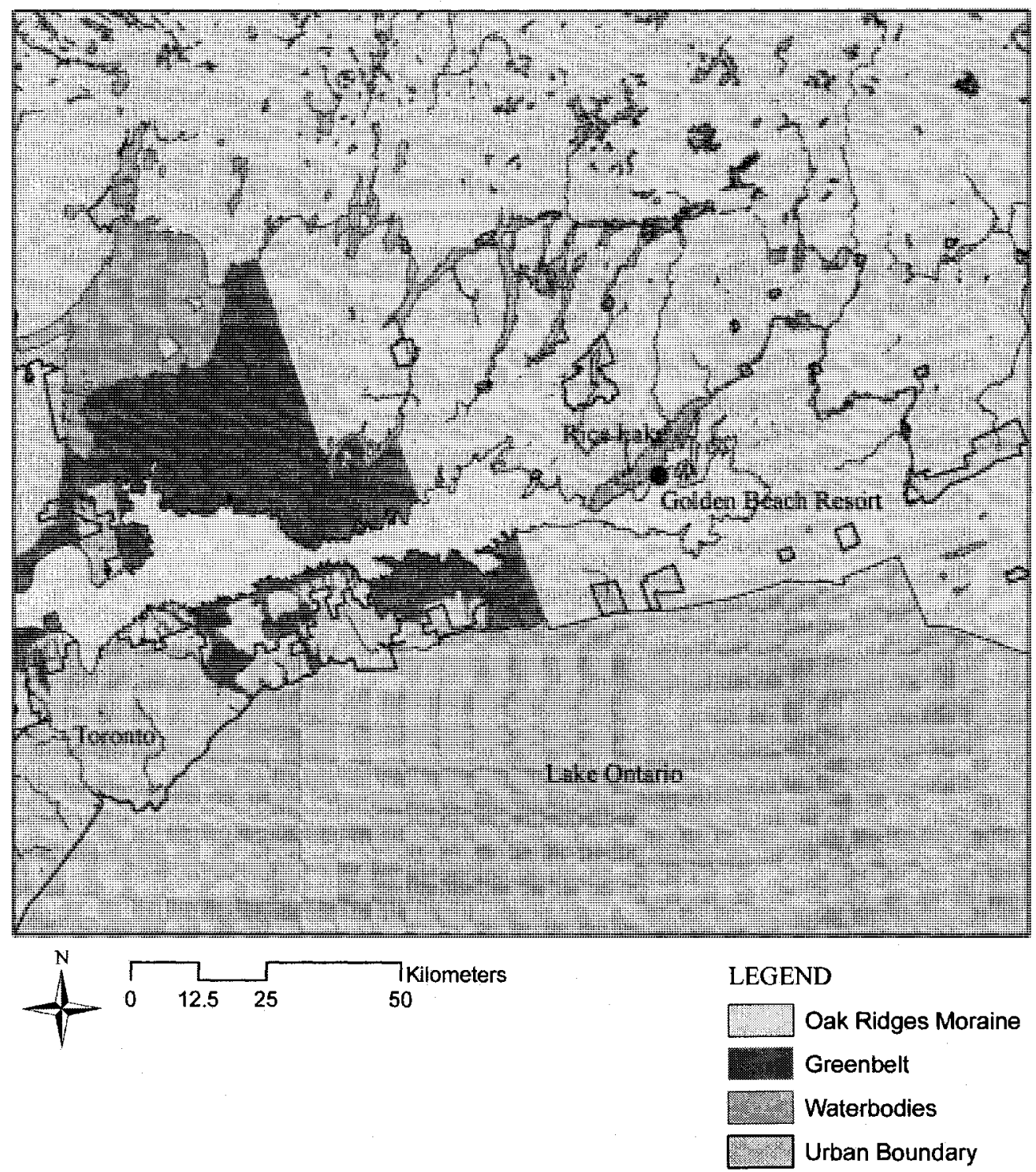

Figure 5.1. Regional Context Map.

Approximately 36 hectares of the Golden Beach Resort property is designated Oak Ridges Moraine which is an irregular shaped ridge formed by glaciation over 12,000 years ago, covering 120,000 hectares in south central Ontario. The ridge stretches $160 \mathrm{~km}$ from the Trent River in the east to the Niagara Escarpment in the west and runs parallel to Lake Ontario. The moraine provides clean water to the headwaters of 65 rivers and streams and acts as a recharge area for groundwater. It provides natural habitat 
for a range of threatened and endangered species in the Greater Toronto Area. It also provides prime agricultural lands and aggregate resources close to market areas.

The Oak Ridges Moraine Conservation Plan (ORMCP), 2001, was established to provide land use and resource management policies for the ecologically sensitive area. It was intended to provide clarity to the long term conservation of the natural resources of the moraine and it takes precedence over municipal Official Plans. The primary objective of the ORMCP is to protect and improve the ecological and hydrological integrity of the area by permitting land and resource uses that maintain, improve, or restore natural features within the moraine boundary.

\section{Golden Beach Resort}

The resort, figure 5.2, is situated on the southern shore of Rice Lake, Ontario, about 90 minutes east of Toronto. It is located in the Township of Alnwick/Haldimand in the county of Northumberland. Golden Beach Resort is known as a family destination offering fishing, children's programs, recreation facilities, cottages, condos, camping, seasonal trailers, and land lease estates all in a natural setting. The resort has been family owned and operated since 1948 . The total area of the property is approximately 155 hectares (383 acres). 

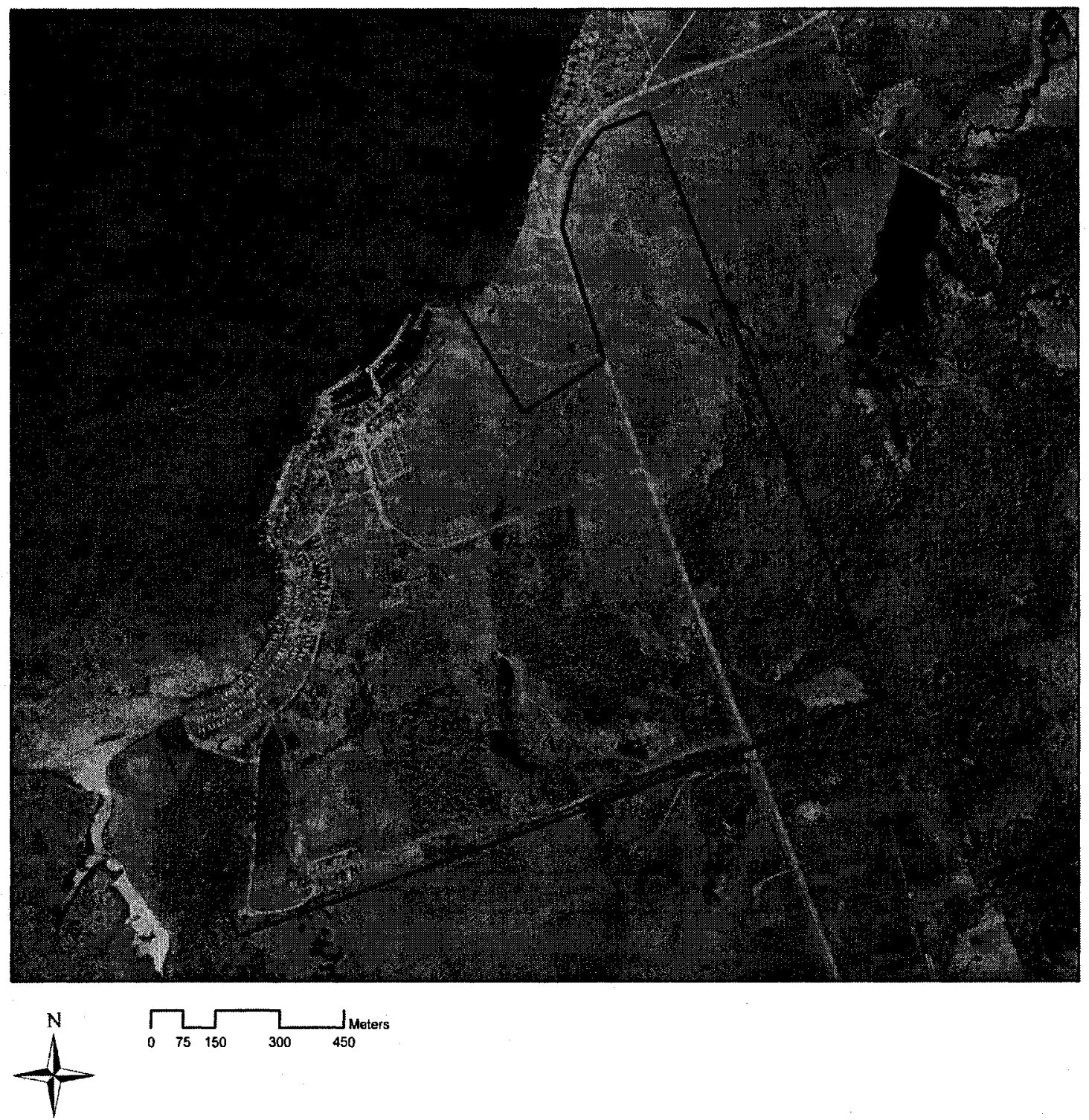

Figure 5.2. Aerial Image Showing Extent of the Golden Beach Resort Property (2001).

\section{Official Plans}

Schedule "A" Land Use Plan of the Official Plan of the Township of

Alnwick/Haldimand and Schedule "C-1" Land Use Plan of the Oak Ridges Moraine

Conservation Plan establish the pattern of development for the Golden Beach Resort.

The majority of the property follows the designations of the Official Plan of the 
Township and is divided into the following land uses: Resort, Rural, and Environmental Protection. Approximately 36 hectares (90 acres) of the property is located within the Oak Ridges Moraine boundary and is designated Natural Core and Countryside Rural. Policies of these designations range from development complementary to resort uses to strict environmental protection of key natural features. Figure 5.3 illustrates the land use designations which apply to the site.

The Resort designation means the predominant use of the land is for existing tourist accommodation and resort commercial uses. Golf courses are a permitted use that is deemed complementary to the basic resort uses. Future resort development is only permitted upon lands designated as Agricultural that demonstrate the following:

1. The lands do not comprise a specialty crop area,

2. There is a demonstrated need for the development,

3. There are no reasonable alternative locations which avoid prime agricultural areas, and

4. There are no reasonable alternative locations in prime agricultural areas with lower priority agricultural lands.

There is a general setback of 30 metres from the high water mark of all waterbodies to minimize disturbance of the natural character of the shoreline and minimal visual impact and adequate protection from flooding.

The Rural designation applies to lands of marginal value for agriculture and has potential for non-agricultural development. The purpose of this designation is to direct low intensity rural uses into these areas in order to protect Agricultural Resource Lands from incompatible, non-agricultural development. 
Lands designated as Environmental Protection are environmentally sensitive and act as constraints for development. They include both Provincially Significant Wetlands and Areas of Natural and Scientific Interest (ANSI). Environmental Protection areas are intended for the preservation and conservation of natural features and they should be managed to complement adjacent land uses. Recreational uses are only permitted where they are compatible with adjacent land uses. Alterations to these areas require authorization from the Municipality or Conservation Authority. Development and site alterations in areas designated Provincially Significant Wetlands are not permitted. Development and site alteration within 120 metres of the wetland requires an Environmental Impact Study outlining the potential impacts of the proposed development and how negative impacts can be minimized or eliminated.

Areas designated as Natural Core in the ORMCP are intended to improve and restore the ecological integrity of the area by preserving key natural heritage features and hydrological functions. Permitted uses are limited to agriculture, fish, wildlife and forest management, transportation and utilities, small scale commercial establishments, and low intensity recreation.

Countryside - Rural designated areas are intended to encourage agricultural and other rural uses by protecting prime agricultural areas and maintaining the rural character of the area. These areas also have the goal of protecting key natural heritage features and hydrological functions. Permitted uses include those allowed in Natural Core Areas but also permit aggregate operations and major recreational uses including golf courses. The land use designations outlined in Schedule "A" of the Official Plan and Schedule "C-1" of the ORMCP influence development policies for the Golden Beach 
Resort property. Golf course development is permitted on the lands designated Resort and Countryside - Rural and is allowed to expand to the areas designated for agriculture.

Key natural features, provincially significant wetlands, and Areas of Natural and

Scientific Interest restrict development in portions of the site and require the design to demonstrate minimal impact on natural features.

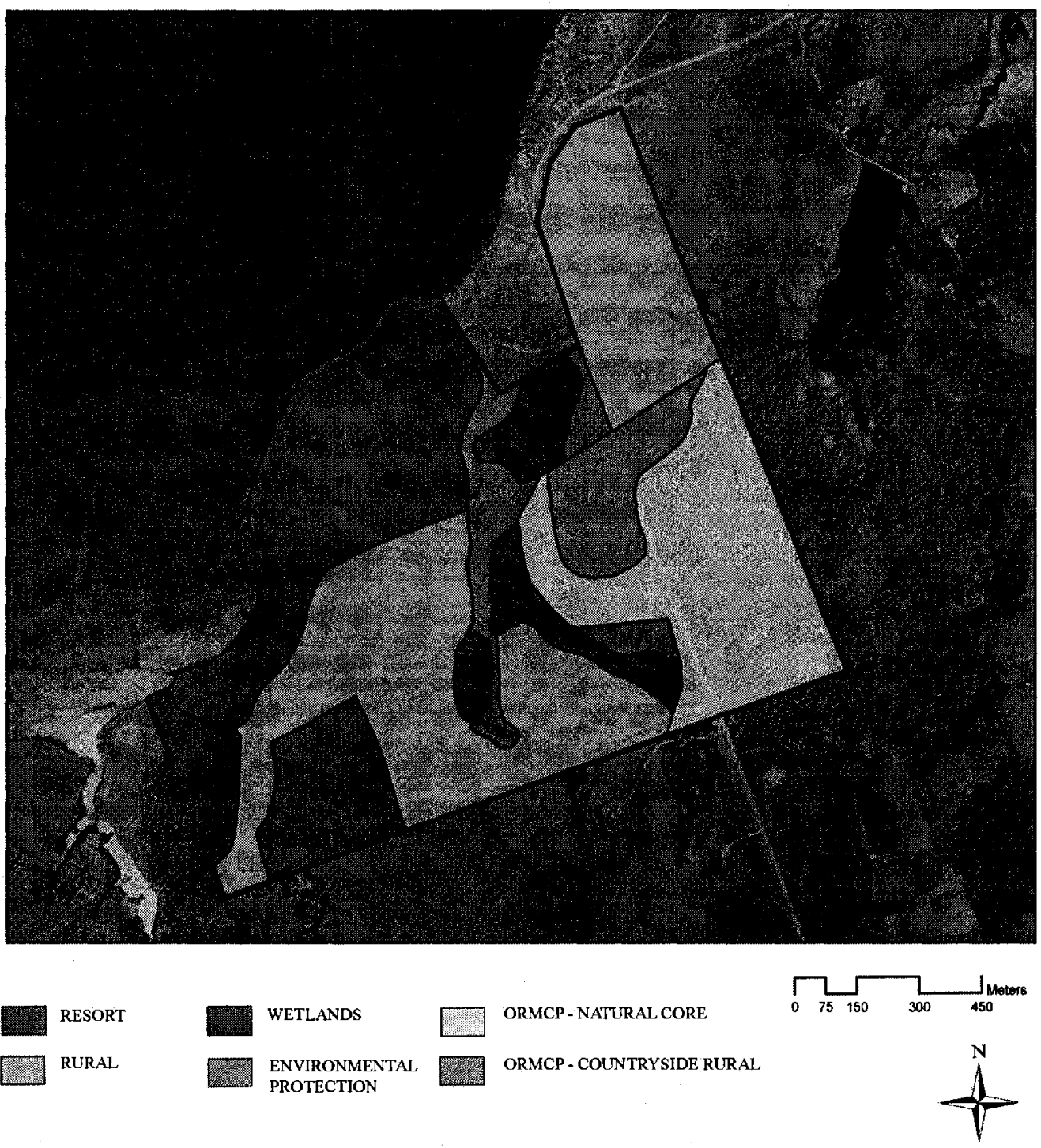

Figure 5.3. Land Use Designations of the Township Official Plan and the ORMCP. 


\section{Site Inventory}

Information about the site was obtained by a site visit in September, 2008, through environmental reports conducted for The Village of Golden Beach Estates, and by using ArcGIS 9.1 and information provided by the University of Guelph Data Resource Center. The inventory for the Golden Beach Resort golf course development is described below.

\section{Site Specific Scale}

A site inventory illustrated in figure 5.4 was completed for the golf course development site. The components examined include existing land uses, vegetation, and wetlands, elevation, slope, hydrologic information, and significant views within the site.

\section{Land Uses}

The existing land use categories on the design site include resort areas, residential estates, working agriculture, an abandoned sand pit, and open fields. There are four private residences located around the site which are occupied either by family members or are rented. The core resort area consists of cottages, condos, seasonal trailers, camping sites, a café, resort center, recreational facilities, and a marina. The Village of Golden Beach Estates, located on the southwest portion of the site is planned to have 265 park model trailer sites and amenities. 


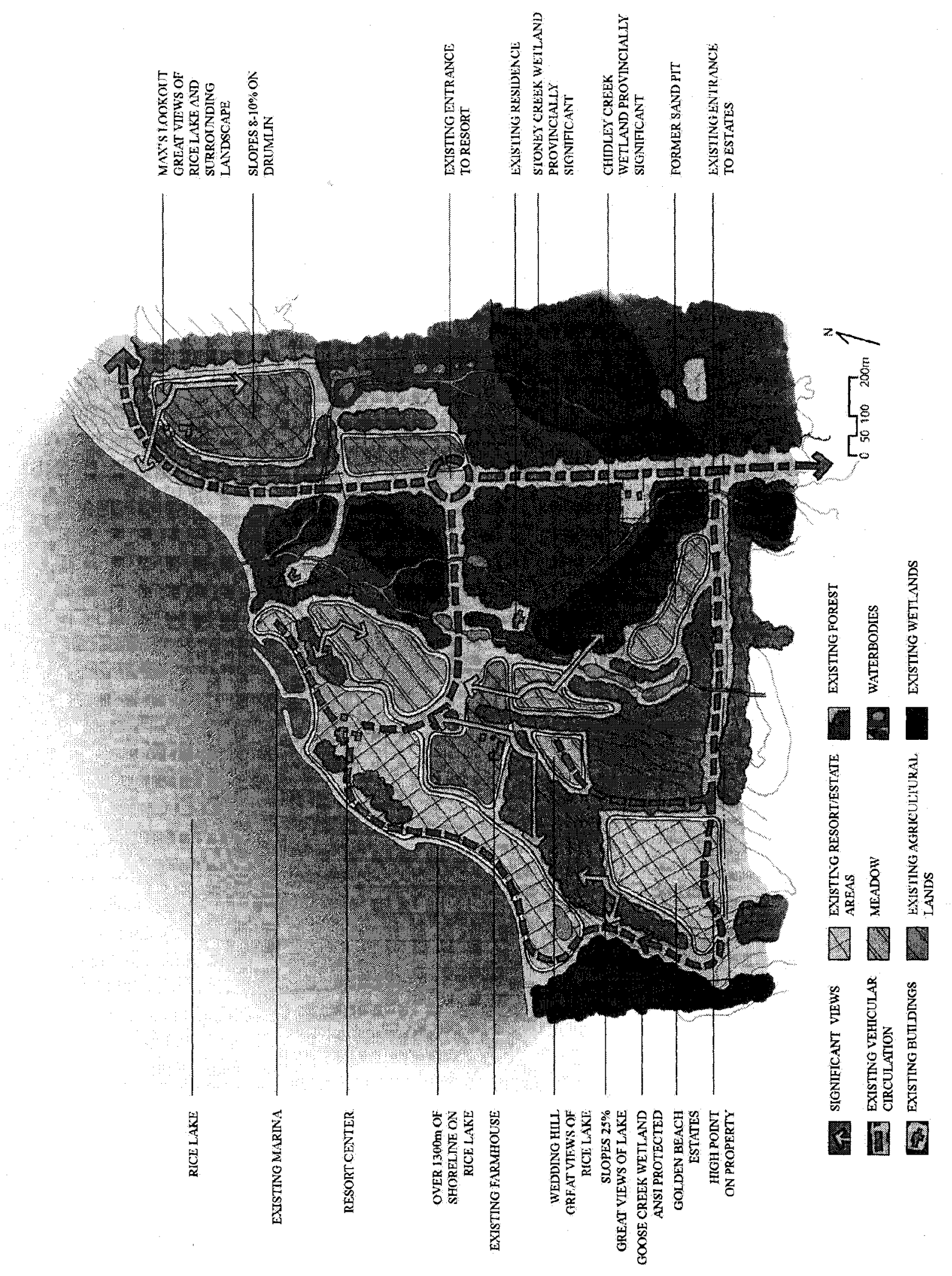

Figure 5.4. Site Inventory Illustrating Existing Land Uses and Natural Features. 


\section{Natural Features}

Currently over 50 percent of the site is forested with deciduous and coniferous species. There is over 78 hectares of forest with 13813 linear metres of edge within the property boundary. The edge to area ratio of forested patches is 177 lin.m./hectare. The upland forests are predominately hardwood species consisting of sugar maple, red oak, white oak, white pine, hemlock, white ash, white cedar, and yellow birch. Throughout the wetland areas, white cedar is the dominant species.

Almost 16 percent of the site is designated Provincially Significant Wetlands, the majority of which are located within the forested areas. A total wetland area of approximately 25 hectares with 4661 linear metres of edge is found within the property boundary. The edge to area ration of wetland patches is 189 lin.m./hectare. Three wetland complexes are found on the site: the watersheds of Stoney Creek, Chidley Creek, and Goose Creek. Stoney Creek is located east of County Rd 18 and is part of the Natural Core area designated in the ORMCP, 2001. Chidley Creek is located on the west side of County $\mathrm{Rd} 18$ and is classified as palustrine. There are two crossings of this watershed used to access the site. The Goose Creek watershed is located on the eastern boundary of the site and is classified as 30 percent palustrine and 70 percent lacustrine. This wetland complex is designated as an Area of Natural and Scientific Interest and is of high priority for protection.

There is approximately 3188 linear metres of streams which flow through the property and into Rice Lake. The streams are concentrated in the lands designated Oak Ridges Moraine or in the forested areas adjacent to the Provincially Significant wetlands in the Environmental Protection zones. The streams are primarily forested as 93 percent 
of the streams length is vegetated. The forest cover is interrupted for road crossings and breaks in hedgerows.
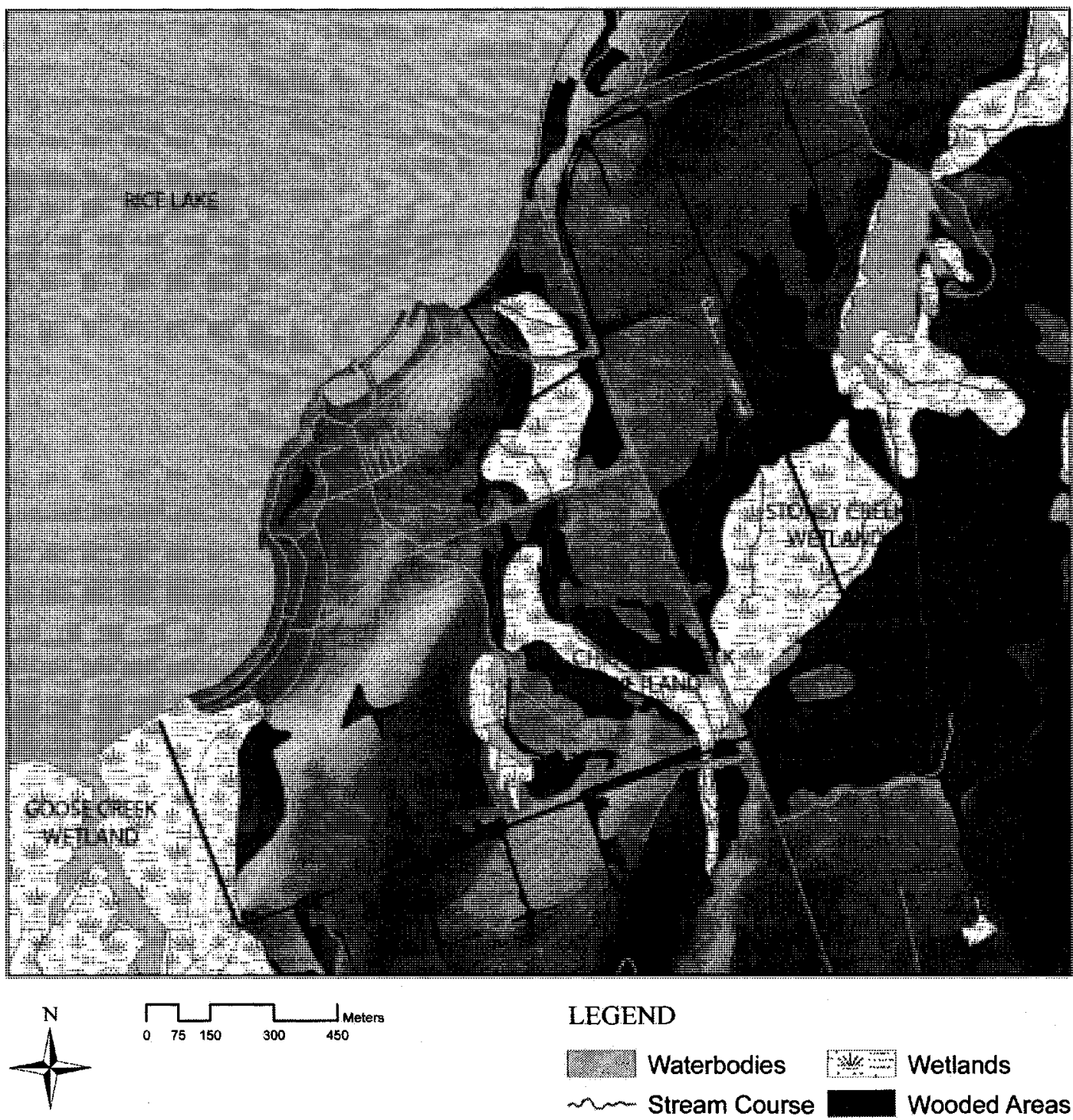

Figure 5.5. Natural Features.

Elevation

An elevation model of the site was created using ArcGIS 9.1 and Digital Elevation Models to illustrate the topography and hydrology of the area. Two drumlins 
define the property providing great views of the property as well as of the lake and surrounding landscape. The high point of the site, at 235 metres, is located on "Wedding Hill" while "Max's Lookout" is at 224 metres. In between the two drumlins the elevation drops to a low of $190 \mathrm{~m}$.
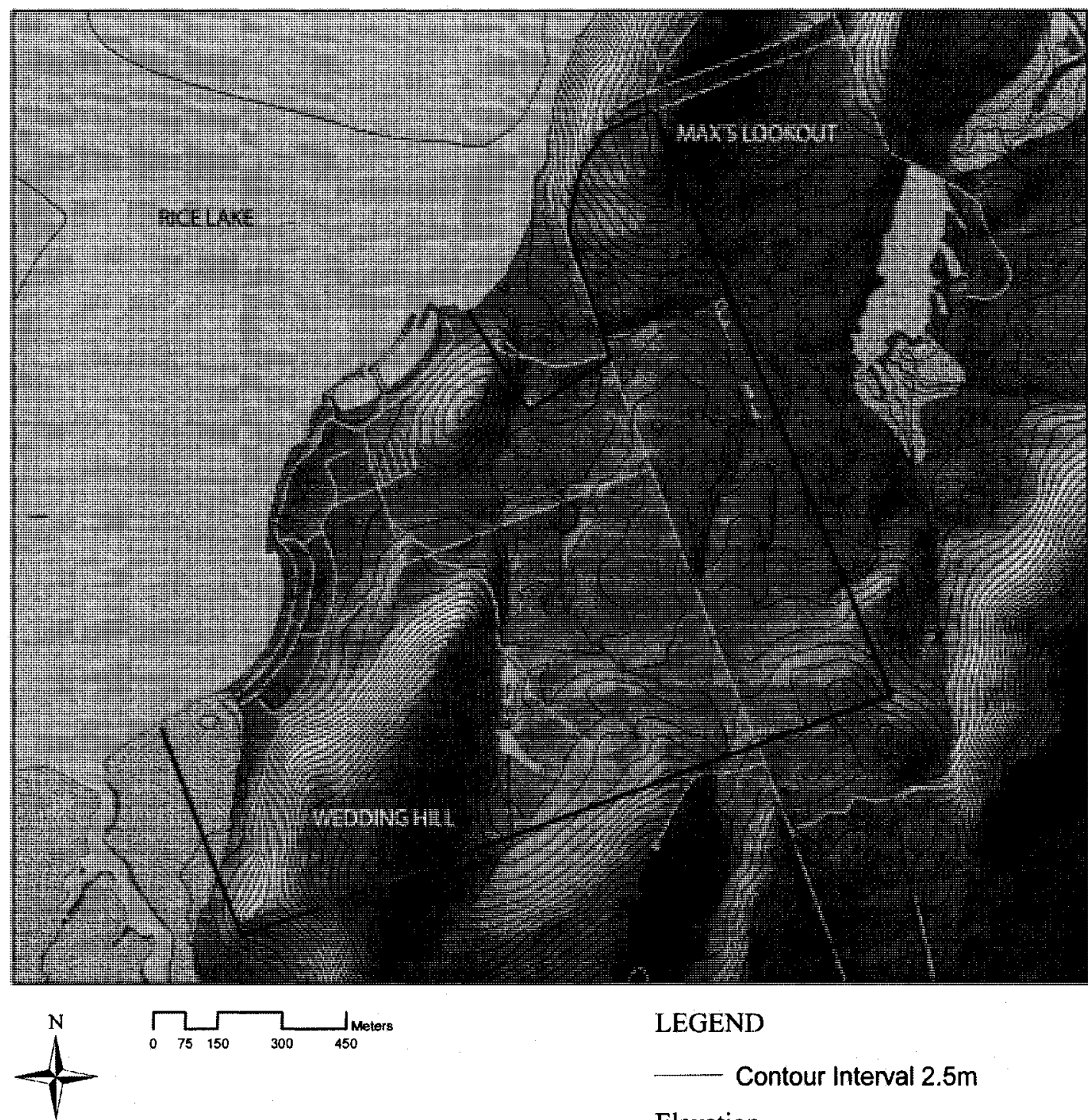

LEGEND

Contour Interval $2.5 \mathrm{~m}$

Elevation

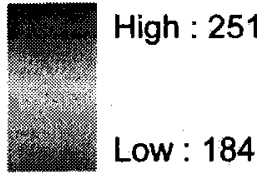

Figure 5.6. Elevation Model. 


\section{Slope Analysis}

A slope analysis was conducted using ArcGIS 9.1 and Digital Elevation Models of the area to illustrate the percent slopes of the site. The analysis revealed that the topography of the Golden Beach Resort site varies between 0 and 35 percent. The ridges along "Wedding Hill" present the steepest slopes with the portion on the east side reaching 35 percent. Slopes on "Max's Lookout" range from 5 to 15 percent. The rest of the site between the two drumlins is relatively flat with slopes between 0 and 5 percent.

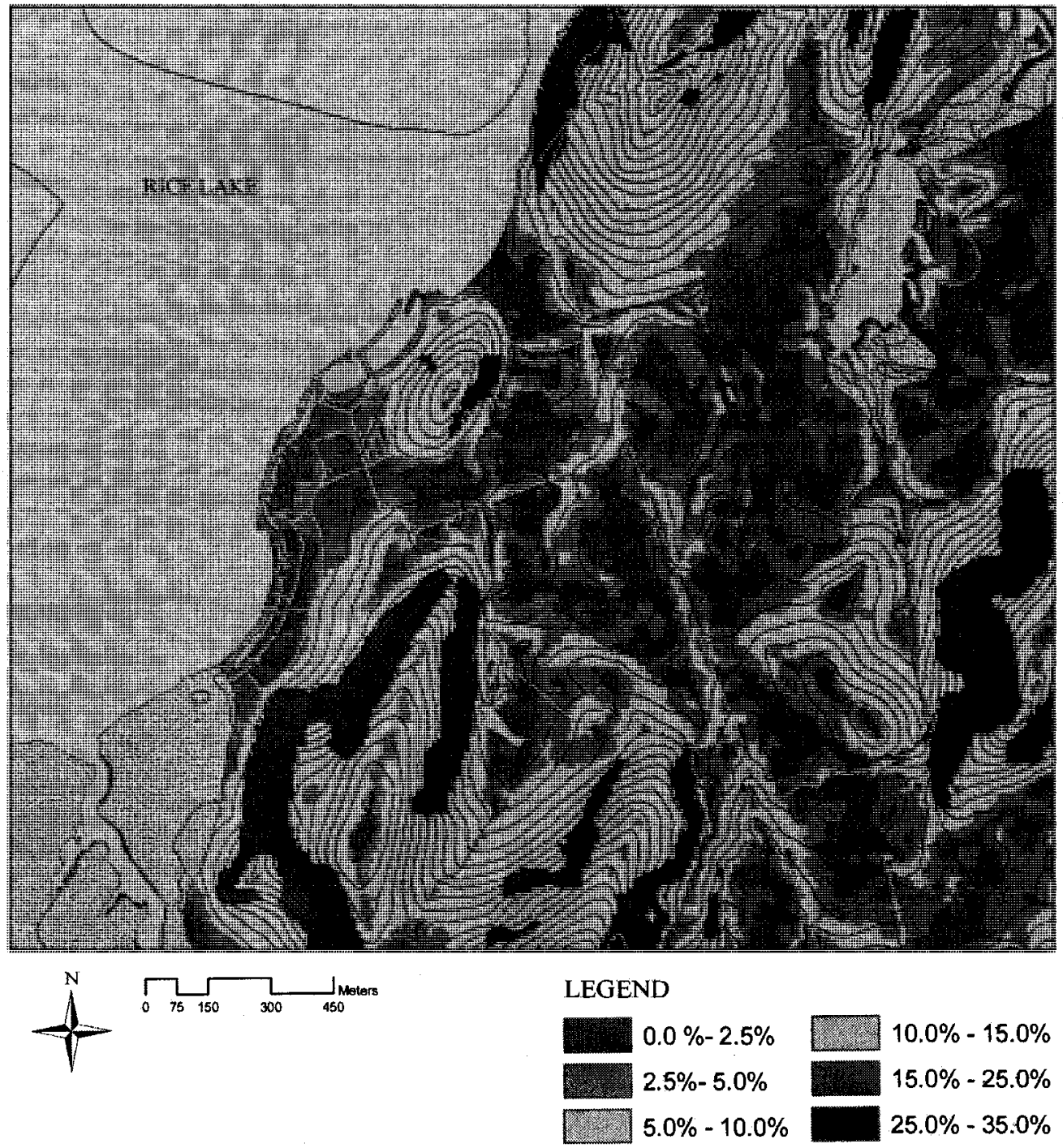

Figure 5.7. Slope Analysis. 


\section{Significant Views}

The site inventory illustrates the significant views both on and off the Golden

Beach Resort site. The highest points on both drumlins offer the most spectacular views of the property as well as of the lake and surrounding landscape. Each point is visible from the other providing visual connectivity between the two areas. There is a small hill close to the lake which offers great views as well.
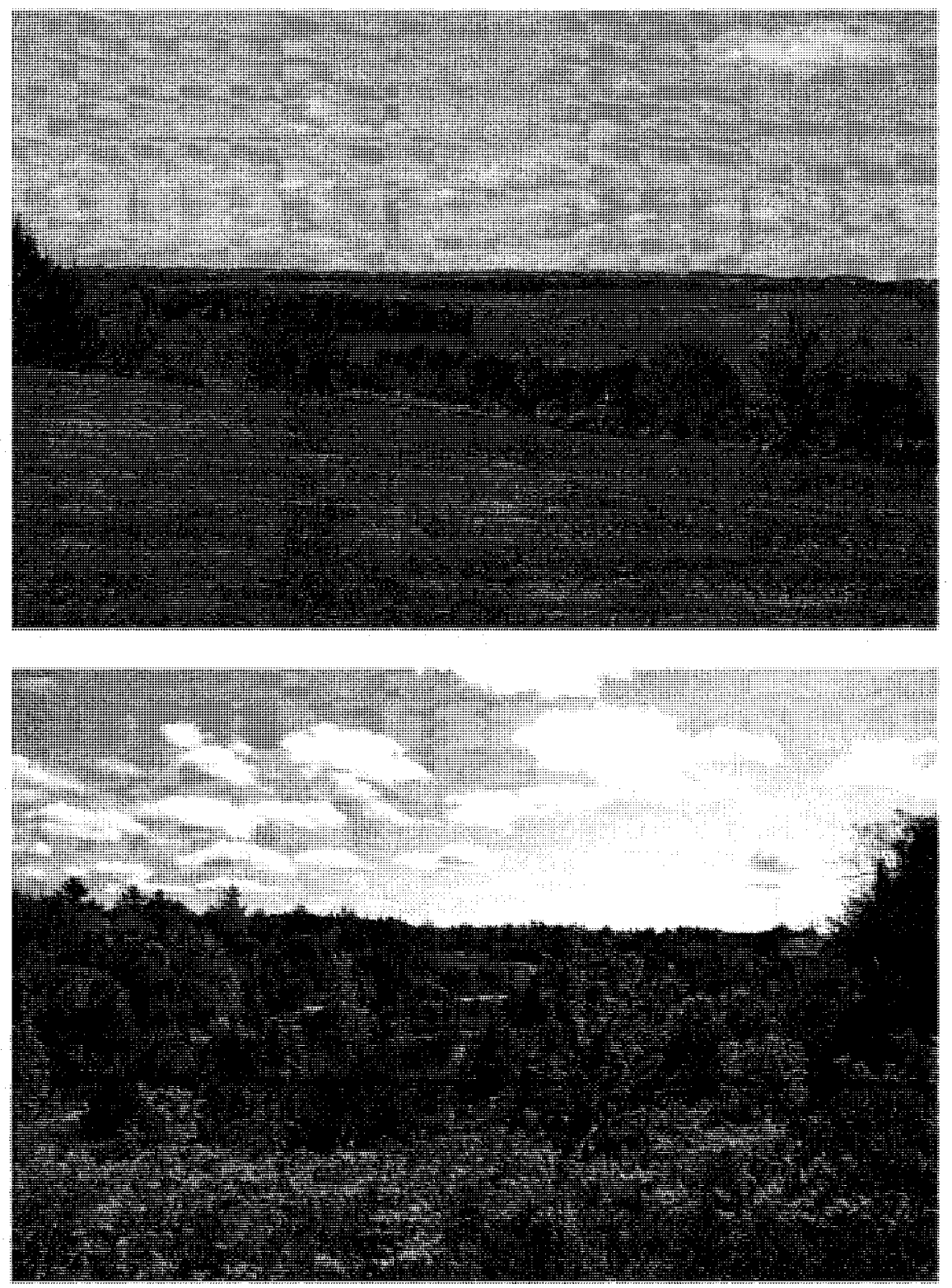

Figure 5.8. View of Rice Lake from Wedding Hill.
Figure 5.9. View Looking Southeast from Wedding Hill. 

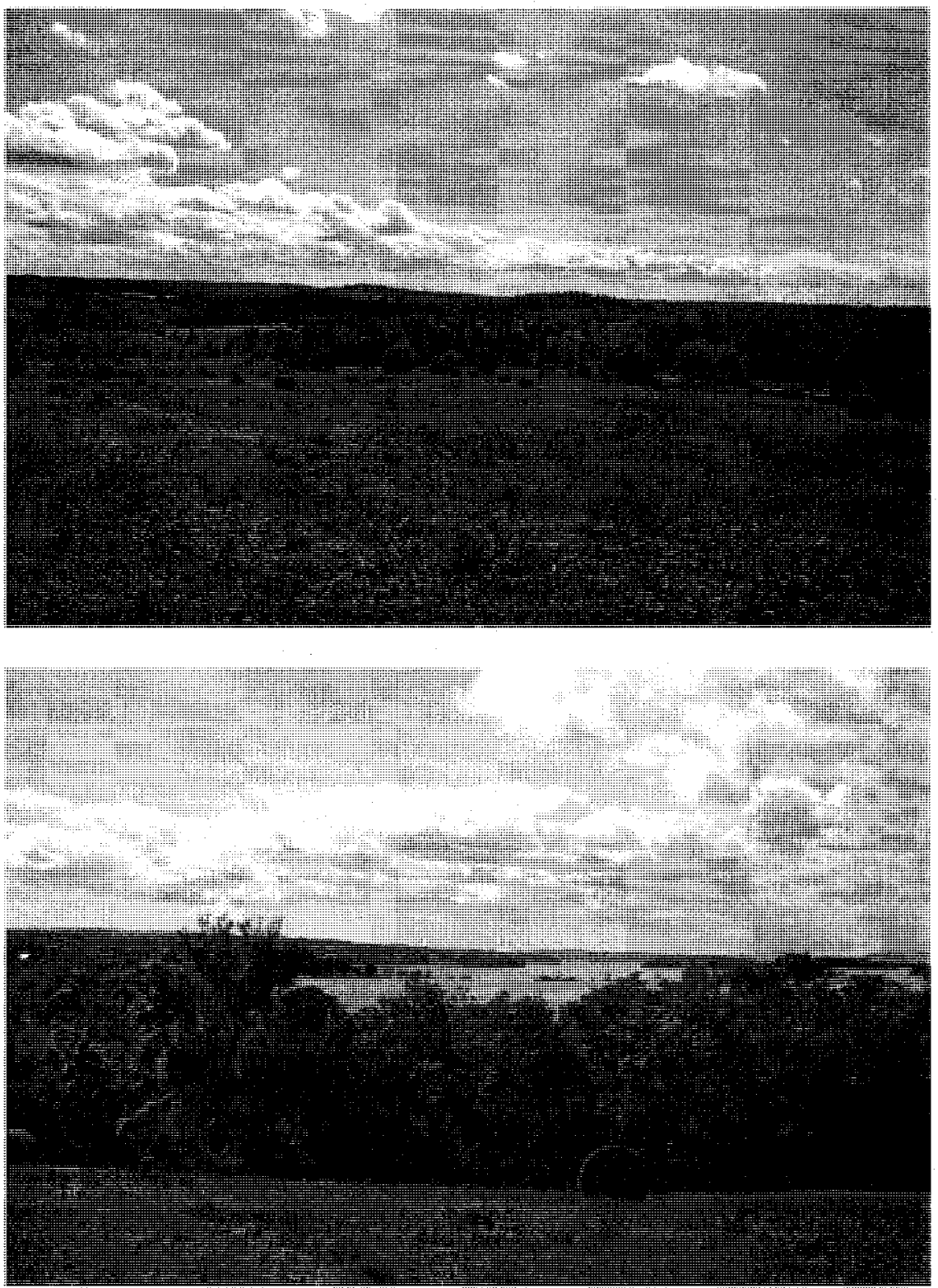

Figure 5.10. View of Surrounding Landscape from Max's Lookout
Figure 5.11. View of Rice Lake from Max's Lookout

\section{Site Analysis}

The following figure 5.12 illustrates the site analysis based on the natural features and site inventory of the Golden Beach Resort site and describes the opportunities and constraints for the integration of an 18-hole Championship golf course into the property. The Oak Ridges Moraine boundary and Provincially Significant Wetlands directed the analysis. These areas should remain untouched and alterations to the surrounding 
vegetation should be minimized. Two areas of land within the property boundary constituting approximately 80 hectares (198 acres) were identified as suitable locations to route the golf course. These areas emerged as suitable because they respect the wetland boundaries of all three complexes and the steep slopes of "Wedding Hill" while taking advantage of the various site features such as the shoreline, ideal terrain, and existing vegetation and water features. "Wedding Hill" was identified as the ideal location for the clubhouse because of its central location and spectacular views of the entire property and of Rice Lake. Other significant views were identified as areas where golfers should pause such as greens and tees allowing them more time to take in the views. 

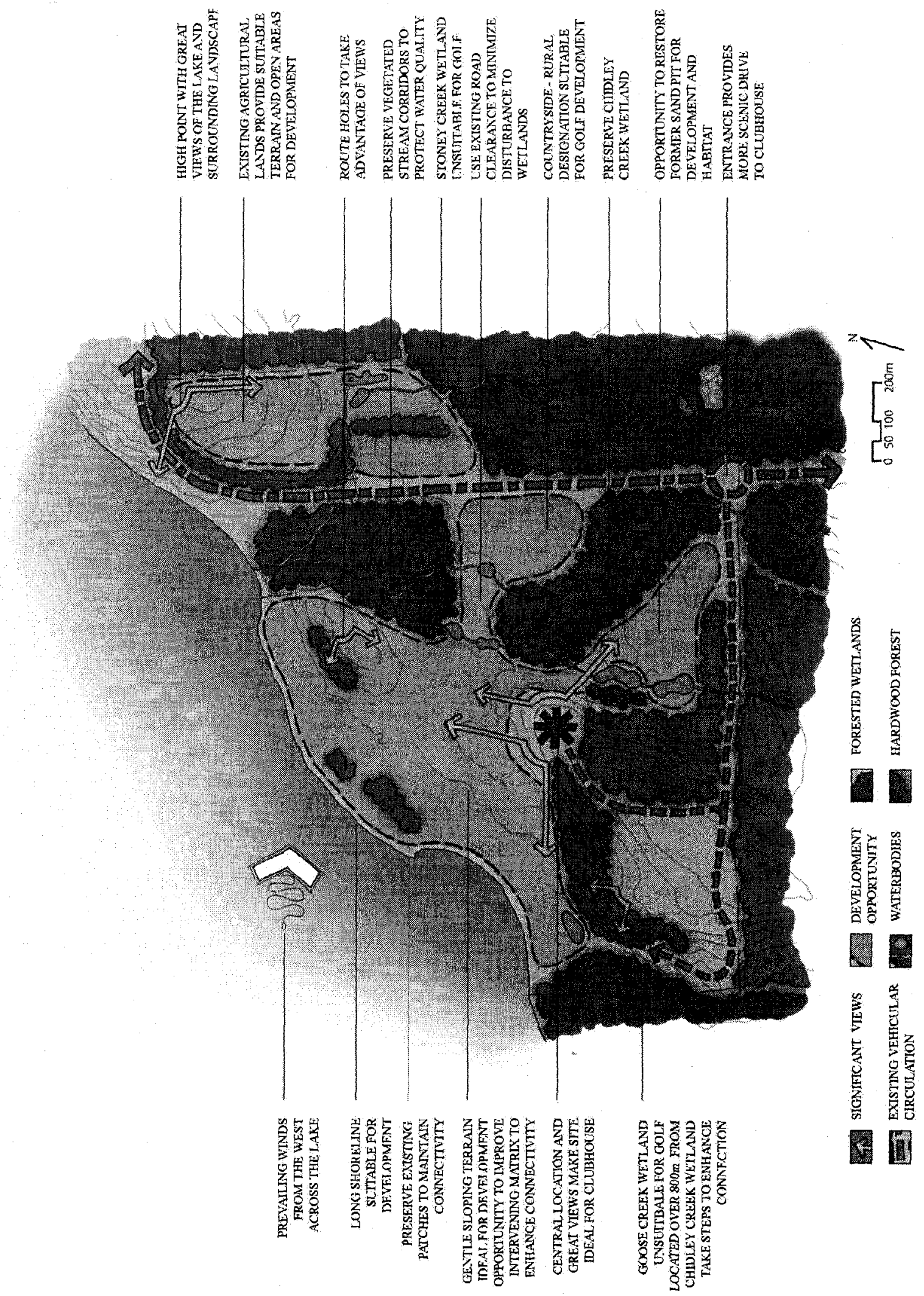

Figure 5.12 Site Analysis Demonstrating Opportunities and Constraints of Development. 


\section{The Design}

The Golden Beach Resort Golf Course Concept Plan in figure 5.13 illustrates the proposed design for the 18-hole championship golf course based on the developed amphibian conservation guidelines from Chapter Four. The following sections and images describe how the design responds to the critical aquatic and terrestrial needs of amphibians as well as how it satisfies principles of golf course design.

\section{Landscape Ecology Features}

The final design is greatly influenced by the existing mosaic of patches, edges, and corridors. The majority of development is directed into the existing resort areas, open fields, and agricultural fields to preserve the large network of patches. The Stoney Creek Wetland Complex is left untouched due to protection by the ORMCP as is Goose Creek Wetland Complex because of its ANSI designation. To maintain connectivity through the site, efforts were made to preserve the Chidley Creek watershed. The proposed first hole makes use of the existing transportation corridor to minimize disturbance through the wetland and the creek is restored to enhance the connection between the two wetland patches. Fragmentation of large patches is minimized and as a result, three large core patches are preserved within the property. 


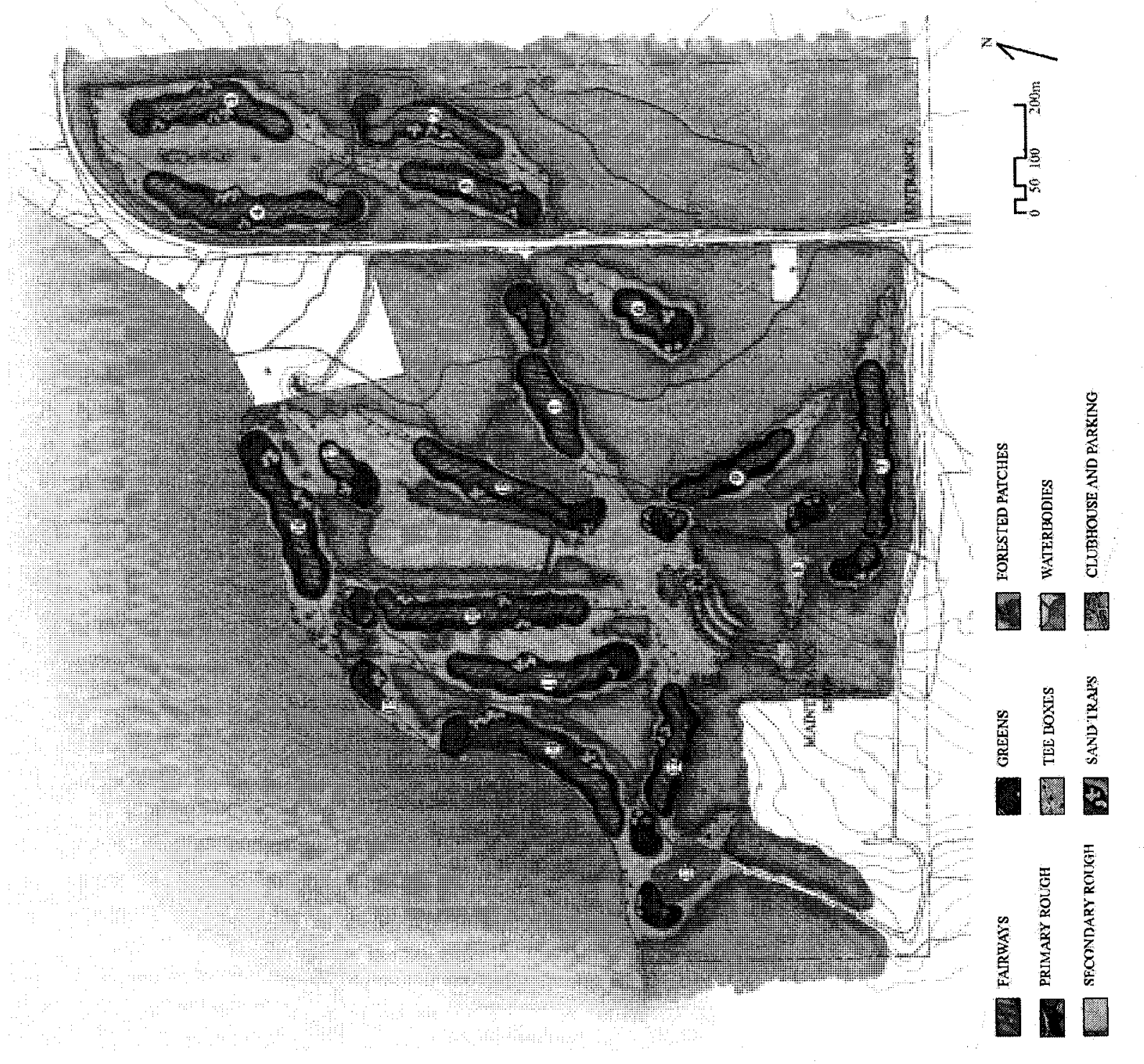

Figure 5.13. Golden Beach Resort Golf Course Master Plan. 
Small patches throughout the former resort area are used as stepping stones to connect Goose Creek Complex with Chidley's Creek. Distances between patches are minimized to less than 200 metres in order to reduce the effects of isolation. A network of patches is developed to provide alternative dispersal routes thus increasing the efficiency of movement. Patches are orientated with their long axis perpendicular to the route of dispersal to increase the probability of colonization. Patches are designed with curvilinear edges with coves and lobes in order to provide greater habitat diversity and to encourage movement across edges.

All stream corridors are vegetated except for when they are used as strategic or aesthetic features for the golf course. The design results in 3170 linear metres of streams, with approximately 80 percent of which are forested. All streams not located in forested areas are buffered by secondary roughs in order to protect water quality. Lengths of the streams which are not vegetated are minimized, especially prior to exiting the property. This is essential to maintain aquatic conditions such as cool water temperatures and high oxygen content as well as to protect the streams against dissolved substances such as nitrates and phosphates from runoff.

\section{Habitat Composition Features}

The influences of habitat composition on the final design are illustrated in figure 5.14 and table 5.1, which highlight the integration of amphibian habitat into the golf course layout and its affect on the existing natural features. Figures 5.15 and 5.16 illustrate typical sections of terrestrial edges and littoral shelves integrated into the design to provide quality habitat. 


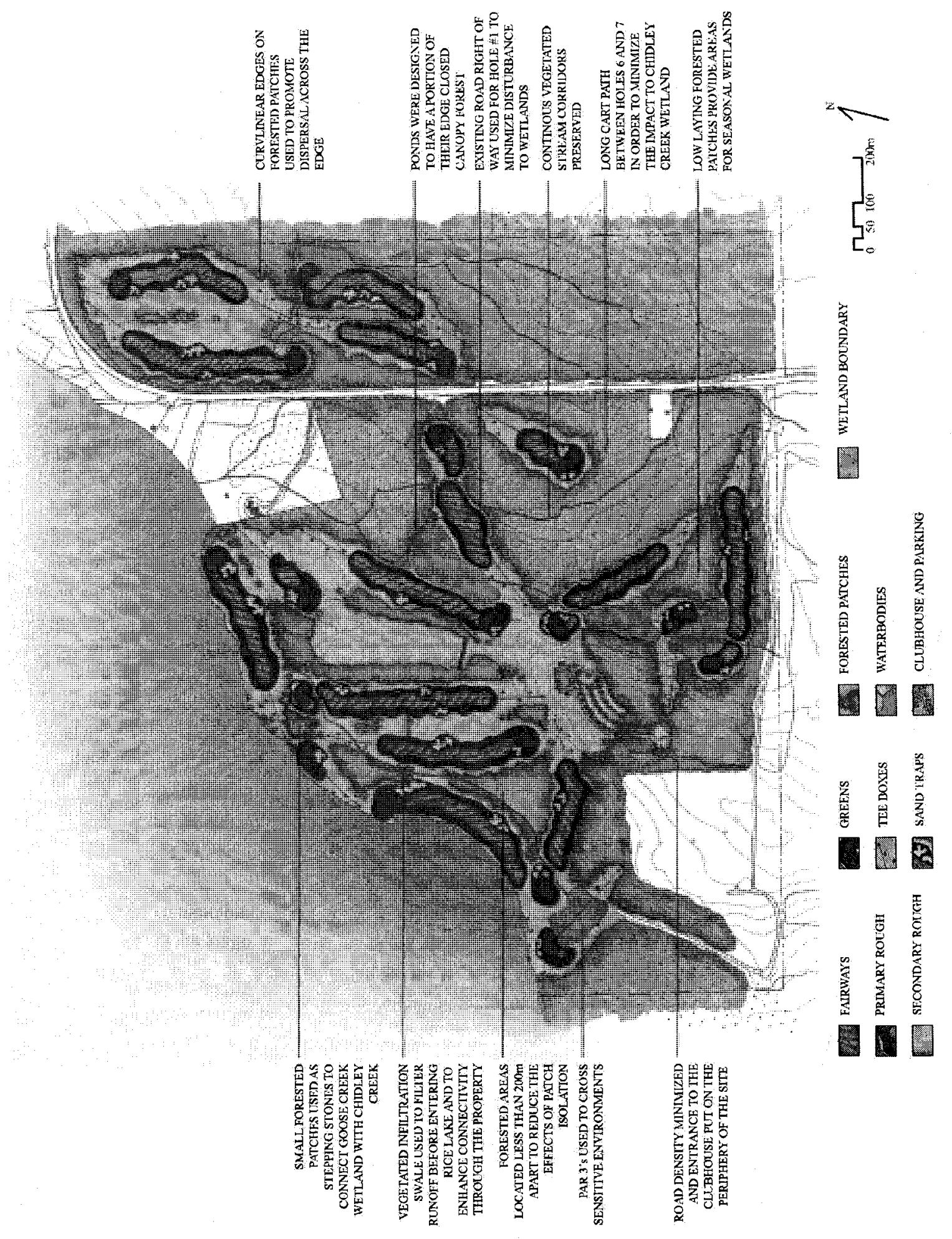

Figure 5.14. Overview of the Integration of the Design Guidelines into the Golf Course Layout. 


\begin{tabular}{|l|c|c|}
\hline \multicolumn{3}{|l|}{ Table 5.1. Summary of Ecological Features } \\
\hline \multicolumn{2}{|l|}{ Total Area: 154.5 hectares } & $\begin{array}{c}\text { After } \\
\text { Development }\end{array}$ \\
\hline Forested Patches & & \\
\hline Total Area & 78.2 hectares & 74.7 hectares \\
\hline Total Length of Edge & 13813 lin.m & 18227 lin.m \\
\hline Edge to Area Ratio & $\begin{array}{c}176.6 \\
\text { lin.m/hectare }\end{array}$ & 244 lin.m/hectare \\
\hline Largest Patch & 22.3 hectares & 22.3 hectares \\
\hline Smallest Patch & 0.2 hectares & 0.2 hectares \\
\hline Connectivity & & \\
\hline Average Distance Between Patches & $102.1 \mathrm{~m}$ & $90.9 \mathrm{~m}$ \\
\hline Continuous Vegetated Streams & & \\
\hline Total Length of Streams & 3188 lin.m & 3170 lin.m \\
\hline Percent of Length Forested & $92.9 \%$ & $79.9 \%$ \\
\hline Roads and Parking & & \\
\hline Total Area & 5.5 hectares & 2.1 hectares \\
\hline Water & & \\
\hline Total Area & 1.7 hectares & 4.9 hectares \\
\hline Total Length of Edge & 2024.6 lin.m & 2439.6 lin.m \\
\hline Percent of Edge Forested & $76.0 \%$ & $42.7 \%$ \\
\hline Largest Pond & 0.4 hectares & 1.5 hectares \\
\hline Golf Course Features Total Area & & \\
\hline Fairways and Roughs & - & 25.5 hectares \\
\hline Greens & - & 1.5 hectares \\
\hline Tees & - & 1.0 hectares \\
\hline Secondary Roughs & -6 hectares \\
\hline
\end{tabular}

The existing site consisted of 78 hectares of forested areas with an edge to area ratio of 177 lin.m./hectare. The conservation of large core areas was a primary objective in order to provide interior habitat suitable for amphibians. The proposed design resulted in 75 hectares of forested areas with an edge to area ratio of 244 lin.m./hectare. This constitutes a 2 percent decrease in total area and an increase of 38 percent in edge to area ratio. These results are largely due to hole 6 which is located in the Countryside-Rural designated area of the Oak Ridge Moraine. The increase in edge to area ratio is also a result of the more curvilinear form of edges done to increase habitat diversity and to promote movement across edges. 
Despite these alterations there are still several large patches providing interior habitat including the Stoney Creek Patch (22.3 hectares), Chidley Creek (18.3 and 7.4 hectares), "Wedding Hill" (12.0 hectares), and Goose Creek (4.1 hectares) along with patches within the course layout ranging from 0.2 to 1.9 hectares. These patches provide sufficient area to provide critical microhabitats consisting of an undisturbed forest floor, understory and a closed canopy. Patches and corridors were designed to be 50 metres wide where space permitted but due to the north-south orientation of many of the holes, the patches become more like stepping stones connecting Goose Creek and Chidley Creek rather than continuous vegetated corridors.

The boundaries of the existing wetlands were not disturbed except for small alterations on holes 1 and 9 , which would require approval by the Municipality or Conservation Authority. Five existing permanent ponds were expanded to function as strategic, aesthetic, and irrigation features. All were designed to be less than 500 metres apart and to have a portion of their edge as a closed canopy forest to enhance connectivity between aquatic and terrestrial habitats. No vertical walls were used and all pond edges were designed to have shallow littoral shelves with emergent vegetation except in front of greens where visibility could be obscured. The large forested areas of the Stoney Creek and Chidley Creek complexes provide a diversity of wetland types with varying hydroperiods. The course was routed to preserve these sensitive areas. The large forested patches within the layout offer opportunities to integrate seasonal wetlands because they are out-of-play and will not affect the strategy, playability, or aesthetics of the course. 
A vegetated infiltration corridor was sited on the back nine to improve connectivity between Goose Creek and Chidley Creek and to collect and filter runoff from the course before it enters Rice Lake. The corridor connects the large patches between the two wetlands improving connectivity by providing a moist vegetated corridor for amphibian individuals to disperse through.

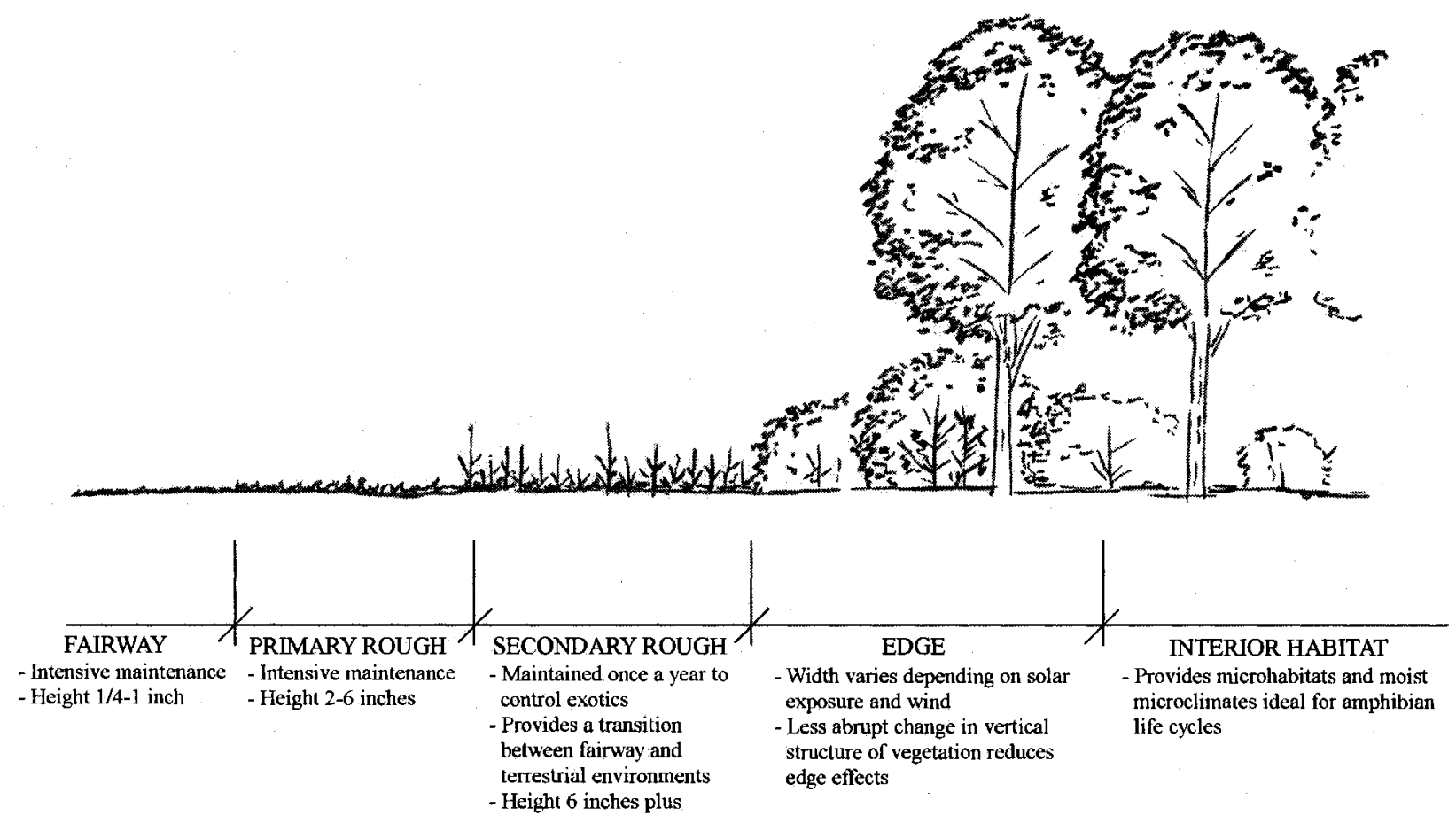

Figure 5.15. Section Illustrating the Vertical Structural Diversity between Fairways and Terrestrial Environments. 


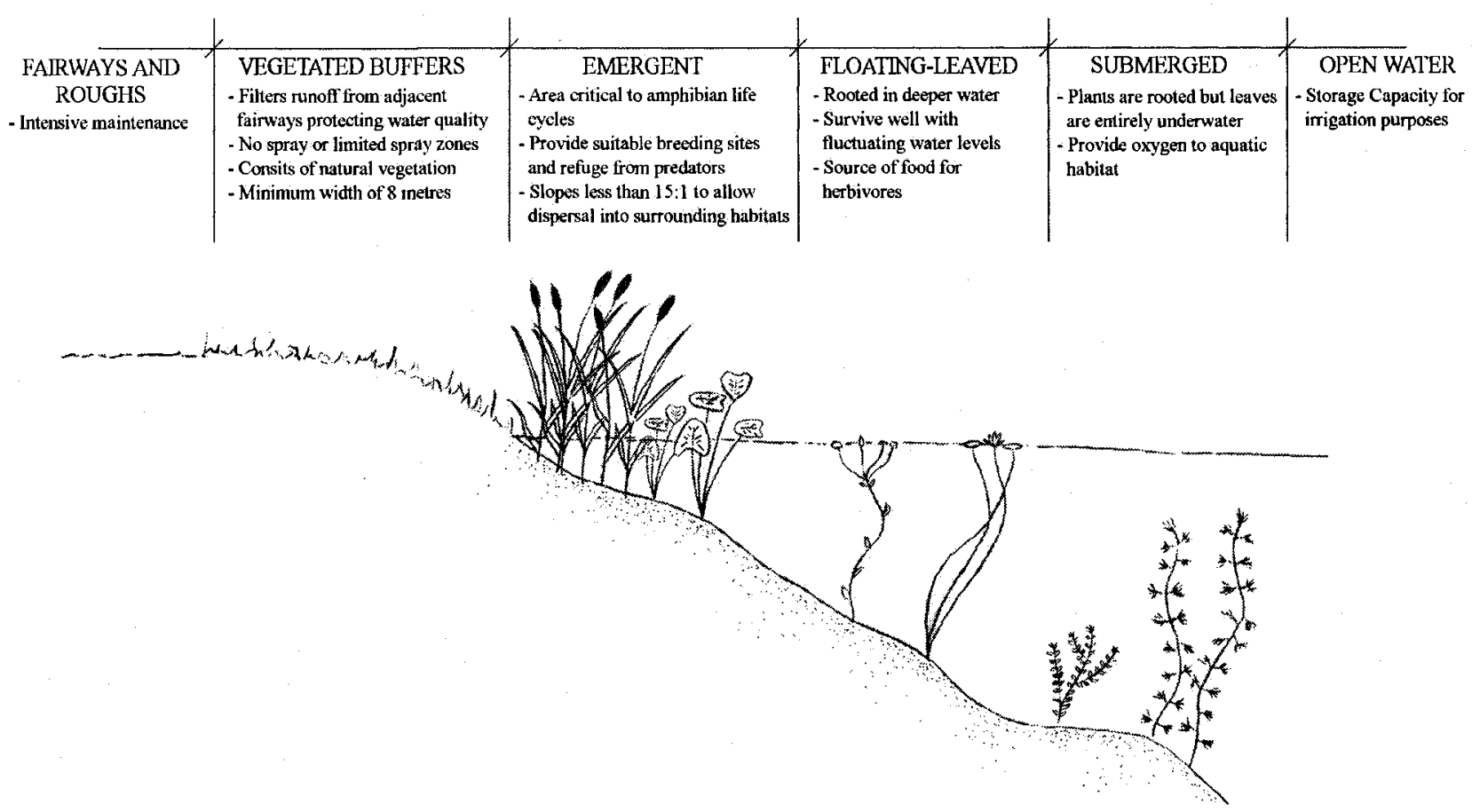

Figure 5.16. Section Illustrating a Littoral Shelf and Natural Edges on Golf Course Ponds.

\section{Habitat Configuration Features}

Habitat configuration played an influential role in the layout of the golf course.

Golf holes were routed to preserve existing natural features as well as to create opportunities to integrate new patches to enhance connectivity. Figures 5.17 and 5.18 illustrate the spatial arrangement of aquatic and terrestrial habitat within the golf course and demonstrate the connectivity between the natural features.

The course was routed to maintain the connection between Stoney Creek and Chidley Creek wetlands. Goose Creek wetland is located over 800 metres away from the nearest portion of Chidley Creek, therefore, efforts were made to enhance connectivity between the two complexes. The vegetated infiltration corridor and network of patches through the former resort area help create a more suitable environment conducive to amphibian dispersal. The existing resort has 5.5 hectares of gravel and paved roads 
which are potential barriers to dispersal. The proposed design replaces the roads with a mosaic of forested patches, a stream corridor, maintained turf, and secondary roughs consisting of fescues and long grasses. This new landscape should be more suitable to migration across the site, improving the connections between the large wetland complexes both on and off the site.

All ponds were designed to have a closed canopy forest on at least a portion of their edge providing core amphibian habitat. The majority of existing wetlands were preserved as core habitat areas providing habitat in the desired 142 to 289 metre range from the pond's edge. Patches are designed to be a minimum of 50 metres in width to protect against edge effects.

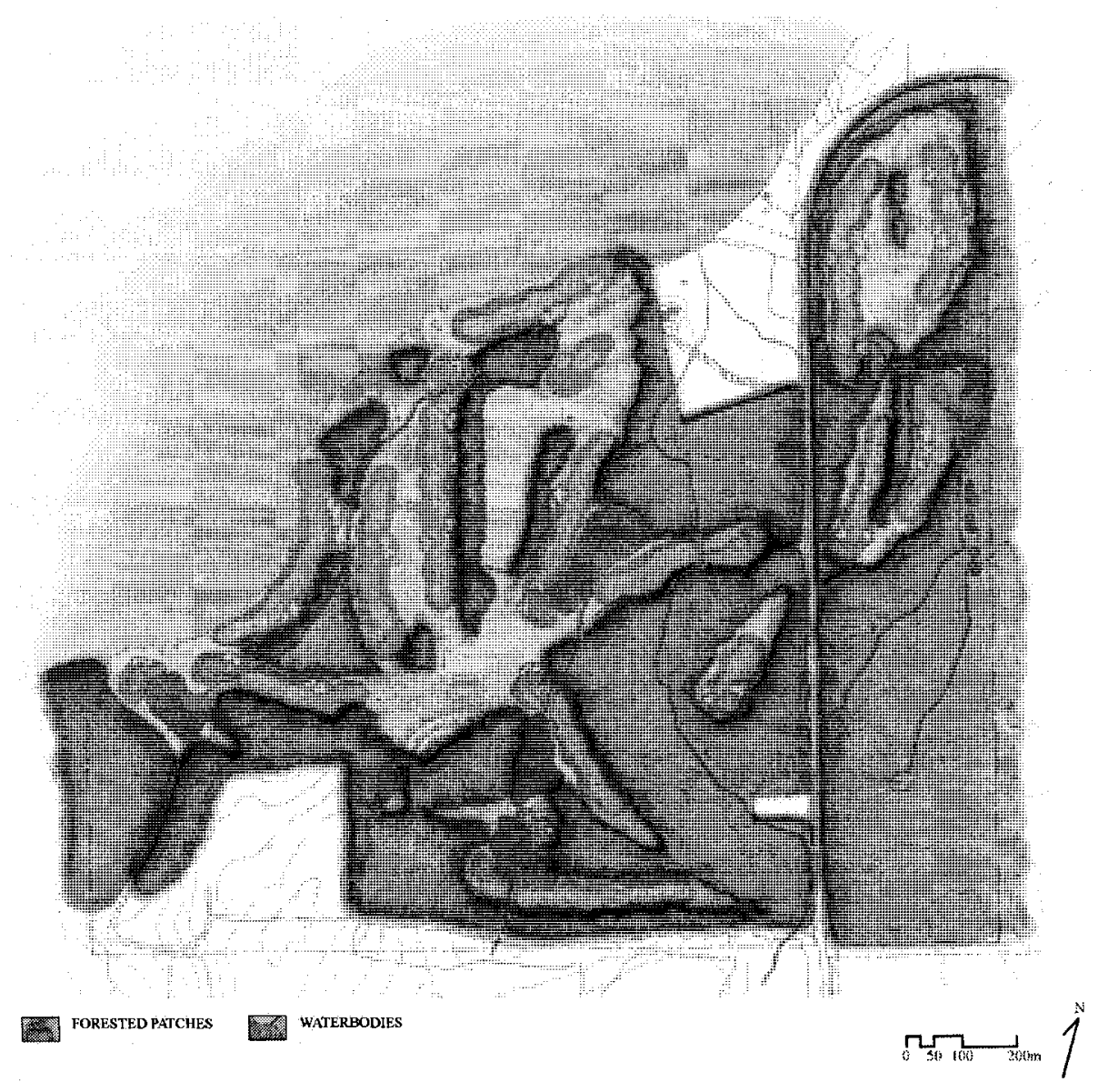

Figure 5.17. Configuration of Aquatic and Terrestrial Habitats. 


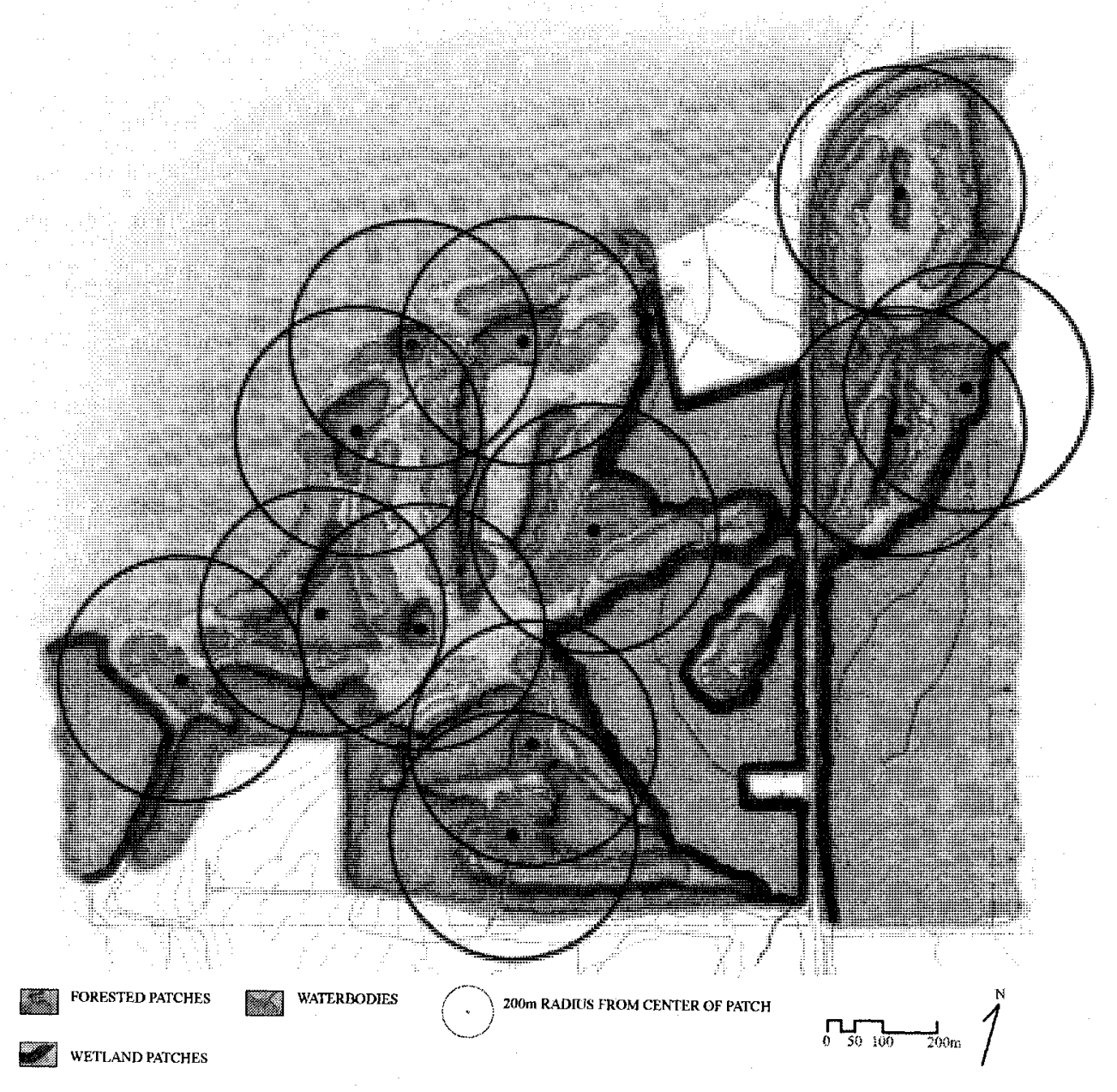

Figure 5.18. Configuration of Patches Within a 200m Radius.

\section{Golf Course Design Features}

A scorecard for the Golden Beach Resort Golf Course is shown in table 5.2 to illustrate the yardage, par, and handicap of the course. Table 5.3 represents the approach shot distances for each hole. A par 71 course was designed on the resort property ranging from 5498 yards from the Red tees to 7009 yards from the Championship tees. Four sets of tees were provided in order to accommodate a range of players with varying skill levels. The 18-hole golf course is organized into two returning nine hole loops originating and returning to the clubhouse located on top of "Wedding Hill." The 
majority of holes are orientated north-south but variation was created in the directions of par-3s and $5 \mathrm{~s}$ in order to present golfers with different winds and views. The two drumlins are used to create both uphill and downhill shots to balance the level holes between the two.

\begin{tabular}{|c|c|c|c|c|c|c|c|c|c|c|}
\hline Hole & 1 & 2 & 3 & 4 & 5 & 6 & 7 & 8 & 9 & Out \\
\hline Black & 441 & 393 & 409 & 516 & 341 & 238 & 537 & 207 & 411 & 3493 \\
Blue & 406 & 369 & 386 & 487 & 320 & 222 & 499 & 183 & 389 & 3261 \\
\hline White & 377 & 334 & 358 & 464 & 302 & 199 & 463 & 167 & 367 & 3031 \\
\hline Handicap & 7 & 11 & 9 & 3 & 15 & 13 & 1 & 17 & 5 & \\
\hline Par & 4 & 4 & 4 & 5 & 4 & 3 & 5 & 3 & 4 & 36 \\
\hline Red & 344 & 308 & 322 & 424 & 274 & 180 & 436 & 143 & 340 & 2771 \\
\hline
\end{tabular}

\begin{tabular}{|c|c|c|c|c|c|c|c|c|c|c|}
\hline 10 & 11 & 12 & 13 & 14 & 15 & 16 & 17 & 18 & In & Total \\
\hline 548 & 457 & 404 & 235 & 575 & 163 & 432 & 221 & 481 & 3516 & 7009 \\
518 & 438 & 381 & 208 & 545 & 143 & 395 & 206 & 454 & 3288 & 6549 \\
\hline 494 & 409 & 362 & 174 & 514 & 126 & 373 & 172 & 412 & 3036 & 6067 \\
\hline 8 & 6 & 10 & 14 & 2 & 18 & 12 & 16 & 4 & & \\
\hline 5 & 4 & 4 & 3 & 5 & 3 & 4 & 3 & 4 & 35 & 71 \\
\hline 457 & 372 & 325 & 121 & 483 & 101 & 338 & 152 & 378 & 2727 & 5498 \\
\hline
\end{tabular}

Table 5.2. Scorecard of the Proposed Golf Course Development.

\begin{tabular}{|c|c|c|c|}
\hline \multicolumn{4}{|c|}{ Approach Shot Distances } \\
\hline \multicolumn{2}{|c|}{ Front Nine } & \multicolumn{2}{|c|}{ Back Nine } \\
\hline 1 & 166 & 10 & 273 \\
\hline 2 & 118 & 11 & 182 \\
\hline 3 & 134 & 12 & 129 \\
\hline 4 & 241 & 13 & 235 \\
\hline 5 & 66 & 14 & 300 \\
\hline 6 & 238 & 15 & 163 \\
\hline 7 & 262 & 16 & 157 \\
\hline 8 & 207 & 17 & 221 \\
\hline 9 & 136 & 18 & 206 \\
\hline
\end{tabular}

Table 5.3. Approach Shot Distances. 
Playability, aesthetics, and safety were the primary influences of the initial layout of the golf course. Holes were routed to incorporate natural features as hazards where they would not adversely affect playability, as well as to take advantage of views both on and off the site. A separation of 80 metres between centerlines of fairways along with 50 metre safety circles around target areas was used to ensure safe playing conditions for golfers. Figure 5.19 demonstrates the safety features integrated into the design. Fairways were designed to be a minimum of 30 metres wide while 10 to 15 metres of primary rough was provided on either side. These guidelines resulted in a clearance of 60 metres between secondary roughs which is used to ensure adequate space sufficient to accommodate play from a diverse range of golfers. The placement of hazards was given careful consideration to challenge scratch golfers while not adversely affecting less-skilled players. Hazards were typically incorporated on the left side of fairways and larger areas were provided on the right sides to accommodate the majority of shots from high handicap players. 


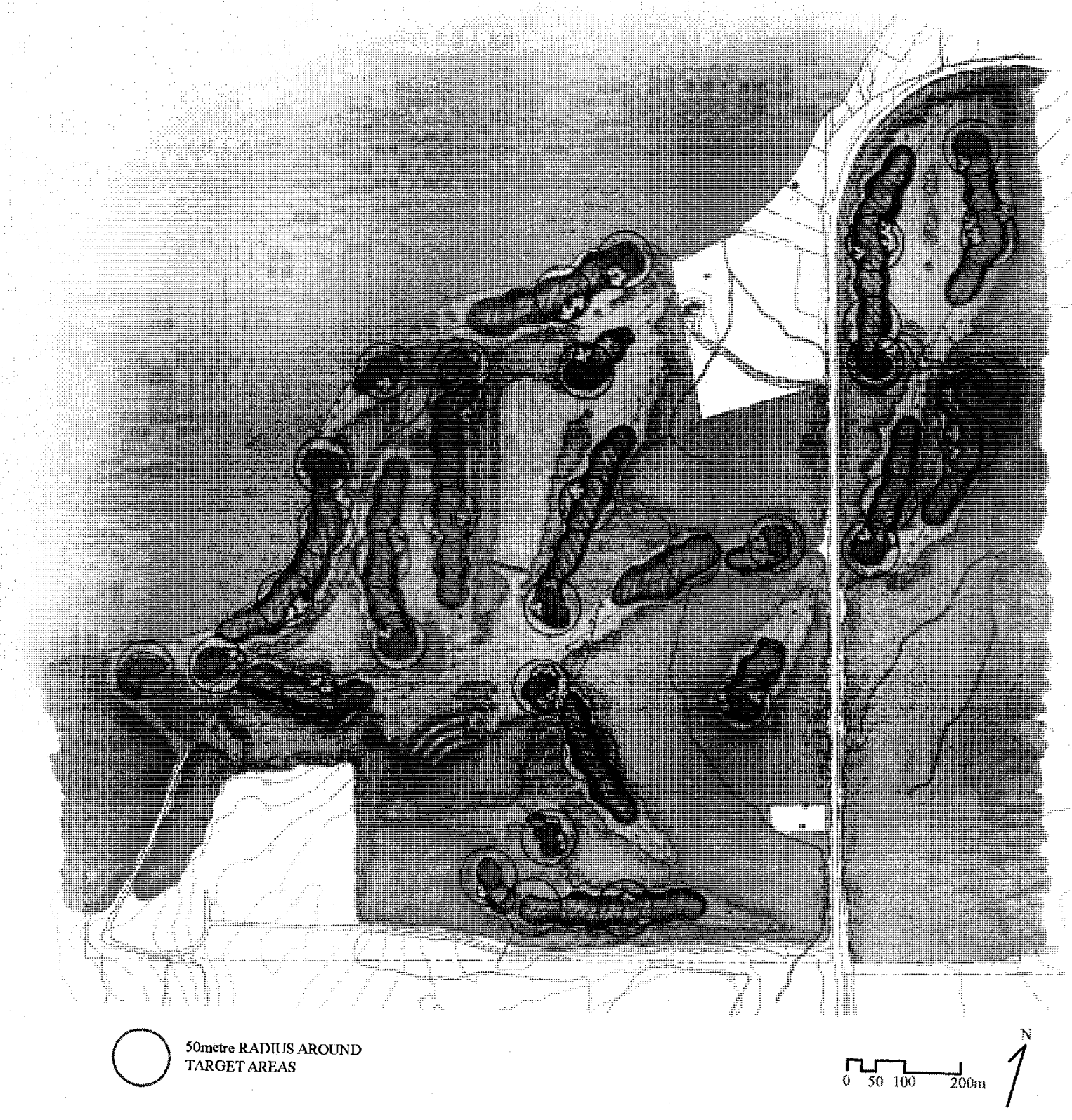

Figure 5.19. Plan Illustrating Safety Considerations and Setbacks Around Target Areas.

Several carries are required due to the number of streams which flow through the property, the majority of which were incorporated in front of greens to enhance the strategy and aesthetics of the course. The lengths of these carries are less than 15 metres in order to reduce the severity of the hazard and to increase the chance of less-skilled golfers successfully hitting over them. Not all of the streams flow year round, which 
means some of the carries are over vegetated corridors rather than over streams. Four longer carries are found on holes $2,4,8$, and 13 , but alternate routes are provided around the water hazards so that less-skilled players have a safer path to reach the green which does not require them to play through the air. Hole 13, a par-3, was used adjacent to Goose Creek watershed so that the wetland boundary could be maintained as golfers play over the environmentally sensitive area. Other environmentally sensitive zones are incorporated in out-of-play areas such as behind greens and tees and, when integrated parallel to holes, sufficient space between the centerline of the fairway and the edge of the zone is provided to maintain playability.

Aesthetics played a critical role influencing the routing of the course. Significant views of Rice Lake, the property, and the surrounding landscape were identified and the course was routed to have golfers pause at these places. Tee boxes on the par- 3 holes 8 and 13, were situated on "Wedding Hill" to create dramatic downhill shots with spectacular views. Golfers are provided with great views of Rice Lake and the surrounding landscape from the third green and fourth tee atop of Max's Lookout. The shoreline was utilized on several holes on the back nine to create a memorable finish to the round.

The course was routed to move golfers through varying landscapes. Portions of the site are heavily wooded while other areas have characteristics of a links style landscape. Four holes are routed along the shoreline while others are orientated to capture views of the lake. Some holes are located on the edge of the two drumlins while others are situated in the low areas between the two. These changes in vegetation, 
landforms, and natural features enhance the aesthetic experience for golfers as they move from one area to the next.

\section{Design Guidelines Application}

The following section demonstrates the integration of the applicable design guidelines into the proposed golf course development. The three images and tables provide a graphic representation of the integration of amphibian habitat into golf course landscapes which are complementary to the principles of golf course design. Note:

1. Only 33 of the 46 guidelines have been demonstrated in this section because it was either not possible to demonstrate the remaining 13 guidelines in plan graphics or they were not included in the design because they did not apply to this site.

2. These are typical representations and are not exclusive to the areas shown in these demonstrations. 


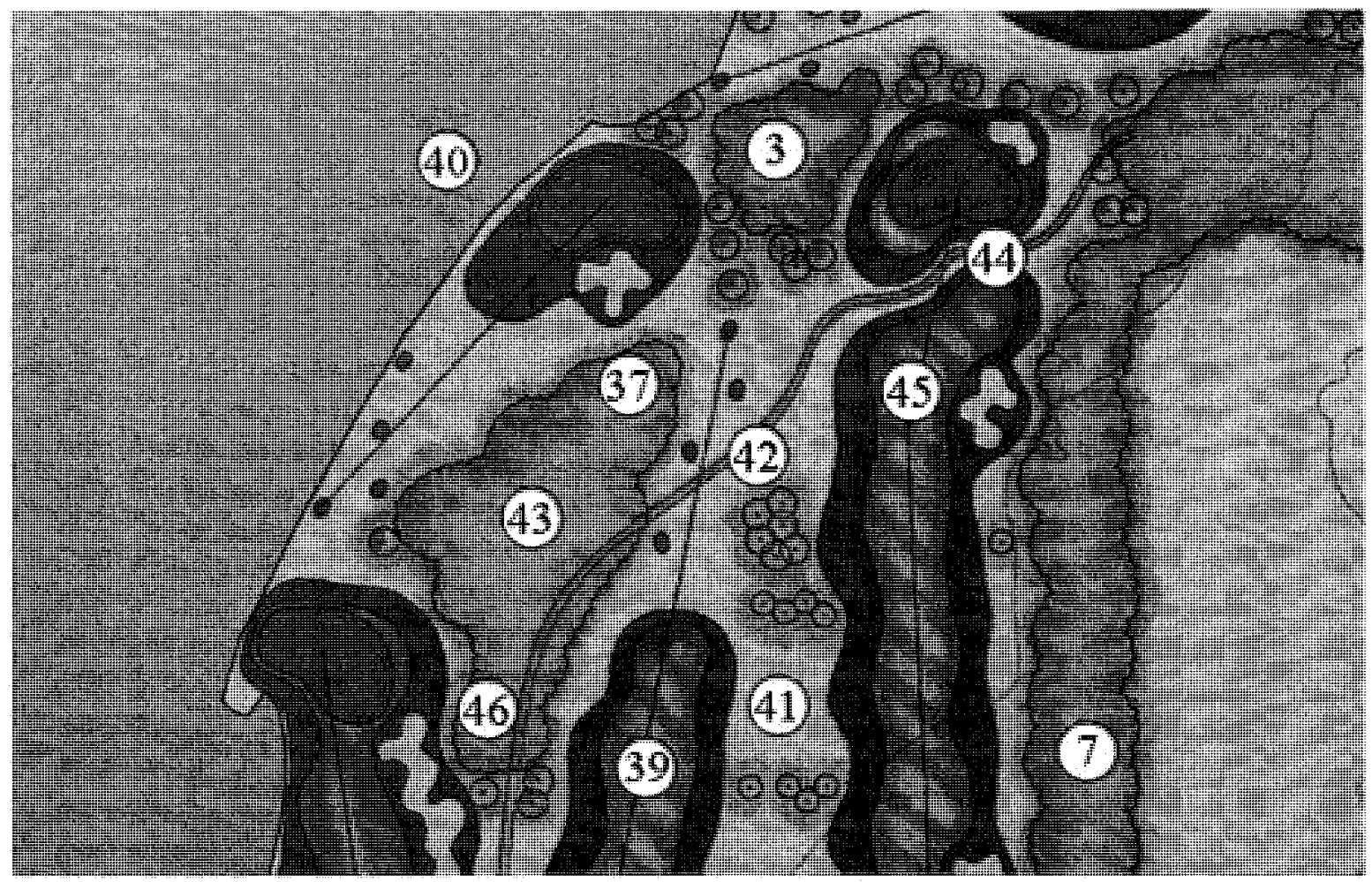

Figure 5.20. Demonstration of the Applied Design Guidelines 1

Table 5.4. Demonstration of the Applied Design Guidelines 1

3. Small patches used as stepping stones to enhance connectivity.

7. Patches were orientated with their long axis perpendicular to the route of dispersal.

37. Existing roads were replaced with terrestrial patches and turf to improve the intervening matrix.

39. To ensure playability, each fairway was designed to be 30-35 metres wide with 10-15 metres of primary rough on both sides.

40. Water hazards were incorporated on the left sides of fairways to challenge scratch golfers.

41. To ensure safety, a minimum of 80 metres between centerlines of fairways was provided.

42. Environmentally sensitive areas were incorporated between tee boxes and fairways in order to control forced carry distances.

43. Habitat areas were incorporated in out of play areas around tee boxes and behind greens.

44. Natural areas in front of greens may need to be maintained for visibility.

45. Areas around landing zones are the least suitable for natural zones because they experience greater play.

46. Terrestrial areas were located a minimum of 16 metres from greens and tees to avoid root competition and affects of shade. 


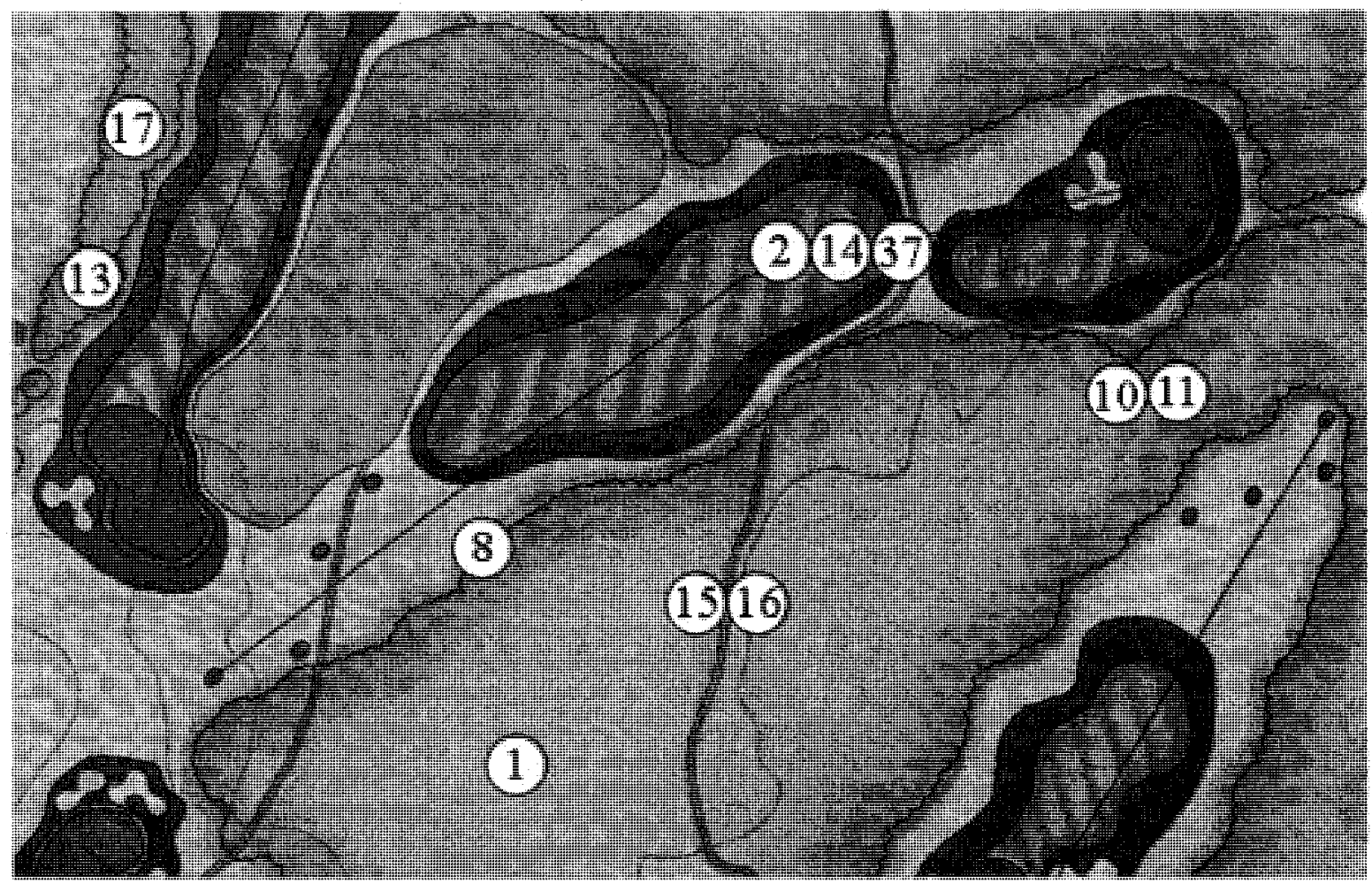

Figure 5.21. Demonstration of the Applied Design Guidelines 2

Table 5.5. Demonstration of the Applied Design Guidelines 2

1. Large Patches were preserved in order to provide a range of habitats.

2. Existing transportation corridor was utilized to avoid the fragmentation and disruption of the Provincially Significant Wetlands.

8. Secondary roughs consisting of fescues were used to provide a transition between the fairway and terrestrial environments.

10. Curvilinear boundaries were used to promote movement across edges.

11. Curvilinear edges with coves and lobes were used to provide greater habitat diversity.

13. Native vegetation was used to create similarity between corridors and patches.

14. Existing road corridor was removed to reduce conduit for evasive species.

15. Wide corridors of dense vegetation preserved to protect water quality of streams.

16. Continuous vegetated stream corridors were preserved to maintain aquatic conditions such as cool water temperatures and high oxygen content.

17. Small patches were used to provide alternate dispersal routes through the property.

37. Existing roads and parking were removed to improve the intervening matrix and to provide environments more conducive for amphibian dispersal. 


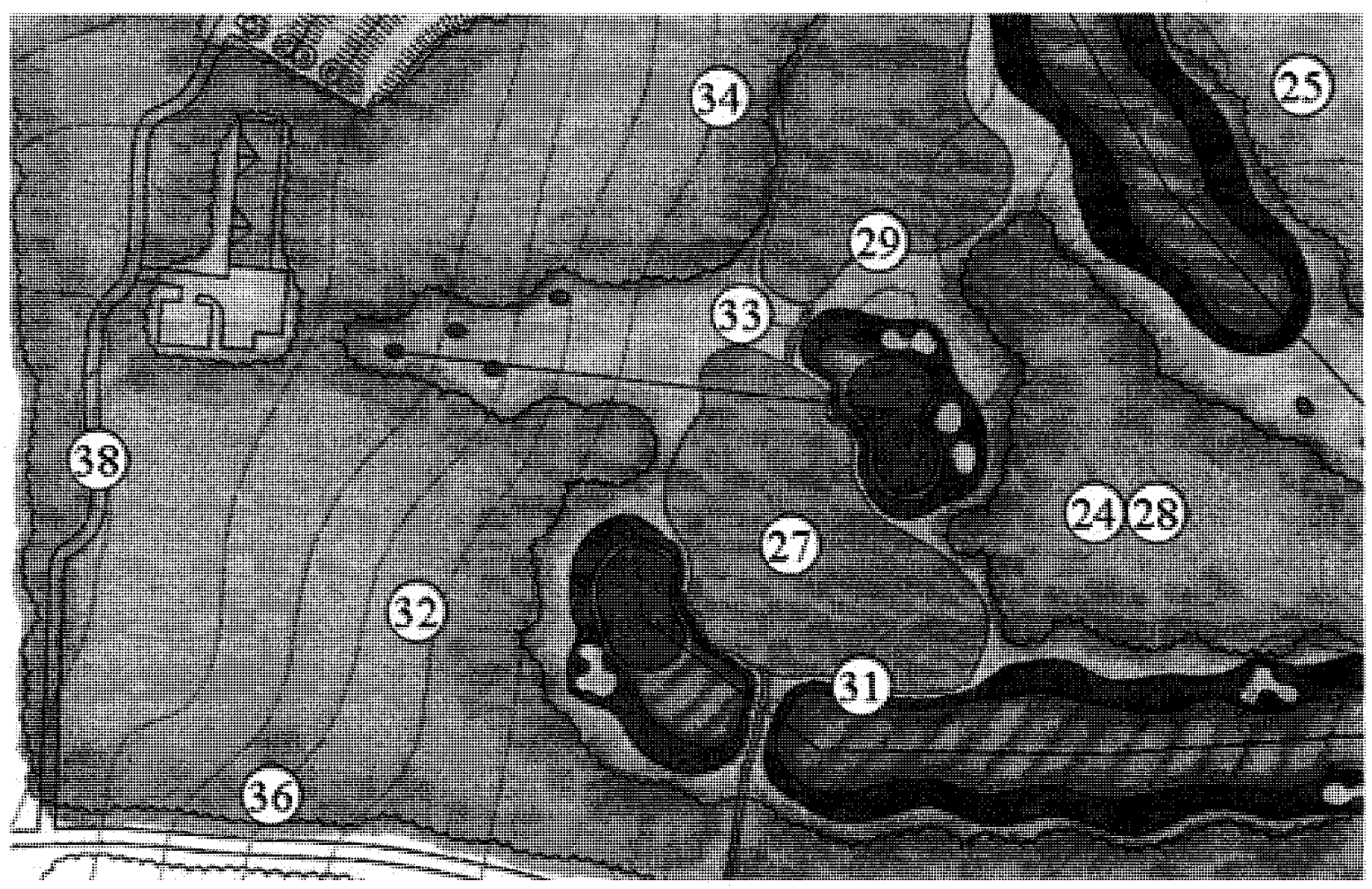

Figure 5.22. Demonstration of the Applied Design Guidelines 3

Table 5.6. Demonstration of the Applied Design Guidelines 3

24. Terrestrial patches provide microhabitats consisting of coarse woody debris, an undisturbed layer of leaf litter, small mammal burrows, and boulders.

25. Terrestrial patches were designed to have horizontal and vertical structural diversity with layers of ground cover, understory, grasses, shrubs, and trees.

27. A variety of aquatic environments were provided with open and closed canopy.

28. Seasonal wetlands with varying hydroperiods were incorporated in low lying terrestrial patches in out of play areas.

29. Aquatic habitats were designed to have a littoral shelf with a slope less than 15:1. No vertical walls were used as all pond edges are planted with emergent vegetation.

31. Vegetated buffer strips surround all ponds to protect against chemical runoff.

32. Terrestrial habitat was preserved 148 - 289 metres from the edge of aquatic environments.

33. Aquatic environments were arranged 200-500 metres apart.

34. Closed canopy forest was provided on a portion of every pond.

36. Habitats were connected to the surrounding landscape.

38. Entrance to the site and all roads were designed on the periphery of the site to lower the probability of mortality when dispersing. 


\section{Conclusion}

The concept for the Golden Beach Resort Golf Course demonstrates a landscape ecology approach to golf course design. Aquatic and terrestrial environments are common elements found on golf courses as strategic and aesthetic features. By understanding the ecology of patches, edges; and corridors as well as the habitat requirements of amphibians, golf course landscapes can be designed to support a diverse range of species and improve landscape connectivity between habitats. An understanding of the characteristics of amphibian habitat and the potential impacts they may have on the game of golf, as well as an understanding of the theories of hazards will ensure that suitable aquatic and terrestrial environments are spatially arranged within the landscape to both support amphibian populations and complement the game of golf. 


\section{Chapter Six - Evaluation and Discussion}

\section{Introduction}

This chapter presents the evaluation of the Golden Beach Resort Golf Course master plan which was developed to demonstrate an integrative approach to golf course design that supports amphibian habitat needs while maintaining playability, strategy, and aesthetics. To assess the achievement of this research goal, the master plan was evaluated from a golf course architecture, course maintenance, and amphibian ecology perspectives. Each evaluator assessed the course based on their experience and was asked to rank the achievement of design objectives using a Likert scale rating system ranging from very successful to failure. Three separate evaluations were designed to be relevant to each evaluator's experiences as they were not required to have knowledge of other professional fields in order to complete their questionnaire. This method was adopted to evaluate the design and its function as both a golf course and as amphibian habitat. A summary of the results from the evaluation is presented, followed by a discussion of the applicability of the evaluation. The evaluative responses can be found in Appendix B.

\section{Golf Course Design and Maintenance}

To evaluate the function of the design as a golf course, Michael Hurdzan and Ian McQueen assessed the course from architecture and maintenance perspectives respectively. The evaluation addressed the areas of layout, playability, strategy, aesthetics, and maintenance in order to assess the spatial arrangement of golf course elements and to determine if the design is suitable and enjoyable for a diverse range of 
golfers. The majority of responses described the design objectives as being either very successfully or successfully achieved in the proposed design. Forty-eight percent of Hurdzan's responses were very successful and forty-three percent were described as successful. McQueen ranked sixty-two percent of the design objectives as being successful and twenty-three percent were described as very successful. Neither of the evaluations described any of the design objectives as being less than moderately successful.

\section{General Layout}

This section was used to evaluate the spatial relationship between golf holes and other course elements, the orientation of starting holes, safety, circulation, length, and par of the proposed design. Orientation, safety, and the balance between the length and par of nines were all described as being very successfully achieved into the design. The length and par was good but Hurdzan suggested including a fifth set of tee boxes with a course length of 5000 yards in order to provide greater variation in lengths and to improve the playability of the resort course. The primary concern for the layout was the circulation between successive holes. Hurdzan described the road crossings between holes 1 and 2 and 5 and 6 along with the distance between holes 6 and 7 as potential disruptions to the round which may leave golfers thinking the course is separated. McQueen expressed concern for the safety of golfers traveling between the ninth and eighteenth greens to reach the first tee as well as behind the fifth green to reach the second green. Hurdzan described the layout as an interesting golf experience but the long 
rides and isolated golf holes could bother resort guests. He described the back nine as being more dramatic which would help.

\section{Playability and Strategy}

This section was used to evaluate the arrangement of hazards and natural features and their effect on the strategic and playable aspects of the course. The amount of water and streams in play was a concern as they could make the course too difficult for lessskilled players. McQueen was concerned with the amount of secondary roughs in play, especially in front of the forward tees. He felt it would be tough visually for a golfer to face a carry from every tee and suggested incorporating mowed rough all the way to the forward tees. Hurdzan thought golfers would find the course very enjoyable and suggested that wider fairways, a set of forward tees, and fewer hazards on the right side would make the course more playable. The variation in approach shot distances and pars of successive holes as well as the orientation of par-3s and $5 \mathrm{~s}$ were described as very successful. McQueen felt the lengths of the par-3s were very long as three are over 200 yards and two require long carries over water. The carries on holes 2, 7, 9, and 13 were also of concern and it was suggested that wider landing areas and safer alternate routes around the hazards be provided to make them less severe. Hurdzan acknowledged the less playable nature of the course was largely due to the natural constraints of the site.

\section{Aesthetics}

This section was used to evaluate the aesthetics of the design and the utilization of natural features and significant views of the property. Hurdzan and McQueen both 
described the aesthetics of the course as very successful. The course was routed to take advantage of both significant views as well as the natural features of the property. They both felt the design moved golfers through a range of landscapes and viewpoints and that a natural experience was provided. McQueen liked the design of the holes along the water's edge. Hurdzan felt it would be better to have a balance between the wooded areas, wetlands, lakes, and ponds on both the front and back nine but the constraints of the site restrict this.

\section{Maintenance}

This section was used to evaluate the considerations of maintenance in the design. McQueen was concerned with the amount of secondary rough incorporated in the design. The natural zones would reduce maintenance costs but they would adversely impact the playability of the course. The natural areas, especially around the greens, could cause root competition and stress on the turf. He was also concerned with the location of the maintenance shop as it is a long way from holes 3 and 4 . The total area of each golf course element was described as sufficient to prevent wear problems. The ponds were described as well situated to harvest surface water and the total areas would be enough to satisfy irrigation requirements. However, since the ponds are in play, McQueen believed they would need to be maintained at capacity for aesthetic reasons. Another source of water may be needed. 


\section{Amphibian Ecology}

To evaluate the function of the design as amphibian habitat, Dr. Raymond Semlitsch assessed the course from an ecology perspective. The evaluation addressed the areas of terrestrial and aquatic habitats as well as connectivity in order to determine if the design is suitable to support diverse amphibian populations. The majority of Semlitsch's responses described the design objectives as being achieved in the design to some level of success. Twenty-nine percent were described as very successful, thirty-eight percent were successful, and nineteen percent were moderately successful. Five percent of the responses were neutral and ten percent were moderately unsuccessful.

\section{Terrestrial Habitat}

This section was used to evaluate the provision of terrestrial habitat within the golf course. The preservation of large core areas to provide interior habitat and the integration of habitat into out-of-play areas was described as very successful. The primary concern with the design was the increased edge to area ratio and the decrease in the percentage of forested streams. Dr. Semlitsch was also concerned that the area was already fragmented so that the changes proposed in the design appear minimal and may still be worse than natural habitats. A comparison with natural areas in the region would provide a better assessment of the ecological features of the design.

\section{Aquatic Habitat}

This section was used to evaluate the provision of aquatic habitat. The preservation of existing wetland complexes, leaving forested areas adjacent to wetlands 
undisturbed, providing a mix of aquatic habitats with varying hydroperiods, and providing shallow pond edges with emergent vegetation were all described as very successfully integrated into the design. Semlitsch was concerned with wetland buffers that consist of mown turf maintained at heights of 3 inches or more. He believes the buffers need to be wider than 8 metres and should consist of natural vegetation as opposed to turf. Overall, Semlitsch felt the provision of aquatic habitats was successfully achieved in the design.

\section{Connectivity}

This section was used to evaluate the spatial arrangement of aquatic and terrestrial habitats. Semlitsch felt that most wetlands were close enough to be connected by dispersal and that the forest patches were used to enhance the connectivity. He was concerned with the road and ditches separating the aquatic environments on the western side of the site with those in the east. He suggested using road 'tunnels' to accommodate movement across the roads. Overall, Semlitsch felt the connectivity of natural features both on and off the golf course was successfully achieved.

\section{Discussion}

The proposed design for the Golden Beach Resort Golf Course was evaluated by individuals with considerable experience in their respective careers. Using their professional knowledge of golf course design, maintenance, and ecology, each assessed the course and commented on how they felt design objectives were achieved in the plan. This peer evaluation method was effective in generating suggestions and 
recommendations on the spatial arrangement of golf course features. From a design and maintenance standpoint, the primary concern with the design was the circulation between successive holes and playability. The constraints posed by the natural features and land use designations resulted in longer distances between golf holes and several forced carries which can create a more difficult course for less-skilled players. Suggestions were made to improve the playability, such as providing wider landing zones, a fifth set of tees, and the mowing of secondary roughs up to the forward tees. From an ecology perspective, concern was expressed for the increased edge to area ratio, the decreased percentage of forested streams, the potential barrier to dispersal posed by the roads and ditches, and the vegetated buffers surrounding wetlands.

Aside from these concerns, the design was described as very successful by all three evaluators. Thirty-three percent of all the evaluative responses ranked the design objectives as being very successfully achieved in the design while forty-nine percent were described as successful. Only four percent were ranked as either neutral or moderately unsuccessful. Overall, Hurdzan felt the logic and application of design criteria was without weakness and he described the design as an excellent job on a very challenging site. McQueen felt the design was good relative to the maintenance of the course. Dr. Semlitsch described the design as a great attempt to improve golf course design. He suggested the integration of habitat into golf course landscapes should be an evolving process where information from new research is utilized in the design process. The design of the Golden Beach Resort Golf Course demonstrates that the spatial arrangement of golf course features with respect to amphibian habitat requirements can 
result in a course that can support a diverse range of species while accommodating the needs of golfers. 


\section{Chapter Seven - Observations and Conclusions}

\section{Summary of Research}

The primary goal of the thesis was to explore an integrative approach to golf course design that supports amphibian habitat requirements while maintaining playability, strategy, and aesthetics. Information on the critical requirements of terrestrial and aquatic habitats was collected through the literature review to get an understanding of landscape composition and configuration characteristics necessary to support amphibian populations. This information was then combined with principles from leading golf course architects and information gathered through key informant interviews from top designers and superintendents to develop guidelines on the integration of these environments into golf course layouts. The intent of these guidelines was to provide recommendations for the design of golf courses that are capable of supporting diverse amphibian populations while providing a strategic, playable, and aesthetically pleasing experience for a range of golfers.

The synthesized conservation guidelines were applied to an 18-hole golf course designed for the Golden Beach Resort to demonstrate the spatial arrangement of quality terrestrial and aquatic habitat within a course layout that are compatible and complementary to the game of golf. The design of the course was evaluated by a golf course architect, a superintendent, and an amphibian ecologist to assess both its function as a golf course and its ecological value as amphibian habitat. The evaluators expressed concern for the circulation and playability of the proposed design. The natural features and land use designations restricted development and resulted in longer distances between golf holes and several forced carries. These hazards may increase the difficulty 
of the course and make it less playable for high handicap golfers. The decrease in playability was necessary to protect the wetlands, streams, and terrestrial patches critical to the provision of amphibian habitat. As a result, playability may need to be sacrificed in order to create environments suitable for amphibian life cycles. During the key informant interviews, Hurdzan revealed that aesthetics were more influential in the design of golf courses than either playability or strategy. Therefore, a less playable course with natural habitat features may be acceptable if it is aesthetically pleasing. In all other areas of golf course architecture and maintenance, the design was described as very successful. The layout, orientation, length, strategy, aesthetics, and maintenance considerations were all described as being well achieved in the design.

The assessment of the ecological features described the provision of terrestrial and aquatic habitats as well as the connectivity between these environments as successfully integrated into the design. Large core terrestrial patches were provided in out-of-play areas, existing wetlands were preserved, a mix of wetlands with varying hydroperiods were provided, and forested areas adjacent to wetland edges were left undisturbed. Suggestions were made to provide tunnels under roads in order to enhance connectivity between aquatic environments as well to provide more suitable wetland buffers consisting of natural vegetation. Overall, the integration of habitat into the proposed golf course was described as successful. As a result, the proposed design for the Golden Beach Resort Golf Course demonstrates an appropriate spatial arrangement of golf course elements that can function both as a golf course and amphibian habitat. 


\section{Applicability of Guidelines}

The developed guidelines are a synthesis of studies based on amphibian biology and ecology and describe the habitat composition and configuration critical to amphibian conservation. The descriptions of habitat characteristics are not species specific; rather, they represent terrestrial and aquatic habitat needs of amphibians in general. This allows the guidelines to be applied to a range of golf courses in varying temperate landscapes. The guidelines can be used to integrate amphibian habitat into private, public, resort, or tournament courses as long as the playability, strategic, and aesthetic requirements of the course types are respected. Furthermore, the guidelines can be applied to courses in rural, suburban, and urban landscapes as they relate to the composition and configuration of patches, corridors, and edges within course layouts.

The design guidelines are also applicable to renovations of existing golf courses. The guidelines provide recommendations on the composition and configuration of critical habitat requirements and can be applied to any golf course development. The guidelines provide opportunities for golf course architects to spatially arrange landscape elements such as patches, edges, and corridors which complement the game of golf while providing valuable amphibian habitat. In renovations, habitat may need to be created during the remodeling of golf course features which will require more time to allow aquatic and terrestrial environments to develop into suitable habitats.

Terrestrial and aquatic environments are commonly found in golf course layouts as strategic, aesthetic, or functional features. An understanding of the microclimates and microhabitats in terrestrial and aquatic environments is critical to amphibian conservation. The spatial arrangement of these habitats based on physiological 
characteristics coupled with an understanding of golf course design and theories of hazard placement will ensure the successful integration of habitat into course layouts that can support diverse populations and complement the game of golf.

\section{Limitations of the Study}

Due to limited resources of the researcher, the number of key informants was limited to three golf course architects and three superintendents. A larger sample size would have provided a more representative perspective of golf course design and maintenance. However, the intent of the key informant interviews was to confirm the information collected through the literature review and to provide a current perspective of design and maintenance influences from top architects and superintendents practicing in southern Ontario.

Another limitation was the general nature of the developed design guidelines. While the guidelines are applicable to a wide variety of golf courses and landscapes, more detailed habitat requirements may be needed for conservation efforts of specific amphibian species. Certain amphibians have unique habitat requirements and therefore habitat composition and configuration characteristics may need to be adjusted if the species is of special concern for conservation. Furthermore, the design guidelines may not be applicable in all landscapes and regions. The majority of studies on amphibian ecology researched were of species in temperate regions in Canada, and the northern United States. The guidelines may not be as applicable in arid or tropical regions where amphibian species have adapted to these different environments. The intention of the developed guidelines was to provide general guidelines that could be used to improve the 
quality and spatial arrangement of habitat within golf course landscapes in order to support diverse amphibian populations.

Another constraint to the research is the limited information on amphibian dispersal across maintained turfgrass and the affect of golf course maintenance practices on this process. Studies demonstrated that salamanders would cross fairways up to 80 metres wide, cart paths up to 2 metres in width and that green frogs preferred to travel on short grass but there is insufficient research on the affects of chemical applications to turf and regular cutting. Fertilizers, pesticides, and cutting may negatively affect dispersal through exposure to chemicals and cause mortality due to maintenance equipment. These studies would improve conservation efforts and would strengthen the developed design guidelines.

The evaluation of the design guidelines was limited to a two dimensional representation of the 18-hole golf course. Therefore, the evaluation of the function of the course both in terms of strategy, playability, aesthetics, and its ecological value as amphibian habitat may be limited. The course's true ecological value can only be assessed through amphibian monitoring after the construction of the course. The intent of the design was to show the spatial arrangement of critical habitat components within a course layout that are suitable for a diverse range of amphibian species. The success of the design is also dependent on management practices that are compatible to amphibian population persistence. Best management practices focused on the preservation of the critical microclimates, microhabitats, and other habitat characteristics are needed to ensure the golf course continues to provide suitable habitat. 


\section{Future Research}

As stated earlier, a limitation to the study was the insufficient research on golf course maintenance practices and their affect on amphibian dispersal. Crossing turf that has had pesticides applied to it may be hazardous to amphibians. Understanding the tolerances of pesticides amphibians come into contact with on the surface of turf could improve maintenance practices. Furthermore, regular mowing of fairways, greens, tees, and roughs may have adverse affects on amphibian populations similar to that caused by vehicular traffic on roads. Studies on the effects of chemical applications and regular mowing of turf on dispersal may lead to suggestions on optimal timing of maintenance practices which are more suitable to movements across golf course features. This research could improve conservation efforts by enhancing the connectivity of golf course landscapes.

More research is needed on the role of golf courses in regional green space or park systems. Research on the planning and zoning for golf courses may result in more suitable locations based on the ecological integrity of regional landscapes. This can improve the role golf courses can play in connecting and preserving key natural heritage features. Research that provides guidelines for the regional planning of golf courses could greatly improve the ecological function of regions and enhance the connections with other existing green spaces and conservation areas.

To truly evaluate the design guidelines and the integration of amphibian habitat into golf course landscapes, golf course features need to be constructed and assessed from a golfer's and maintenance perspective. The physical characteristics of amphibian habitat can be researched in order to assess the effectiveness of the design guidelines in the 
provision of quality habitat into areas that are complementary to the game of golf. The impact on the game of golf can be assessed by surveying players and maintenance staff to ensure the provision of habitat does not adversely affect the playability, strategy, or aesthetics of the course. This evaluation would be more comprehensive than an assessment of a two dimensional representation of the proposed design. 


\section{References}

Babbie, E. (1998). The Practice of Social Research (Eighth ed.). Belmont: Wadsworth Publishing Company.

Bailey, C. A. (2007). A Guide to Qualitative Field Research (2nd ed.). Thousand Oaks: Pine Forge Press.

Baldwin, R. F., Calhoun, A. J. K., \& deMaynadier, P. G. (2006). Conservation Planning for Amphibian Species with Complex Habitat Requirements: A Case Study Using Movements and Habitat Selection of the Wood Frog Rana sylvatica. Journal of Herpetology, 40(4), 442-453.

Barclay, J. A. (2000). The Toronto Terror. Chelsea: Sleeping Bear Press.

Beebee, T. J. C., \& Griffiths, R. A. (2005). The amphibian decline crisis: A Watershed for conservation biology? Biological Conservation, 125, 271-285.

Birchfield, G. L., \& Deters, J. E. (2005). Movement Paths of Displaced Northern Green Frogs (Rana clamitans melanota). Southeastern Naturalist, 4(1), 63-76.

Blaustein, A. R., \& Kiesecker, J. M. (2002). Complexity in conservation: lessons from the global decline of amphibian populations. Ecology Letters, 5, 597-608.

Blaustein, A. R., Kiesecker, J. M., Chivers, D. P., Hokit, D. G., Marco, A., Belden, L. K., et al. (1998). Effects of Ultraviolet Radiation on Amphibians: Field Experiments. American Zoologist, 38, 799-812.

Blaustein, A. R., \& Wake, D. B. (1995). The Puzzle of Declining Amphibian Populations. Scientific American, April, 52-57

Blaustein, A. R., Wake, D. B., \& Sousa, W. P. (1994). Amphibian Declines: Judging Stability, Persistence, and Susceptibility of Populations to Local and Global Extinctions. Conservation Biology, 8(1), 60-71.

Boone, M. D., Semlitsch, R. D., \& Mosby, C. (2008). Suitability of Golf Course Ponds for Amphibian Metamorphosis When Bullfrogs Are Removed. Conservation Biology, 22(1), 172-179.

Carey, C., Cohen, N., \& Rollins-Smith, L. (1999). Amphibian declines: an immunological perspective. Developmental and Comparative Immunology, 23, 45-472. 
Carlson, D. W., \& Groot, A. (1997). Microclimate of clear-cut, forest interior, and small openings in trembling aspen forest. Agricultural and Forest Meteorology, 87, 313-329.

Chen, J., Franklin, J. F., \& Spies, T. A. (1993). Contrasting microclimates among clearcut, edge, and interior of old-growth Douglas-fir forest. Agricultural and Forest Meteorology, 63, 219-237.

Collins, J. P., \& Storfer, A. (2003). Global amphibian declines: sorting the hypotheses. Diversity and Distributions, 9, 89-98.

Crawford, J. A., \& Semlitsch, R. D. (2007). Estimation of Core Terrestrial Habitat for Stream-Breeding Salamanders and Delineation of Riparian Buffers for Protection of Biodiversity. Conservation Biology, 21(1), 152-158.

Creswell, J. W. (1994). Research Design: Qualitative \& Quantitative Approaches. Thousand Oaks: Sage Publications, Inc.

Cushman, S. A. (2006). Effects of habitat loss and fragmentation on amphibians: A review and prospectus. Biological Conservation, 128, 231-240.

Davis, N. M., \& Lydy, M. J. (2002). Evaluating Best Management Practices at an Urban Golf Course. Environmental Toxicology and Chemistry, 21(5), 1076-1084.

deMaynadier, P. G., \& Hunter Jr., M. L. (1998). Effects of Silvicultural Edges on the Distribution and Abundance of Amphibians in Maine. Conservation Biology, 12(2), 340-352.

Dillman, D. A. (2000). Mail and Internet Surveys: The Tailored Design Method (Second ed.). New York: John Wiley \& Sons, Inc.

Doak, T. (1992). The Anatomy of a Golf Course. Short Hills: Burford Books.

Dodson, R. G. (2000). Managing Wildlife Habitat on Golf Courses. Chelsea: Ann Arbor Press.

Dodson, R. G. (2005). Sustainable Golf Courses: A Guide to Environmental Stewardship. Hoboken: John Wiley \& Sons, Inc.

Doubledee, R. A., Muller, E. B., \& Nisbet, R. M. (2003). Bullfrogs, disturbance regimes, and the persistence of California red-legged frogs. Journal of Wildlife Management, 67, 424-438.

Dramstad, W. E., Olson, J. D., \& Forman, R. T. T. (1996). Landscape Ecology Principles in Landscape Architecture and Land-use Planning. Washington: Island Press. 
Duellman, W. E., \& Trueb, L. (1986). Biology of Amphibians. New York: McGraw-Hill.

Dupuis, L. A., Smith, J. N., \& Bunnell, F. (1995). Relation of Terrestrial-Breeding Amphibian Abundance to Tree-Stand Age. Conservation Biology, 9(3), 645-653.

Eigenbrod, F., Hecnar, S. J., \& Fahrig, L. (2008). The relative effects of road traffic and forest cover on anuran populations. Biological Conservation, 141, 35-46.

Faccio, S. D. (2003). Postbreeding Emigration and Habitat Use by Jefferson and Spotted Salamanders in Vermont. Journal of Herpetology, 37(3), 479-489.

Fahrig, L., Pedlar, J. H., Pope, S. E., Taylor, P. D., \& Wegner, J. F. (1995). Effect of Road Traffic on Amphibian Density. Biological Conservation, 73, 177-182.

Fazio, T., \& Brown, C. (2000). Golf Course Designs. New York: Harry N. Abrams, Inc.

Forman, R. T. T. (1995a). Land Mosaics: The Ecology of Landscapes and Regions. Cambridge: Cambridge University Press.

Forman, R. T. T. (1995b). Some general principles of landscape and regional ecology. Landscape Ecology, 10(3), 133-142.

Forman, R. T. T., \& Godron, M. (1986). Landscape Ecology. New York: John Wiley \& Sons.

Gamble, L. R., Kevin, M., \& Compton, B. W. (2007). Fidelity and dispersal in the pondbreeding amphibian, Ambystoma opacum: Implication for spatio-temporal populations dynamics and conservation. Biological Conservation, 139, 247-257.

Gardner, T. A., Barlow, J., \& Peres, C. A. (2007). Paradox, presumption and pitfalls in conservation biology: The importance of habitat change for amphibians and reptiles. Biological Conservation, 138, 166-179.

Gibbons, J. W., Winne, C. T., Scott, D. E., Willson, J. D., Glaudas, X., Andrews, K. M., et al. (2006). Remarkable Amphibian Biomass and Abundance in an Isolated Wetland: Implications for Wetland Conservation. Conservation Biology, 20(5), 1457-1465.

Gilchrist, T. D. (1983). Trees on Golf Courses. London: Arboricultural Association.

Graves, R. M., \& Cornish, G. S. (1998). Golf Course Design. New York: John Wiley \& Sons, Inc.

Guerry, A. D., \& Hunter Jr., M. L. (2002). Amphibian Distributions in a Landscape of Forests and Agriculture: an Examination of Landscape Composition and Configuration. Conservation Biology, 16(3), 745-754. 
Hakim, C. (1987). Research Design: Strategies and Choices in the Design of Social Research. London: Allen \& Unwin Ltd.

Halliday, T. R. (2008). Why amphibians are important. International Zoo Yearbook, 42, $7-14$

Harding, J. H. (1997). Amphibians and Reptiles of the Great Lakes Region. Ann Arbor: The University of Michigan Press.

Hecnar, S. J., \& M'Closkey, R. T. (1996). Regional Dynamics and the Status of Amphibians. Ecology, 77(7), 2091-2097.

Hodgkison, S., Hero, J.-M., \& Warnken, J. (2007). The efficacy of small-scale conservation efforts, as assessed on Australian golf courses. Biological Conservation, 136, 576-586.

Hofrichter, R. (2000). The Encyclopedia of Amphibians. Toronto: Key Porter Books Limited.

Hurdzan, M. J. (2004). Golf Greens: History, Design, and Construction. Hoboken: John Wiley \& Sons.

Hurdzan, M. J. (2006). Golf Course Architecture: Evolutions in Design, Construction, and Restoration Technology (Second Edition ed.). Hoboken: John Wiley \& Sons, Inc.

IUCN. (2007). 2007 IUCN Red List of Threatened Species. Retrieved January 20, 2008, from www.iucnredlist.org.

Kats, L. B., \& Ferrer, R. P. (2003). Alien predators and amphibian declines: review of two decades of science and the transition to conservation. Diversity and Distributions, 9, 99-110.

Knutson, M. G., Sauer, J. R., Olsen, D. A., Mossman, M. J., Hemesath, L. M., \& Lannoo, M. J. (1999). Effects of Landscape Composition and Wetland Fragmentation on Frog and Toad Abundance and Species Richness in Iowa and Wisconsin, U.S.A. Conservation Biology, 13(6), 1437-1446.

Kolozsvary, M. B., \& Swihart, R. K. (1999). Habitat fragmentation and the distribution of amphibians: patch and landscape correlates in farmland. Canadian Journal of Zoology, 77, 1288-1299.

Kvale, S. (1996). InterViews: An Introduction to Qualitative Research Interviewing. Thousand Oaks: Sage Publications. 
Laan, R., \& Verboom, B. (1990). Effects of Pool Size and Isolation on Amphibian Communities. Biological Conservation, 54, 251-262.

Libby, G., Harker, D., \& Harker, K. (2004). Managing Wetlands on Golf Courses. Hoboken: John Wiley \& Sons, Inc.

Lilly, S. (1999). Golf Course Tree Management. Chelsea: Ann Arbour Press.

Logier, E. B. S. (1952). The Frogs, Toads and Salamanders of Eastern Canada. Toronto: Clarke, Irwin \& Company Limited.

Mackenzie, D. A. (1982). Golf Architecture. Worcestershire: Grant Books Ltd.

Maret, T. J., Snyder, J. D., \& Collins, J. P. (2006). Altered drying regime controls distribution of endangered salamanders and introduced predators. Biological Conservation, 127, 129-138.

Marsh, D. M., \& Trenham, P. C. (2001). Metapopulation Dynamics and Amphibian Conservation. Conservation Biology, 15(1), 40-49.

Marshall, C., \& Rossman, G. B. (2006). Designing Qualitative Research (Fourth ed.). Thousand Oaks: Sage Publications, Inc.

McCarty, L. B. (2005). Best Golf Course Management Practices (Second ed.). Upper Saddle River: Pearson Education, Inc.

McDonough, C., \& Paton, P. W. C. (2007). Salamander Dispersal Across a Forested Landscape Fragmented by a Golf Course. The Journal of Wildlife Management, 71(4), 1163-1169.

Meyer, J. L., Strayer, D. L., Wallace, J. B., Eggert, S. L., Helfman, G. S., \& Leonard, N. E. (2007). The Contribution of Headwater Streams to Biodiversity in River Networks. Journal of the American Water Resources Association, 43(1), 86-103.

Montieth, K. E., \& Paton, P. W. C. (2006). Emigration Behaviour of Spotted Salamanders on Golf Courses in Southern Rhode Island. Journal of Herpetology, 40(2), 195-205.

Murcia, C. (1995). Edge effects in fragmented forests: implications for conservation. Trends in Ecology and Evolution, 10, 58-62.

Nicklaus, J., \& Millard, C. (2002). Nicklaus by Design. New York: Harry N. Abrams, Inc. 
Paton, P. W. C., \& Egan, R. S. (2002). Strategies to Maintain Pond-Breeding Amphibians on Golf Courses [Electronic Version]. USGA Turfgrass and Environmental Research Online, 1, 1-7. Retrieved February 19, 2008.

Pechmann, J. H. K., \& Wilbur, H. M. (1994). Putting Declining Amphibian Populations in Perspective: Natural Fluctuations and Human Impacts. Herpetologica, 50(1), 65-84.

Porej, D., \& Hetherington, T. E. (2005). Designing wetlands for amphibians: the importance of predatory fish and shallow littoral zones in structuring of amphibian communities. Wetlands Ecology and Management, 13, 445-455.

Porter, K. R. (1972). Herpetology. Philadelphia: W.B. Saunders Company.

Pough, F. H., Andrews, R. M., Cadle, J. E., Crump, M. L., Savitzky, A. H., \& Wells, K. D. (2004). Herpetology (Third ed.). Upper Saddle River: Pearson Prentice Hall.

Ranvestel, A. W., Lips, K. R., Pringle, C. M., Whiles, M. R., \& Bixby, R. J. (2004). Neotropical tadpoles influence stream benthos: evidence for the ecological consequences of decline in amphibian populations. Freshwater Biology, 49, 274285.

Richardson, F. L., \& Fine, M. K. (2006). Bunkers, Pits \& Other Hazards. Hoboken: John Wiley \& Sons, Inc.

Rittenhouse, T. A. G., \& Semlitsch, R. D. (2006). Grasslands as movement barriers for a forest-associated salamander: Migration behavior of adult and juvenile salamanders at a distinct habitat edge. Biological Conservation, 131, 14-22.

Rothermel, B. B., \& Semlitsch, R. D. (2002). An Experimental Investigation of Landscape Resistance of Forest versus Old-Field Habitats to Emigrating Juvenile Amphibians. Conservation Biology, 16(5), 1324-1332.

Scott, D. E., Metts, B. S., \& Gibbons, J. W. (2002). Seasonal Wetlands and Golf Courses [Electronic Version]. USGA Turfgrass and Environmental Research Online, 1, 17. Retrieved February 19, 2008.

Semlitsch, R. D. (1998). Biological Delineation of Terrestrial Buffer Zones for PondBreeding Salamanders. Conservation Biology, 12(5), 1113-1119.

Semlitsch, R. D. (2000). Principles for Managment of Aquatic-Breeding Amphibians. The Journal of Wildlife Management, 64(3), 615-631.

Semlitsch, R. D. (2002). Critical Elements for Biologically Based Recovery Plans of Aquatic-Breeding Amphibians. Conservation Biology, 16(3), 619-629. 
Semlitsch, R. D., \& Bodie, J. R. (1998). Are Small, Isolated Wetlands Expendable. Conservation Biology, 12(5), 1129-1133.

Semlitsch, R. D., \& Bodie, J. R. (2003). Biological Criteria for Buffer Zones around Wetlands and Riparian Habitats for Amphibians and Reptiles. Conservation Biology, 17(5), 1219-1228.

Semlitsch, R. D., Boone, M. D., \& Bodie, J. R. (2007). Golf Courses Could Bolster Amphibian Communities [Electronic Version]. USGA Turfgrass and Environmental Research Online, 6, 1-16. Retrieved April 2, 2008.

Shackelford, G. (2003). Grounds for Golf: The History and Fundamentals of Golf Course Design. New York: St. Martin's Press.

Sinsch, U. (1990). Migration and orientation in anuran amphibians Ethology Ecology \& Evolution, 2, 65-79.

Snodgrass, J. W., Komoroski, M. J., Bryan Jr., A. L., \& Burger, J. (2000). Relationship among Isolated Wetland Size, Hydroperiod, and Amphibian Species Richness: Implications for Wetland Regulations. Conservation Biology, 14(2), 414-419.

Thomas, J., George C. (1927). Golf Course Architecture in America: Its Strategy and Construction. Los Angeles: The Times-Mirror Press.

Timm, B. C., McGarigal, K., \& Compton, B. W. (2007). Timing of large movement events of pond-breeding amphibians in Western Massachusetts, USA. Biological Conservation, 136, 442-454.

Vallan, D. (2000). Influence of forest fragmentation on amphibian diversity in the nature reserve of Ambohitantely, highland Madagascar. Biological Conservation, 96, 3143.

Vasconocelos, D., \& Calhoun, A. J. K. (2004). Movement Patterns of Adult and Juvenile Rana sylvatica (LeConte) and Ambystoma maculatum (Shaw) in Three Restored Seasonal Pools in Maine. Journal of Herpetology, 38(4), 551-561.

Wake, D. B. (1991). Declining Amphibian Populations. Science, 253(5022), 860.

Welsh Jr., H. H. (1990). Relictual Amphibians and Old-Growth Forests. Conservation Biology, 4(3), 309-319.

Wengraf, T. (2001). Qualitative Research Interviewing: Biographic Narrative and SemiStructured Methods. London: Sage Publications, Inc. 
Weyrauch, S. L., \& Grubb Jr., T. C. (2004). Patch and landscape characteristics associated with the distribution of woodland amphibians in an agricultural fragmented landscape: an information-theoretic approach. Biological Conservation, 115, 443-450.

White, B. (2000). Turf Managers' Handbook for Golf Course Construction, Renovation, and Grow-In. Chelsea: Sleeping Bear Press.

Willson, J. D., \& Dorcas, M. E. (2003). Effects of Habitat Disturbance on Stream Salamanders: Implications for Buffer Zones and Watershed Management. Conservation Biology, 17(3), 763-771.

Wyman, R. L. (1990). What's Happening to the Amphibians. Conservation Biology, 4(4), 350-352. 


\section{Appendix A - Key Informant Interview Questions}

\section{Golf Course Architects}

Introduction

My research is focused on the spatial arrangement of specific elements within the golf course landscape. I'm most interested in exploring the factors which influence decisions regarding their placement. The goal is to develop guidelines which will improve the relationship between elements within the course layout as well as with existing features in the surrounding landscape.

\section{Design Process Questions}

The first set of questions addresses the overall design process and seeks to explore what influences the design of golf courses.

1. Are the principles listed influential in your designs? Would you add or remove any from the list? Can you please rank them from most influential to least.

a. Briefly, how do these principles change for the typical course classifications of public, private, resort, or tournament?

b. What influences the rankings of these design principles?

2. What physical characteristics make a site suitable for a golf course?

3. How much influence does the client have on your designs?

a. What is their primary wish when developing a course?

4. When renovating an existing course, what are the motivations for and the goals of the redesign?

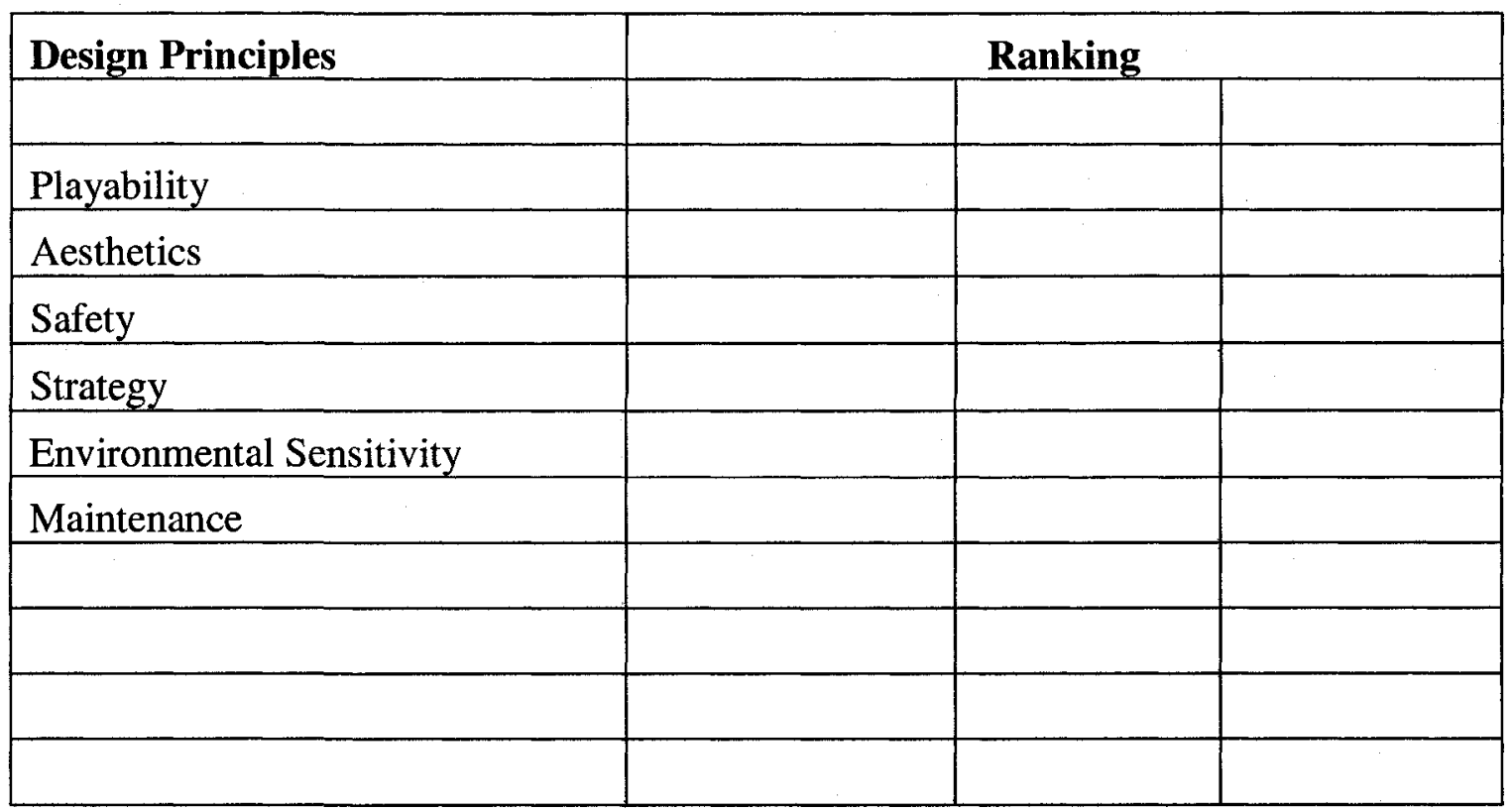


Surrounding Landscapes

The second set of questions deals with the influence of surrounding landscapes and land uses on the design.

1. How does the landscape surrounding the project site influence the design of golf courses?

2. What characteristics or elements of surrounding landscapes and land uses do you identify during a site analysis?

3. How far beyond the property line do you typically analyze the surrounding landscape?

4. To what degree can golf courses be integrated into regional greenway or open space systems?

Water Hazards and Terrestrial Uplands

This sequence explores the design of specific elements within the golf course landscape.

1. How does the function of a water hazard influence its placement within the course layout?

a. Briefly, how do the design principles discussed earlier influence their placement?

b. Is the location of a water hazard influenced by the proximity to other water hazards or to forested areas?

2. How does the existing vegetation influence the routing of the course?

a. Are large core areas of forest protected?

b. Are corridors created to connect forest and aquatic patches?

3. Visual Question: Which areas within the course layout offer the best opportunity for terrestrial areas which can be left natural with minimal maintenance?

a. What areas are least suitable for natural forested areas?

4. What influences the size and width of terrestrial areas between fairways?

a. Are there general guidelines which you follow?

5. How do wetlands influence your design?

a. Are they protected or conserved in their natural condition or are they altered to better suit the game of golf?

6. Are there opportunities to incorporate seasonal or temporary wetlands into layouts?

7. What influences the size of water hazards? 
8. Visual Question: Which of the two designs to you prefer and briefly explain why?

a. How does forest canopy around a portion of a water hazard change its function?

9. When designing the banks of water hazards, do you have a preference between vertical walls and sloping walls? What about between maintained or non maintained banks?

10. Visual Question: Which areas of a water hazard offer the best opportunity for natural vegetated banks which are minimally maintained?

Wildlife Questions

The last set of questions deals specifically with wildlife and golf course design.

1. What role can golf course architects play in wildlife habitat conservation?

2. Are wildlife requirements considered during the design process?

a. How does wildlife habitat influence designs?

b. Do you identify existing wildlife and conserve habitat?

3. What obstacles are there to incorporating wildlife habitat into golf course designs?

4. What is needed to improve wildlife habitat on golf courses?

5. What are the benefits to including wildlife habitat on golf courses?

6. What resources are there available to architects to aid in wildlife design?

a. What would be an effective resource for designers?

b. Would you consider incorporating amphibian habitat into golf course designs if there were resources available to assist you?

In closing, do you have any final recommendations about wildlife habitat and golf courses which could assist my research? 


\section{Golf Course Superintendents}

Introduction

My research is focused on the spatial arrangement of specific elements within the golf course landscape. I'm most interested in exploring the factors which influence decisions regarding the maintenance of these elements. The goal is to develop guidelines which will improve the relationship between elements within the course layout as well as with existing features in the surrounding landscape.

Background

1. How many years have you worked as a Superintendent?

2. What training have you received?

Overall Course Maintenance

The first set of questions addresses the Golf Course Maintenance in general and seeks to explore what influences how the course is maintained.

1. Are the principles listed influential in golf course maintenance? Would you add or remove any to the list? Can you please rank them from most influential to least?

2. How do these principles change for the typical course classifications of public, private, private, resort, or tournament?

3. What influences the rankings of these principles?

4. What are your biggest concerns as a superintendent in terms of maintenance?

\begin{tabular}{|l|l|l|l|}
\hline Course Maintenance Principles & \multicolumn{3}{|c|}{ Ranking } \\
\hline Playability & & & \\
\hline Aesthetics & & & \\
\hline Safety & & & \\
\hline Strategy & & & \\
\hline Environmental Sensitivity & & & \\
\hline Budget & & & \\
\hline Efficiency (Human Resources) & & & \\
\hline & & & \\
\hline & & & \\
\hline
\end{tabular}


Surrounding Landscape

The second set of questions deals with the influence of surrounding landscapes and land uses on course maintenance.

1. How does the surrounding landscape and land uses influence how you maintain the golf course?

2. What characteristics or elements of the surrounding landscape do you consider or address?

3. To what degree can golf courses be incorporated into regional green or park systems?

4. What can be done within the golf course property to improve and conserve regional biophysical processes?

Water Hazards and Terrestrial Uplands

This sequence explores the maintenance of specific elements within the golf course landscape.

1. Visual Question: Which areas within the course layout offer the best opportunity for terrestrial areas which can be left natural with minimal maintenance?

a. What areas are least suitable for natural forested areas?

2. Are certain holes better than others for providing natural areas?

3. Are large core areas of forest left not maintained?

a. Are corridors left not maintained to connect patches?

4. How far off the fairways edge do you maintain rough areas? Is there are standard distance used in order to maintain play?

5. How far from teeing areas do you start to maintain forested areas along the edge of the fairway?

6. Why is the understory of forested areas typically cleared?

7. How would more natural areas impact the course of play? How would they impact the maintenance of the course?

8. How do you determine which areas are suitable as out-of-play areas?

9. Do you have a preference between vertical walls and sloping walls on water hazards? What about between maintained or non maintained banks?

a. How would leaving the banks of water hazards more natural impact the course of play? 
10. Visual Question: Which areas of a water hazard offer the best opportunity for natural vegetated banks which are minimally maintained?

\section{Wildlife Questions}

The last set of questions deals specifically with wildlife and golf course maintenance.

1. What role can golf course superintendents play in wildlife conservation?

2. How does wildlife habitat influence golf course maintenance?

3. What are the benefits to including wildlife habitat on golf courses?

4. What do you think is needed to improve wildlife habitat on golf courses?

5. What obstacles are there to incorporating wildlife habitat on golf courses? 


\section{Visual Questions}

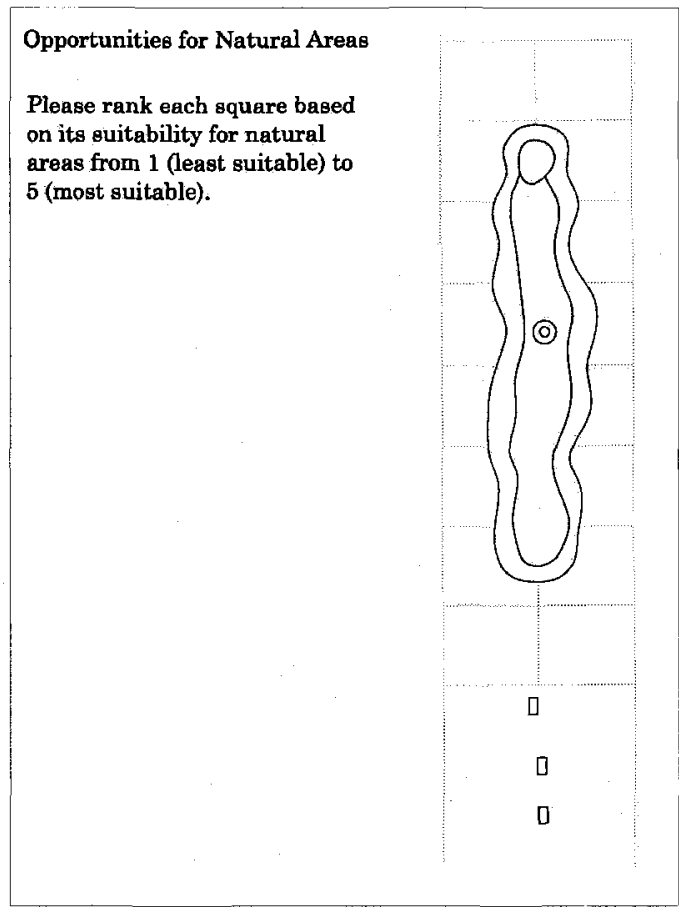

Opportunities for Natural Areas in Aquatic Environments

Please rank each square based on its suitability for out-of-play natural areas from 1 (least suitable) to 5 (most suitable).
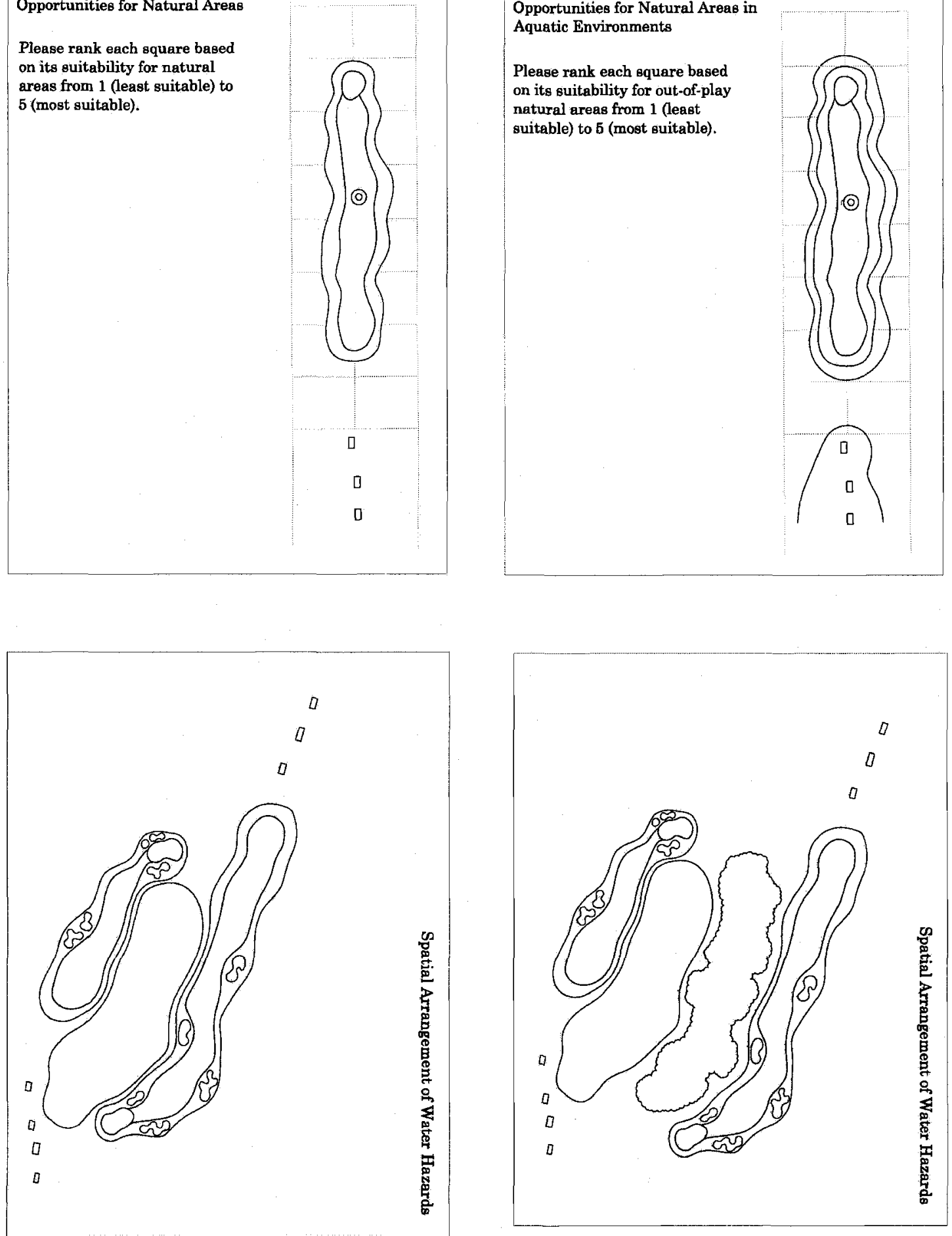


\title{
Appendix B - Evaluative Responses
}

\section{Cover Page}

\section{INTEGRATING AMPHIBIAN HABITAT INTO GOLF COURSE LANDSCAPES}

\author{
DESIGN EVALUATION
}

The following evaluation was constructed to assess the design portion of my thesis. An 18 hole golf course was designed near Rice Lake, Ontario to demonstrate the application of landscape ecology principles and the provision of aquatic and terrestrial environments in golf course landscapes. The applicability of the design will be evaluated from a golf course architecture, maintenance, and ecology perspective to assess its function both as a golf course and as amphibian habitat.

I appreciate you taking the time to complete this evaluation. Your knowledge and experience in your field is invaluable to my research and education in golf course design and landscape ecology. Your assessment of my design will play an inportant role in me achieving the goals and objectives of my thesis.

Instructions:

1. Open the pdf questionnaire in Adobe Reader 7 or later or in Adobe Acrobat.

2. The pdf is form fillable so please place a check in the applicable box for each question and provide comments in the text boxes following each section.

3. To insert comments into the text boxes, click once and wait for a cursor to appear.

4. Use the background information to assist with your answers.

5. Upon completion, save the file to a location of your choosing.

6. Attach the file to an email and return it to me at daniel@uoguelnh.ca

7. Please ignore the submit button located in the top right corner of the first page.

If you prefer, you can print the form and complete it by hand using a pen and then fax it to me at 519-767-1686 with my name as the subject.

Thank-you,

Daniel Jackson 


\section{Dr. Michael Hurdzan}

The following questionnaire is designed to evaluate the proposed master plan for the Golden Beach Resort Golf Course. A set of design principles related to the integration of amphibian habitat into golf course Jandscapes was developed and applied to the resort property to demonstrate the provision of terrestrial and aquatic environments with respect to golf course features. Using your knowledge and experience in golf course architecture, please assess the design and its function as a golf course.

The following list represents the primary ecological design objectives for the proposed master plan. Using the following rating scale, Very Successful(VS), Successful(S), Moderately Successful(MS), Neutral(N), Moderately Unsuccessful(MU), Unsuccessful(U), and Failure (F), please select the one whicli best describes the extent of which you think each design objective is achieved in the proposed plan.

General Layout

1. Locate the clubhouse in close proximity to holes $1,9,10$, and 18 as well as with practice facilities.

2. Orientate the first three holes and three finishing holes with respect to the morning and setting sun respectively.

3. Provide appropriate starting holes to maintain speed of play and the loading of the course

4. Provide adequate space between holes to create a safe playing environment.

5. Maintain circulation between successive holes with appropriate distances between greens and the next tee.

6. Provide an appropriate length/par for a resort course accommodating a range of golfing abilities.

7. Achicve a balance between the length and par between nines.

8. Overall, how would you rate the layout of the golf course?

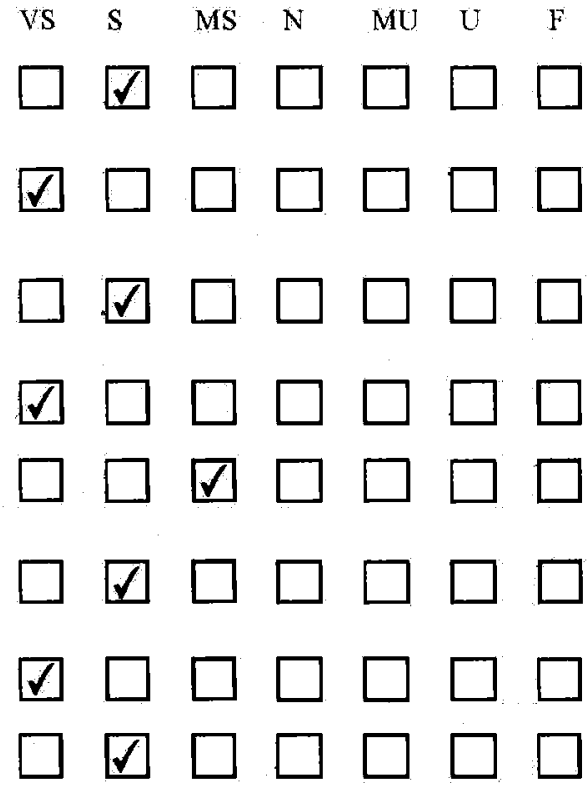

Comments about General Layout

Evaluation Point (EP) \#1. Given the clubhouse location at the top of the hill you did as well as can be expected for proximity issues. If you could have shortened \#10 to a par 4 and moved the tees down the hill, perhaps you could move the range tee back, closer to the clubhouse and \#1 tee, as well as make it larger to handle resort outings. Par 70 on a resort course is not a problem and you may be able to pick up a par 5 elsewhere.

EP \#2. You did a good job with orientation of holes.

EP \#3. The water on the left of \#1 could be a problem for speed of play, especially from a high tee elevation. 1 know you were restricted by the road width. You may want to widen that first landing area and make it extra wide. Hole \#10 looks OK.

EP \#4. Great job with safety.

EP \#5. Given the site problems you did pretty well, but it could be better. The travel from \#1 green to \#2 tee and across the road would start to disturb golfers, so I would try to switch \#5 and \#2 holes to reduce the distance going from \#6 to \#7 and \#8 to \#9 will leave people thinking the course is too separated. Not much you can do except put in a half way house to entertain them.

EP \#6. Personally I would rather see $7000,6600,6200,5500$ and 5000 yards total yardage.

EP \#7. Good job.

EP \#8. I think it could be an interesting golf experience but the long rides and isolated golf holes like \#6 would bother resort guests. The back nine will be more dramatic than the front and that is OK. 
Playability and Strategy

1. Provide adequate widths of fairways and roughs to accommodate play from golfers with a range of skills.

2. Minimize forced carries. When unavoidable, incorporate carries from tees

3. Provide alternate routes around hazards to accommodate a diverse array of golfers.

4. Place hazards to challenge seratch golfers.

5. Locate aquatic and terrestrial habitats in areas which will not adversely affect the game of golf.

6. Vary approach shot distances so golfers use every club in their bag.

7. Provide variation in the pars of successive holes.

8. Create diversity in the orientation of par $3 \mathrm{~s}$ and 5 s.

9. Overall, how would you rate the playability and strategy of the course?

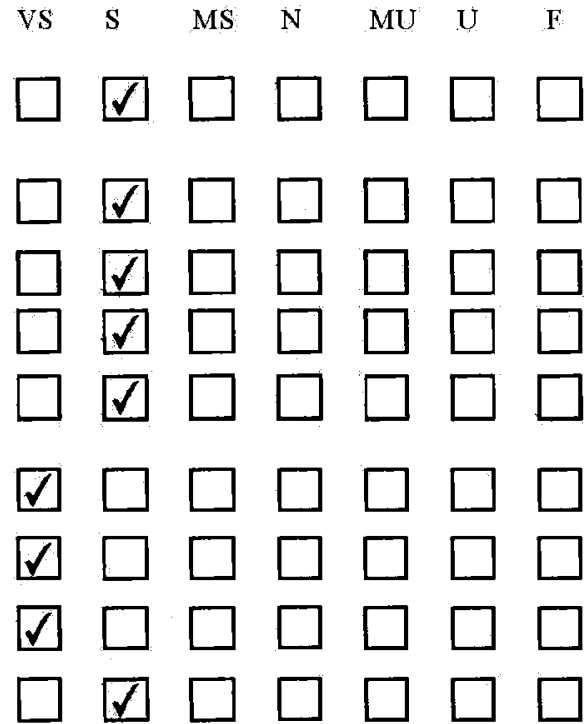

Comments about Playability and Strategy

EP \#1. Most areas look adequate but I would just be extra wide on holes \#1, \#2 by the green, \#7 by the green and second shot on \#9 and \#18.

EP \#2. Hole \#2 looks great onpaper but might be too hard for resort players, especially when it doesn't look like it has to be a forced carry. Hole \#13 is pretty nasty, too, without much fairway. The streams on $\# 7$ and \#9 might be the biggest problem of forced carries.

EP \#3. You have done as well as possible given the constraints of the site

EP \#4. On the back nine there may be too many short, right side hazards for average resort golfers. Just be sensitive to that area.

EP \#5. Without question, water and streams would impact play on lots of holes, but that is the nature of the site and there isn't much you can do about it.

EP \#6. Great job.

EP \#7. Excellent only one place you had 3-par $4 \mathrm{~s}$ in a row and you varied the approach distance to make them play differently.

EP \#8. You did as well as possible with this site.

EP \#9. I think golfers would find it very enjoyable with the few modifications that I suggest to make it easier for poorer players, i.e., forward tees, wider fainways, fewer shots, right hazards, etc.

Aesthetics

1. Route the course to take advantage of significant views.

2. Route the course to take advantage of the natural features of the property.

3. Move golfers through a range of landscapes.

4. Provide a uatural experience for golfers.

5. Overall, how would you rate the aesthetics of the course?

$\begin{array}{lllllll}\text { VS } & \text { S } & \text { MS } & \text { N } & \text { MU } & \text { U } & \text { F } \\ \square & \square & \square & \square & \square & \square & \square \\ \square & \square & \square & \square & \square & \square & \square \\ \square & \square & \square & \square & \square & \square & \square \\ \square & \square & \square & \square & \square & \square & \square \\ \square & \square & \square & \square & \square & \square & \square\end{array}$


Comments about Aesthetics

EP \#1. From what I can determine you did as well as possible. The only hole that could be a problem is hole \#6 unless there are features there that I cannot see.

EP \#2. Excellent job in fitting in the golf holes.

EP \#3. You definately accomplish this objective.

EP \#4. Actually you would have to work a bit not to make it too natural and scary for some people.

EP \#5. Clearly the front nine is in the woods and wetlands while the back nine is lakes and ponds.

Perhaps you might have tried to balance these a bit more between the nines, but that doesn't look

like it would be too easy given the site restraints.

Overall comments about the design.

Overall, I think you did an excellent job on a very challenging site that would require significant study and intelligent compromises to maximize the golf potential of the property. I would like to have tried a couple of routings from the new clubhouse location at the old marina and kept that choice of location. My reasoning is that filling in the marina will require lots of fill material and permits that may be problematic and there is an attraction about taking your boat to the golf course for resort people.

Obviously you have spent a good deal of time looking at routing options and there are lots of reasons for favoring or discarding them that I am unaware of. Your logic and application of design criteria are without weakness, and you should be proud of this effort. Good job.

Sincerely,

Michael J. Hurdzan, Ph.D. 


\section{Ian McQueen}

The following questionnaire is designed to evaluate the proposed master plan for the Golden Beach Resort Golf Course. A set of design principles related to the integration of amphibian habitat into golf course landscapes were developed and applied to the resort property to demonstrate the provision of terrestrial and aquatic environments with respect to golf course features: Using your knowledge and experienee in golf course maintenance, please assess the design and its function as a golf course.

The following list represents the primary ecological design objectives for the proposed master plan. Using the following rating scale, Very Successful(VS), Successful(S), Moderately Successful(MS). Neutral(N),

Moderately Unsuccessful(MU), Unsuccessful(U), and Failure(F), please select the one which best describes the extent of which you think each design objective is achieved in the proposed plan.

General Layout

1. Locate the clubhouse in close proximity to holes $1,9,10$, and 18 as well as with practice facilities.

2. Orientate the first three holes and three finishing holes with respect to the morning and setting sun respectively.

3. Provide appropriate starting holes to maintain speed of play and the loading of the course.

4. Provide adequate space between holes to creale a safe playing environment.

5. Maintain circulation between successive holes with appropriale distances between greens and the next tec.

6. Provide an appropriate length/par for a resort course accommodating a range of golfing abilities.

7. Achieve a balance between the length and par between nines.

8. Overall, how would you rate the layout of the golf course?

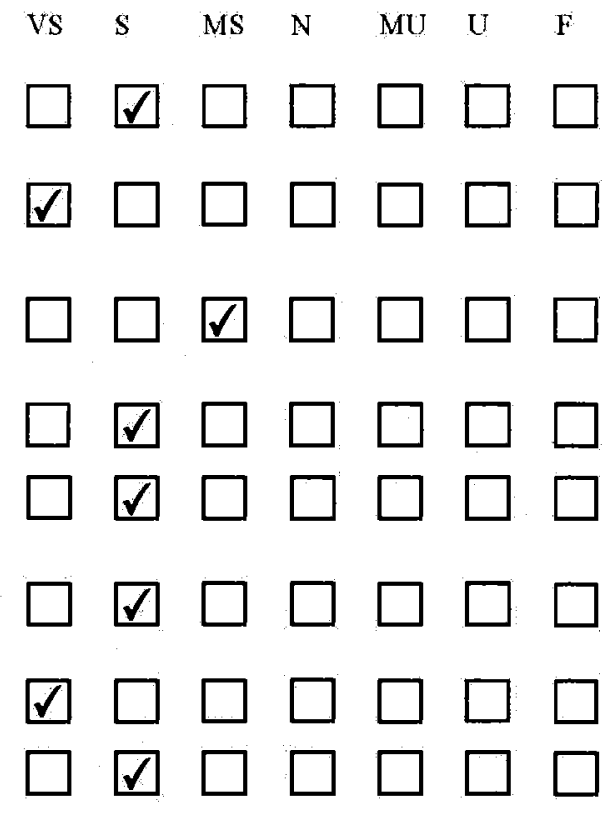

Comments about General Layout

- all golfers must travel between \#18 and \#9 green to get to the 1st tee, could cause traffic or slow
play because golfers are stopping for other golfers on there way to the 1 st tee to start there round.
Distance between the two greens could be a safety issue
- Distance between holes is great; travel distance from \#6 \& \#7 the longest but very acceptable.
- Driving by \#5 green to get to \#2 tee could be a safety issue, if possible \#2 tees should move a little
more to the east for safety reasons from \#5 green.
- Holes \#12 green, \#13 green, and \#14 tee seem close together, I would be a little concern with \#1.4
tee shot and \#12 green.
- Length of course for a resort course is good.


Playability and Strategy

1. Provide adequate widths of fairways and roughs to accommodate play from golfers with a range of skills.

2. Minimize forced carries. When unavoidable, incorporate carries from tees.

3. Provide alternate routes around hazards to accommodate a diverse artay of golfers.

4. Place hazards to challenge seratch golfers.

5. Locate aquatic and terrestrial habitats in areas which will not adversely affect the game of golf.

6. Vary approach shot distances so golfers use every club in their bag.

7. Provide variation in the pars of successive holes.

8. Create diversity in the orientation of par 3 's and $5 \%$.

9. Overall, how would you rate the playability and strategy of the course?
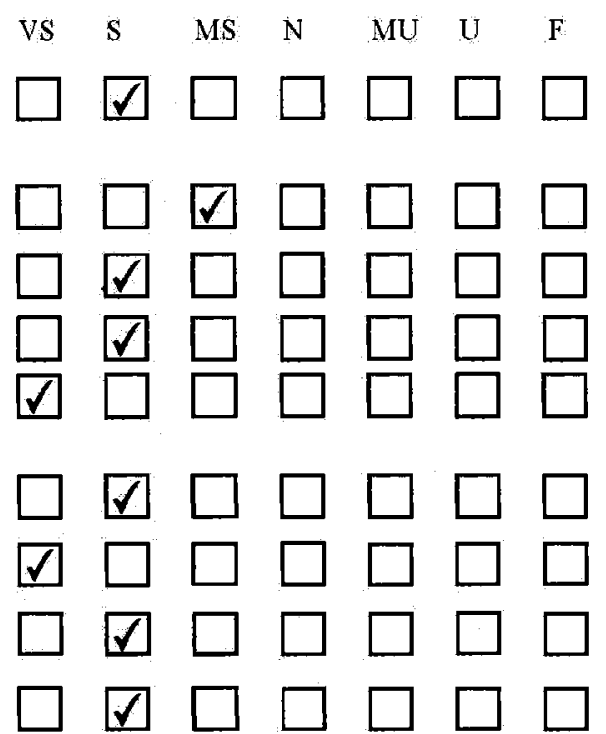

Comments about Playability and Strategy.

- From forward tees having beginners or lady golfers hit over all Secondary Rough to reach the fairway or even mowed rough is a playabilty issue. You should incorporate mowed rough all the way to the forward tees, no secondary rough between them and the hole.

- Forced carry of all water on two par 3's and the par 4 \#2 with no bailout area could be tough for forward tees, beginners and senior golfers. May want to adjust forward tees so they are not all carry. - Par 3's are very long for all golfers. With 3 out of 5 over $200 y d s$ makes most par 3's difficult, especially with 200 yd+ carries over water.

- length of Par 4's and 5's very good, total yardage is excellent.

- \#2 tough second hole with no bailout to the left of the green with fwy.

Aesthetics

1. Route the course to take advantage of significant views:

2. Route the course to take advantage of the natural features of the property.

3. Move golfers through a range of landscapes.

4. Provide a natural experience for golfers.

5. Overall, how would you rate the aesthetics of the course?

$\begin{array}{lllllll}\text { vs } & \text { S } & \text { MS } & \text { N } & \text { MU } & \text { U } & \text { F } \\ \square & \square & \square & \square & \square & \square & \square \\ \square & \square & \square & \square & \square & \square & \square \\ \square & \square & \square & \square & \square & \square & \square \\ \square & \square & \square & \square & \square & \square & \square \\ \square & \square & \square & \square & \square & \square & \square\end{array}$


Comments about Aesthetics

- I like how you designed the holes along the waters edge

- you take the golfers through a range of elevation changes and viewpoints.

- taking the golfer through treed holes, open holes to water holes was done very well.

Maintenance

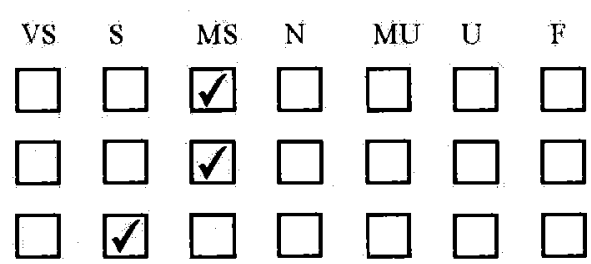

1. Reduce maintenance costs by incorporating natural zones in out of play areas.

2. Situate maintenance shop in a central location with good access.

3. Create ponds to surface harvest water to meet irrigation requirements.

4. Overall, how would you rate the consideration of golf course maintenance in the design?

Comments about Maintenance

- You incorporated a lot of natural zones with secondary rough grass, you might want to look at the amount you have around tees and along some landing areas. Tough visually for a golfer to stand on every tee knowing he/she has to clear natural areas to get the ball to the playing surface of the hole. - Secondary rough grass $100 \mathrm{ft}$ of the centre of the hole is tough. There is less cost with natural areas but it is a fine line with playabiltiy for all range of golfers.

- Maintenance shop is located on the entrance road for the clubhouse. hidden in the bush very well, is a long way from holes \#3 and \#4. Could you enter and put the shop on another road in the middle of the course by \#5 green or \#1 green?

- looking at the elevations you have done a good job on catching as much surface water as you can. I estimate you will need approximately $30-40$ million gallons druing grow-in and 17-25 million gallons to maintain. The total area of ponds you have would be enough but keep in mind these ponds are in play: so you would want them to be maintained at capacity, you will need a significant source for this.

- Overall I feel you have completed a good design relative to the maintenance of the golf course. Areas of concern I see are the amount of Secondary rough in play and the amount of trees around greens and tees. You might have some competition with the trees later on causing stress on turf.

- Overall total area of each item, greens, tees, fwy/roughs are very good to prevent wear problems. 


\section{Dr. Raymond Semlitsch}

The following questionnaire is designed to evaluate the proposed master plan for the Golden Beach Resort Golf Course. A set of design principles related to the integration of amphibian habitat into golf course landscapes were developed and applied to the resort property to demonstrate the provision of terrestrial and aquatic environments with respect to golf course features: Using your knowledge and experience in amphibian ecology, please assess the design and its function as habitat.

The following list represents the primary ecological design objectives for the proposed master plan. Using the following rating scale, Very Successful(VS), Successful(S), Moderately Successful(MS), Neutral(N), Moderately Unsuccessful(MU), Unsuccessful(U), and Failure (F), please select the one which best describes the extent of which you think each design objective is achieved in the proposed plan.

Terrestrial Habitat

1. Maximize the amount of forest cover on the golf course.

2. Preserve large core areas to provide interior habitat.

3. Avoid the fragmentation of existing habitats.

4. Provide terrestrial habitat in out-of-play areas in order to provide microhabitats consisting of coarse woody debris, leaf litter, and cool moist microclimates.

5. Minimize edge effects by providing a transition of vegetation heights between maintained turf areas and forested patches.

6. Overall, how would you rate the provision of terrestrial habitat within the golf course?

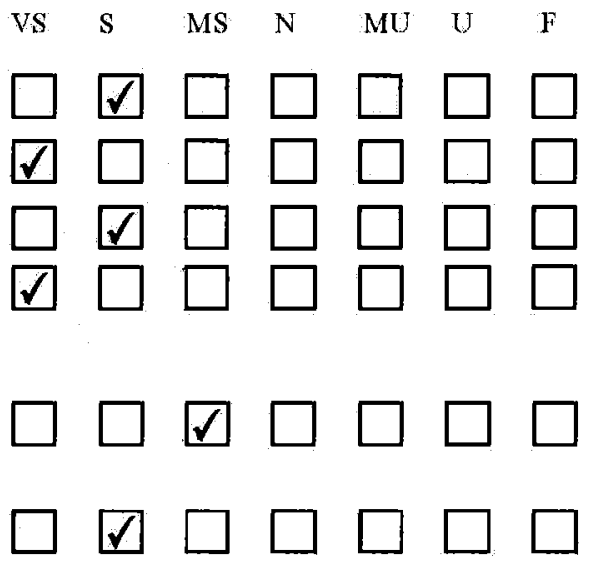

Comments about Terrestrial Habitats

Based on what I can see in the documents, I am concerned that the area was already fragmented so that changes appear minimal but overall may still be worse than more natural habitats. It would be nice to know what these data look like for more natural areas in the region. The edge ratio is pretty high and $\%$ of forested stream has gone down. 
Aquatic Habitat

1. Preserve existing wetland eomplexes within the property.

2. Provide closed canopy forest adjacent to pond edges.

3. Leave forested areas adjacent to wetland edges undisturbed.

4. Provide a mix of aquatic habitats with varying hydroperiods.

5. Maximize the amount of continuous vegetated stream corridors.

6. Provide shallow pond edges with emergent vegetation.

7. Naturalize all pond edges to provide a buffer between maintained turf areas and aquatic environments.

8. Overall, how would you rate the provision of aquatic habitat within the golf course?

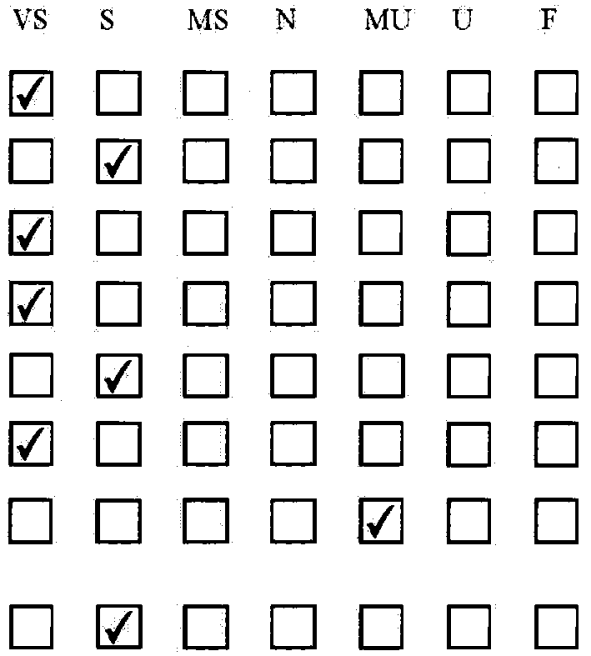

Comments about Aquatic Habitats

Based on what it says in Figure 1.12, lam very concerned that the wetland buffers consist of mown turf ( $>3$ inches)! I really believe these need to be wider and consist of natural vegetation, at least along some percentage of the wetland edge. Maybe 1 am missing this:

\section{Connectivity}

1. Preserve connections to habitat in the surrounding landscape.

2. Enhance the connectivity between the natural features within the property.

3. Improve the mosaic between habitats to provide more suitable environments for amphibian dispersal through the property.

4. Arrange aquatic and terrestrial habitats 200 500 metres apart.

5. Use smaller patches within the course layout to serve as stepping stones.

6. Reduce the amount of vehicular traffic through the property.

7. Overall, how would you rate the connectivity of natural features both on and off the golf course?

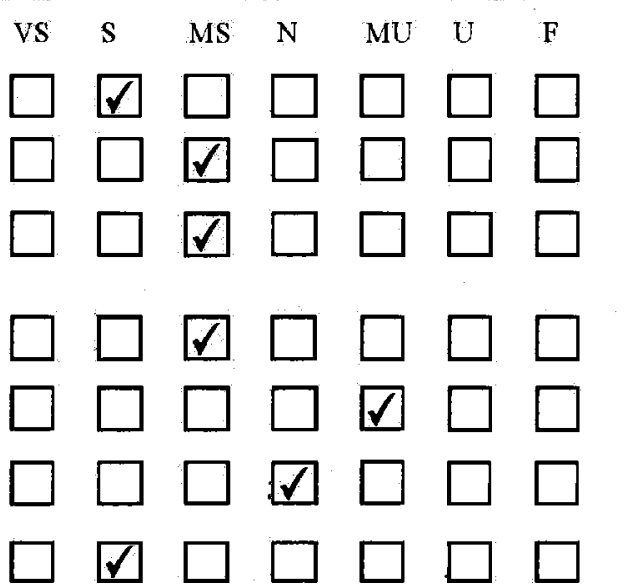


Comments about Connectivity

Again, based on what I can see in the documents, most wetlands are close enough to be connnected by dispersal and several forest patches are used to enhance that movement. That is good. But, in Figure 1.10 there is a disconnect between the 3 most western ponds and those in the east. There is a gap $>200 \mathrm{~m}$. This could be remedied by adding a small wetland inbetween to serve as a stepping stone. Further, it is not possible for me to tell if road banks or ditches may hinder movement. You might consider road 'tunneis' in key places to enhance movement across roads. Last, although difficult and beyond your control, landscape and habitat features of adjoining land should also be considered in terms of connectivity and isolation.

Overall comments about the integration of amphibian habitat into the proposed golf course.

Great attempt to improve golf course design. This should be an evolving process where new information is added as the results of science grow. We really need to evaluate such efforts and assess the 'health' of amphibian populations on such planned courses relative to old designs. 